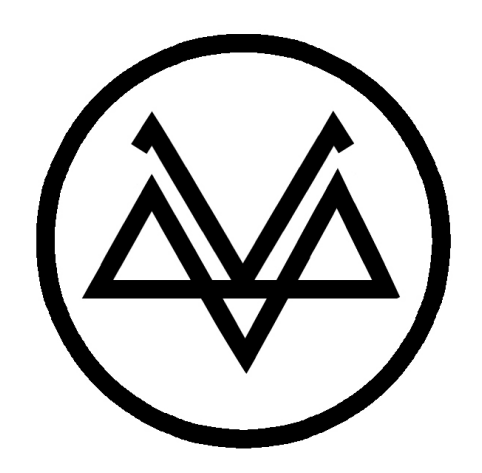

\title{
A TALE OF PLACE
}

BY

\author{
JAZMYN EDWARDS
}

\begin{abstract}
A 120-point thesis
submitted to the Victoria University of Wellington in fulfilment of the requirements for the degree of Master of Interior Architecture
\end{abstract}

Victoria University of Wellington School of Architecture 


\section{$\begin{array}{lllllllll}A & B & S & T & R & A & C & T\end{array}$}

The purpose of this research is to develop a cultural centre for Paraparaumu College that will aim to counter the number of students leaving school without any formal qualifications. The need for such a centre, with particular reference to Māori, was identified with the publishing of the 2013 census, which saw a third of Māori aged 15 years and over make up this demographic. While this number has decreased in comparison to earlier census results, this percentage still sits high above the national average.

From the standpoint of Māori, the reason for this statistic has been speculated by many theorists claiming Māori disconnection from their ancestral roots and the assimilation into European culture as a potential cause. Yet, while the Māori arts and language have declined in terms of common practice, the prevalence of western society is an aspect of life that modern-day youth have become accustomed to.
Therefore, it is proposed that the medium of interior architecture can serve as a tool to explore the notion of culture and identity in the built environment. While the success of Māori students is of particular interest to this investigation, the issues outlined are not exclusive to this cultural group. As such, this research will seek to generate a physical form that will pay homage to the unique blend of cultures that make up the Kapiti region as a means to anchor the building to its environment. Additionally, as a nation of people who have travelled to this land, the overarching theme of journey will serve as the basis with which the subject of identity in architecture will be explored. It is hoped that by establishing a strong sense of identity this will service the student in a way that a standardised education system may fail. 


\section{A C KNOWLEDGEMENTS}

I would like to take this moment to thank everyone who has supported me and guided me throughout this past year. I am grateful for the experience and skills that I have gained and I am appreciative of the help offered for the duration of this thesis.

In particular I would like to thank Paraparaumu College for the opportunity to work with them in the formation of this centre and Leah Gifford who was a constant point of support.

I would also like to acknowledge Victoria University for awarding me with the Tu Horomata scholarship, which aided in the completion of this thesis. 
This thesis is dedicated to my parents who have encouraged me from the start. 
Abstract

\section{Chapter I: Pre Design Considerations}

1. Introduction .................................................... 3

2. Give the design purpose (.................................... 5

3. Remember who you're designing for ................ 13

4. Conclusion .......................................................... 19

Chapter II: A Design Overview ....................................... 21

1. Introduction .................................................. 23

2. Embrace the environment …............................. 25

3. Fulfil the basics ….......................................... 35

4. Create a design environment that's flexible ....... 43

5. Conclusion …............................................... 51

Chapter III: A Focus on Education …………..................... 53

\section{$\begin{array}{llllllll}C & \mathrm{~N} & \mathrm{~N} & \mathrm{~T} & \mathrm{E} & \mathrm{N} & \mathrm{T} & \mathrm{S}\end{array}$}

1. Introduction ................................................. 55

2. Make learning important .............................. 57

3. Find moments outside the classroom to encourage learning

4. Promote success ……….............................. 75

5. Conclusion ….................................................. 85

Chapter IV: People are Important ................................... 87

1. Introduction ..................................................... 89

2. Highlight the cultural differences ..................... 91

3. Design for the time .......................................... 99

4. Conclusion ........................................................ 107

Chapter V: Final Conclusions .......................................... 109

Bibliography …............................................. 113

Appendix ...................................................... 117 


\section{$\begin{array}{llllllllllllllll}T & H & E & S & \text { I } & S & F & O & R & M & A & T\end{array}$}

This body of research is the culmination of a project that has taken place throughout the span of a year. This particular venture used interior architecture as a means to transform an existing educational building into a tool for social change. What has resulted in the conclusion of this work is a series of ten points that should be considered when undertaking a project of this nature.

Through its presentation as a guide, the following section will proceed to explain the four chapters that define this thesis. Beneath each chapter will sit a number of points that refer specifically to concerns that were identified during the formation of Paraparaumu College's cultural centre. In total, covering a range of design considerations, these points can be implemented as a tool for interior architects to bring social and cultural awareness to our educational environments.

\section{Chapter One: Pre-Design Considerations,}

Addresses concerns that take place before any formal designs are conceived. To ensure a strong foundation for the design itself, the following points focus on matters relating to purpose and people.

Chapter Two: A Design Overview,

Is an outline of the design's fundamental basics. These points consider inhabitation of the space, the environmental setting, and programmatic function of the design in general.

\section{Chapter Three: A Focus on Education,}

Concentrates on meeting the educational prerequisites of a building based within a school environment. Its intention is to ensure learning has the platform it needs to be expressed in a variety of ways, while encouraging the success of students learning achievements. 
Chapter Four: People are Important

Considers the social and cultural implications of the design. This chapter makes reference to both future and current needs of the com-

munity that intend to inhabit the space outside of an educational program.

\section{Chapter Five: Final Conclusions}

Offers a critical review of the findings undertaken throughout this design research. 


\section{PRE-DESIGN CONSIDERATIONS}


“Culture is universal in man's experience yet each local or regional manifestation of it is unique."

(Herskovits, 1964, p.4)

Interior architecture has the ability to impact matters of social and cultural consideration and as such, this research will use interior architecture as a means to facilitate a cultural agenda. The approach taken throughout this research is to attribute meaning throughout the centre, to foster a sense of curiosity and intrigue in the physical environment that leads to moments of discovery.

The tale of the Kapiti region's history, people and myths will serve as a basis upon which this centre will harness its story.

The following chapter will explore the pre-design considerations associated with a design project of this nature, delving into the site and determining this centre's purpose. 
GIVE THE DESIGN PURPOSE 
As a whole, this project will focus on identity being used as a cultural anchor for the student to the school. The intention is that from this sense of purpose students, who may feel detached in a conventional educational structure, will instead feel a sense of engagement with their environment. It is anticipated that this, in turn, will resonate with their desire to succeed in terms of their own learning and growth. It is proposed that the use of narrative in the formation of design and environmental understanding will serve as a fixture in a way that a traditional school environment may fail.
This sense of purpose will derive its meaning from the history of the Kapiti region and the culture that defines its people. Events that shaped the modern day landscape will play a significant role, from the formation of Kenakena $\mathrm{Pa}$ and the unique confederation of iwi that co-exist within the Kapiti region today. Additionally, the mythology behind the naming of the Kapiti area in Māori culture will also play a part in instilling a sense of site awareness. To understand where we are going we must first understand where we have been and where we come from. This centre will be representative of that journey as students begin to prepare themselves for life outside the confines of secondary education. 


\section{THEORETICAL A NALYSIS}

Denys Lasdun, in his text The Architecture of Urban Landscape, commented that it was imperative for each architect to establish their "own creative myth". This myth would lend itself to be a number of principles that would both guide and stimulate the creative process. Lasdun remarked that while these principles should be "sufficiently objective" the myth should also be "partly an expression of the architect's personality and partly of his time, partly a distillation of permanent truths and partly of the ephemerae of the particular moment."(Lasdun, 1984, p. 137) He went on to state that his own creative myth engaged with history. It is Lasdun's work with narratives and the means by which he attributes meaning and purpose to his spaces that sets the precedence for this body of research.

In addition to Lasdun's work, Michael Hays went on to further add that architecture is:

An epiphenomenon, dependent on socioeconomic, political, and technological processes for its various states and trans- formations. Moreover, as a functional support for human institutions and as a ratification of a collective volition, architecture ennobles the culture that produces it; architecture reconfirms the hegemony of culture and helps to assure its continuity. (Hays, 1984, p. 16)

Both Lasdun and Hays agree that the external world influences the meaning attributed to an intervention and, that as designers of our built environments, we should be able to exert a sense of control over this quality. Narrative can be used as tool for assigning meaning and as a generator for this sense of purpose we can look to our external setting and history as a means of inspiration.

As the sense of purpose for this cultural centre is to be derived from place, the work of Neil Leach also holds a particular fascination with him theorising, "architecture is often linked to questions of cultural identity. ... And yet architectural theorists have seldom broached the question of how people actually identify with their en- 
vironment.”(Leach, 2002, p. 126) Certainly, to ensure the success of the narratives we put in place, a meaningful discussion must first occur between educators and designers at the initial planning stages of a project. This process is an essential factor in the formation of a scheme that succeeds both in terms of form and function. Additionally, it is of particular importance for a project that seeks to challenge the conventional method of educational architecture. 


\section{$\begin{array}{lllllllll}C & A & S & E & S & T & U & D & Y\end{array}$}

If we look at our built world as being a tool for social, political and cultural change then perhaps one of the greatest pioneers with whom the success of culturally invested design can be measured is Sir Apirana Ngata. "Ngata had developed his own, uniquely Māori view of independent cultural development. Arguing that social inequalities would disappear if Māori retained their own distinct identity."(Brown, 1999, p. 253) It was this desire to see his people flourish that lead Ngata to establish the School of Māori Arts and Crafts. From its inception the school endeavoured to teach its students by "redeveloping traditional, structural, functional, philosophical and multi tribal architectural concepts in order to address what Ngata believed to be contemporary Māori needs.” (Brown, 1999, p. 253)
With a similar social and cultural agenda in mind, Ngata also sought to address the issue of Māori underachievement and disengagement through the revitalisation of traditional practices. Where he initiated the teachings of traditional art forms such as whakairo, kowhaiwhai and tukutuku panelling as a means to communicate Māoris unique heritage, this centre will aim to generate that same sense of cultural connection through the communication of Kapiti's history in the centre's design.

It is proposed that through generating a form of understanding for both history and place, a feeling of connection and pride can begin to take root within the individual ensuring a sense of identity can flourish. 


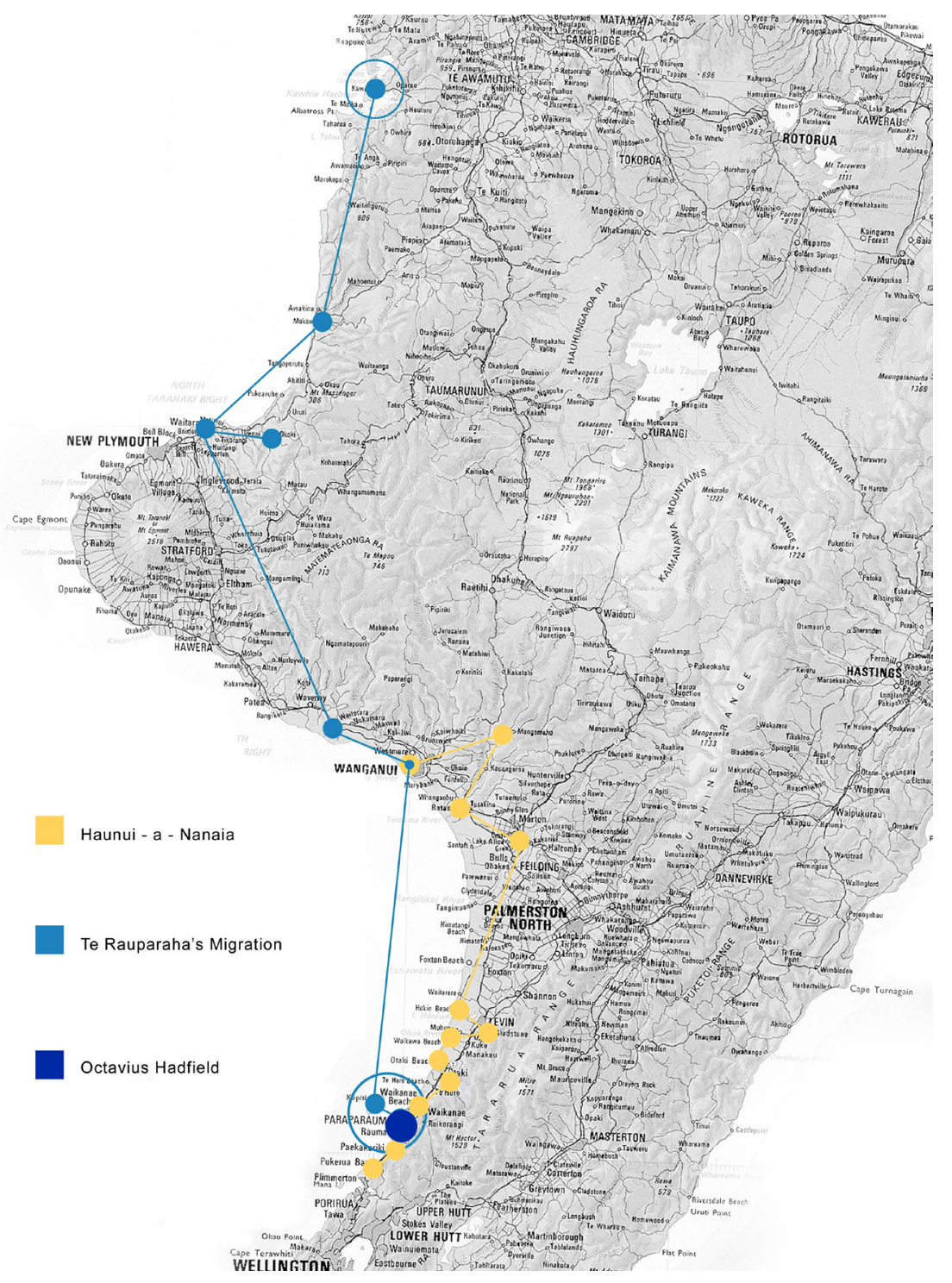

Figure 1: A diagrammatic migrational map of the Kapiti region

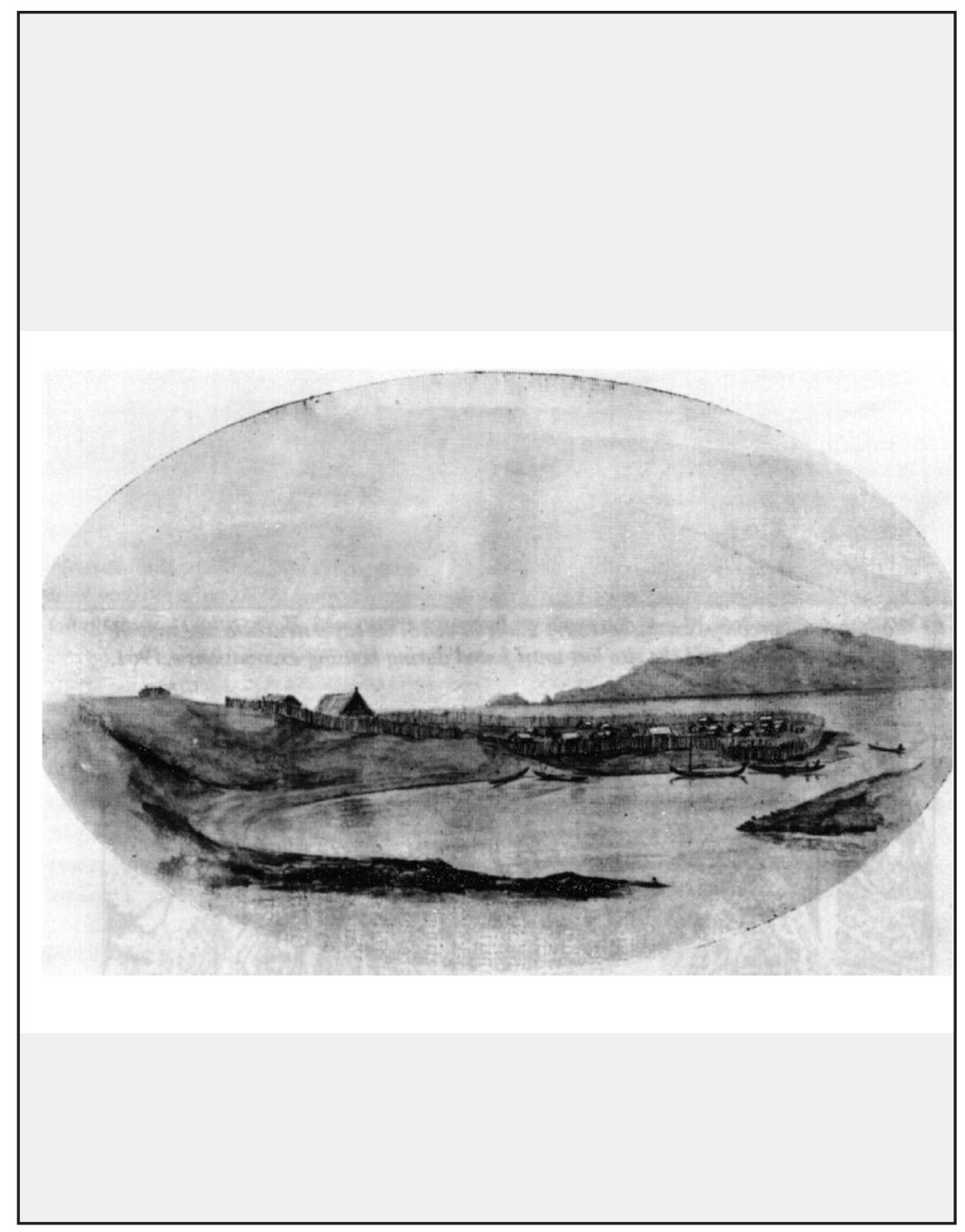

Figure 2: Kenakena Pa and the Church of Octavius Hadfield 


\section{\begin{tabular}{l|lllllllllll}
$S$ & I & $T$ & $E$ & $A$ & $N$ & $A$ & $L$ & $Y$ & $S$ & I & $S$
\end{tabular}}

As the encompassing theme of this centre will focus on the notion of journey, the map depicted (fig 1.) showcases three expeditions that are significant to the formation of the Kapiti region today.

The first journey references the travels of a Māori explorer named Haunui-a-Nanaia who was pursuing his wife who was believed to have run away in the company of two companions. As Haunui-a-Nanaia traversed the lower North Island he would stop to name the landmarks he came across ranging from the Whanganui River to Otaki, and from Waikanae to the Rimutaka's. (Winter, 2010) To date, the names Haunui-a-Nanaia assigned to these places still stand in use and are of such significance to the area that Paraparaumu College used Haunui's travels as a means to rename their school houses. (Paraparaumu College, 2014)
The second tale speaks of Te Rauparaha, a Māori chief of the Ngati Toa tribe who led his people from their homelands of Kawhia to the Kapiti Coast as a means to escape the land wars that plagued the 1800 s. His presence was also pivotal in the establishment of Kenakena $\mathrm{Pa}$, which was the largest Māori settlement of its time and a communal hub. (fig. 2)

The third historical figure of significance is Octavius Hadfield, a British born missionary. Upon arriving in New Zealand and initially working in Paihia, he made his way south and eventually settled at Kenakena working as a minister within a church that was established on site. He was a European influence on what was a Māori dominated settlement and his presence and authority was representative of a collaboration of cultures. 
REMEMBER WHO YOU'RE DESIGNING FOR 
Students starting Paraparaumu College this year will graduate in 2020. Over a span of five years it is difficult to anticipate our changing social, environmental and educational climate. Yet, whether or not these students merely endure or flourish, as young adults will be, in some part, determined by their college experience. As interior architects we can only anticipate what is to come and provide a vehicle with which they can navigate this landscape.
This following point seeks to reinforce the importance of people in the formation of an interior scheme. It references the magnitude of community involvement, educational engagement and fostering student interest from the initial stage of design. 


\section{THEORETICAL ANALYSIS}

When starting an architectural project the first point of call for a designer is the establishment of a brief. While a brief is undoubtedly important, Lackney holds an interesting point of view stating, "It becomes a poor stepchild of a far richer description of teaching and learning activity that remains to be communicated between educator and architect." (Lackney, 2009, p. 184)

Certainly, it is not unfounded to suggest the need for a dialogue between client and designer, especially with regards to a project that is used as a tool for social progression. Yet, while the need for communication is vital to the success of this project, it is not limited to a conversation between educators and architects alone. An open forum for communication will also need to involve the wider community, with this branding of community being inclusive of the parents whose children will attend Paraparaumu College and the Kapiti region where the school itself is situated. It should seek feedback from local iwi and be used as a means to establish a relationship between both Primary and Intermediate Schools based within the town of Paraparaumu. If these relationships can be established and cultivated it creates a centre that is not only embedded physically within the school, but a cultural centre that is of social significance to the Kapiti area itself. 


\section{S I T E A N A L Y S I S}

This centre, as mentioned in the prior point Give the Design Purpose, will establish its identity through weaving a multitude of stories into an interior space with an overarching theme of journey. Journey as a symbol of the people's historical migration to the Kapiti area and journey with regards to the student's individual voyage into the world outside of formal education.

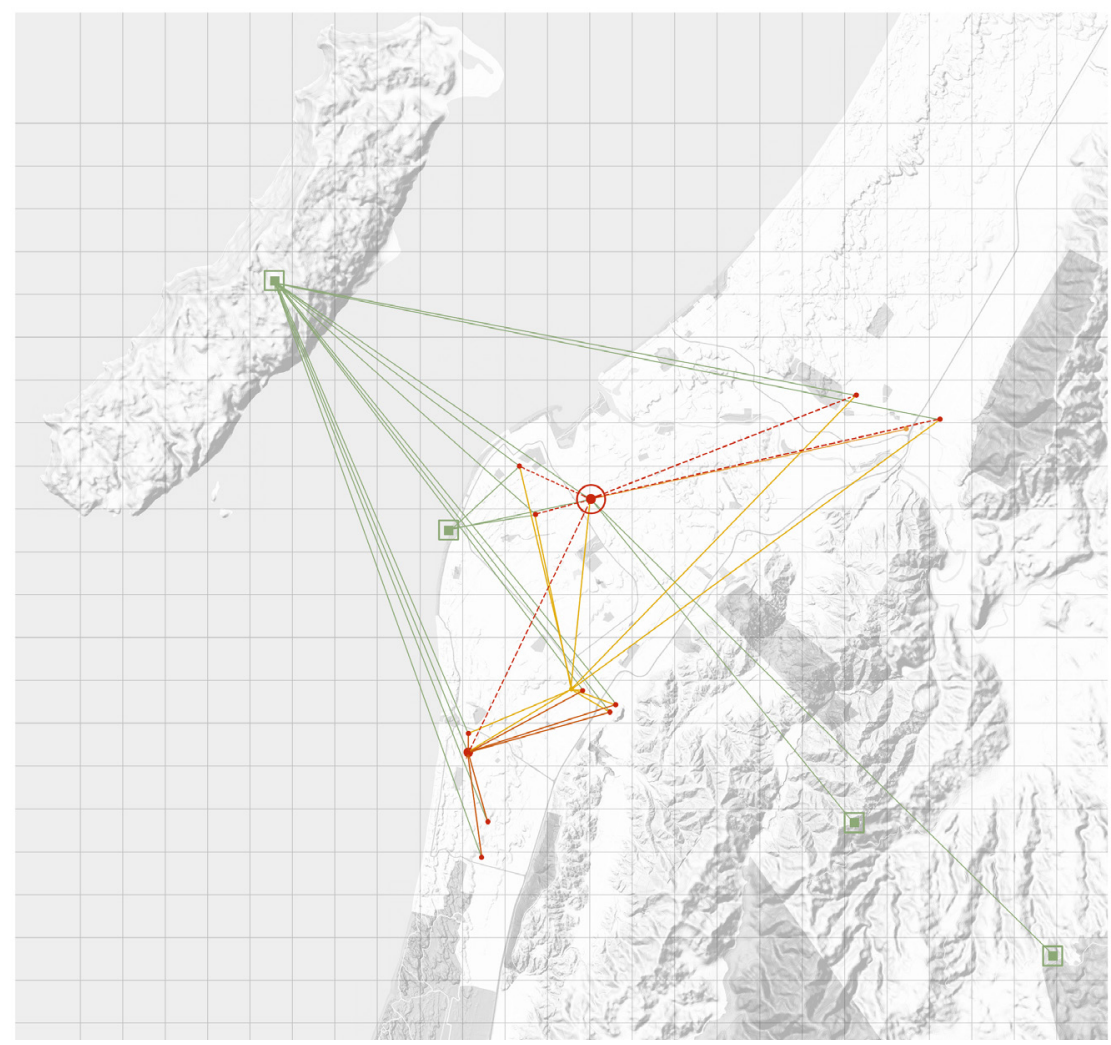

Figure 3: Layers of cultural considerations for Kapiti region 
From these historical considerations we then move towards tales that shape the landscape of the Kapiti region today. The maps depicted left (fig. 3) show each point from which we can begin to measure the external environment the cultural centre, shown as a red circle, will be set within. The green squares in this image show environmental points of cultural interest, with these places being identified as Paraparaumu Beach, the Waikanae River, the Tararua Ranges and Kapiti Island. The next map is referred to as the primary nodes depicted by green lines. In the context of this research the primary nodes are places of cultural significance as determined by the Paraparaumu College house names and the journey of Haunui-a-Nanaia. These points range from maunga to marae. The next layer, shown in yellow, represents the structures that are of social consequence such as established community centres, while the fourth map, outlined in red, pinpoints the location of all schools within the Kapiti area. Lastly, the fifth layer of this map, in blue, looks at the immediate area that Paraparaumu College is set within, taking note of street grids the college is set within

From these points we can reiterate the importance of designing for people. By designing for people we, as interior architects, need to take their voices, their histories and their lifestyles into account with the formation of our built world. It is unwise to assume and imperative to understand the reasoning that generates a need for a cultural centre. By simply opening the paths of communication and immers- ing oneself with the environment a project is guaranteed a greater level of acceptance and success in the eyes of its inhabitants. 


\section{$C O N \quad C \quad L \quad U \quad S \quad I \quad O \quad N$}

The Pre-Design considerations so far have established the importance of purpose in the initial stages of a project. With particular reference to the formation of a cultural centre, it is vital that both purpose and people sit at the forefront of any design considerations.

The perspectives voiced by both Lackney and Leach reaffirm the significance of becoming involved in the community with which you seek to establish a design. Through learning of the place, its people and its past a stronger design will flourish that harbours the ability to unite people with the built form.

This connection is essential to the success of any project purporting a cultural agenda, as people are the caretakers of our environment. If they appreciate and respect the space, if they understand its stories and aspirations then this sense of guardianship can be passed from person to person, strengthening a community and allowing a centre and school to prosper. 


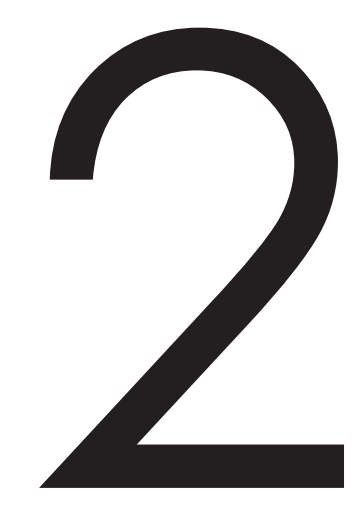

$$
\begin{aligned}
& \text { A DESIGN } \\
& \text { OVERVIEW }
\end{aligned}
$$


Culture is stable, yet it is also dynamic, and manifests continuous and constant change,

(Herskovits, 1964, p.4)

The following chapter, A Design Overview, will provide a breakdown of the overall design and an account of how the complete scheme operates as a cohesive unit. It takes the points referenced in the previous chapter, Pre-Design Considerations and demonstrates the way that these viewpoints can be applied as a means to generate design.

The body of work covered in this chapter will range from site analysis, conceptual designs, to developed schemes. The following chapter is comprised of three points that will explore the significance of embracing the environment that surrounds the site; of ensuring the fundamental basics are fulfilled from the initial design stage and that, as a social space, the scheme holds a degree of flexibility to meet the needs of both groups and individuals. 
EMBRACE THE ENVIRONMENT 
This research has already made the comparison of a school being a social vehicle. If, as mentioned in the points covered under pre-design considerations, we begin to fully engage the school as a means to activate social change then we should in fact be looking beyond the architectural shell itself for a design influence. By giving the design purpose and remembering who we are designing for we are already starting to openly accept the need to engage with our school environment and beyond.

Neil Leach states "as individuals identify with an environment, so their identity comes to be constituted through that environment. Architecture therefore offers a potential mechanism for inscribing the self into the environment."(Leach, 2002, p.132) From here we can begin to approach the notion of environment as an opportunity to further our cultural agenda through the means of interior architecture.
As the opening point under the chapter: A Design Overview, this particular point bridges the gap between the initial pre-design considerations and the physical formation of space. It acts as an introduction to the proposed cultural centre for Paraparaumu College and how this intervention will seek to both reference and connect with the physical school environment and wider Kapiti region. 


\section{THEORETICAL ANALYSIS}

It is not ground breaking to reiterate the importance of place when developing an interior intervention. Nor is it rare to use place as a conceptual driver for the formation of space. However, when a project has a clear social motivation it is imperative that place factors into the equation during the creative process. Winston Elting highlights the importance of the built form in relation to environmental engagement when he remarked, "architecture unqualified, should be an integral part of education. It holds the power of environment." (Elting) Elting's comment speaks of architecture as a means to both establish an environment through design itself in addition to being a mechanism that can be used to determine a person's interaction with the surrounding area outside a proposed site.

In fact "all responses to the environment, whether internal or external, are dependent to a large extent on a person's experience." (Hershberger, 1970, p. 43) As interior architecture lends itself to be used as a means to influence a person's interaction with a space then, as both Elting and Hershberger have alluded to, it will also serve as a valuable device with which environment engagement can be implemented. If we seek to establish a purpose that is derived from both history and place then it is important that we consider the actions of form in terms of environmental experience and environment as a social anchor.

Thus far, we have predominantly spoken about the environment in two parts. The first being a physical manifestation of space, both already existing in terms of site and conceptually with regards to intended design moves. The second manner in which we have referred to environment has been as a social tool. While we have already established that these considerations of environment are intertwined, it is not unwise to suggest that the social implications are what we are more concerned with as we look to generate physical space. It is important that if we continue to address the significance of environment that, as the Third Teacher suggests, "we begin to build 
relationships with existing community services such as libraries and recreational facilities, and perhaps even make a new home together." (OWP/P Architects, VS Furniture, Bruce Mau Design, 2014) While we can certainly take these considerations into the wider community spectrum it seems more appropriate to address these relationships on a more intimate level. Connection to existing school facilities such as open spaces, the library and school offices will serve as a means to anchor the centre to an already established school environment. 


\section{DES I GN AN A L Y S I S}

The design investigation undertaken with consideration towards embracing the environment focussed primarily on issues of site and engagement with the immediate school environment. The following section offers a site analysis of Paraparaumu College where this cultural centre will be based (fig. 4). The following analysis will be demonstrated firstly with a focus on the site, as it stands today, moving on to the initial conceptual models, before progressing to how the developed design will be integrated into this setting.

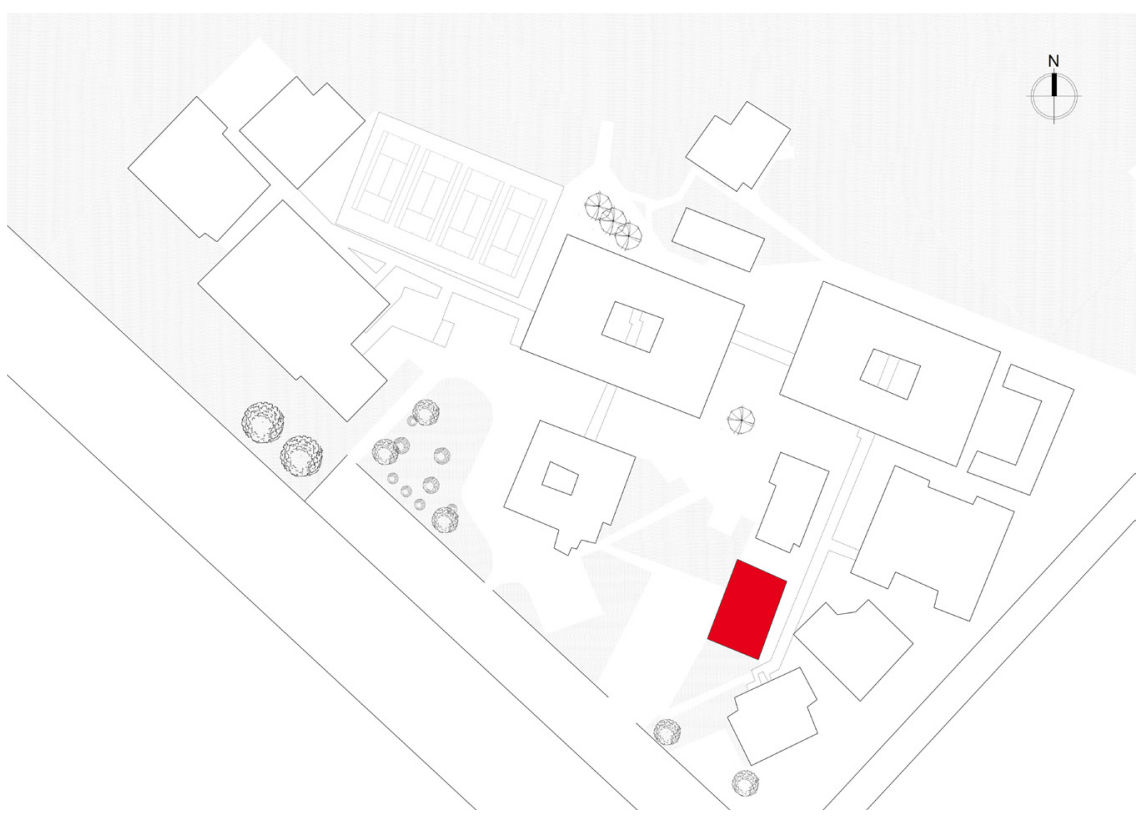

Figure 4: Diagrammatic school plan including site for cultural centre 
One of the problems faced by Paraparaumu College at present is its lack of visual identity. The college sits on Mazengarb Road in a suburban area of Paraparaumu. While the road itself sees a moderate amount of traffic use and as such an adequate physical presence in terms of community awareness, it fails to make any kind of visual impact. The entry into the school is made up of multiple points that span almost its entire threshold along Mazengarb Road, meaning that the school fails to generate any kind of visual focal point.

As depicted in the image on the right (fig. 5) the proposed cultural centre seeks to combat these factors and use them to its advantage within the interior

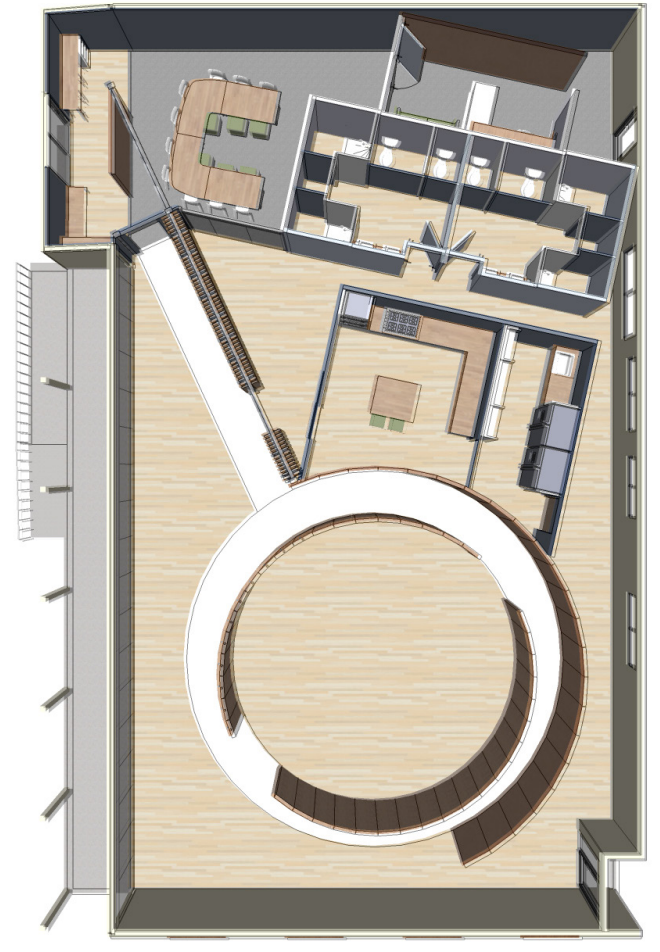

Figure 5: Cultural Centre in Plan 
The building that has been identified by the school for repurposing as the cultural centre (fig. 6) is located at the forefront of Paraparaumu College along this Mazengarb Road threshold. With regards to location, it serves as an ideal site due to its close proximity to existing library facilities, open spaces, the administration block and the school hall. Its location at the heart of the school's social space gives the centre the prime opportunity to establish itself as a generator of communal identity. Furthermore it gives the centre the opportunity to present this sense of identity to both the Paraparaumu public from its point at the front of the school grounds and to the student body who will need to navigate the pathways along which the cultural centre is situated upon.

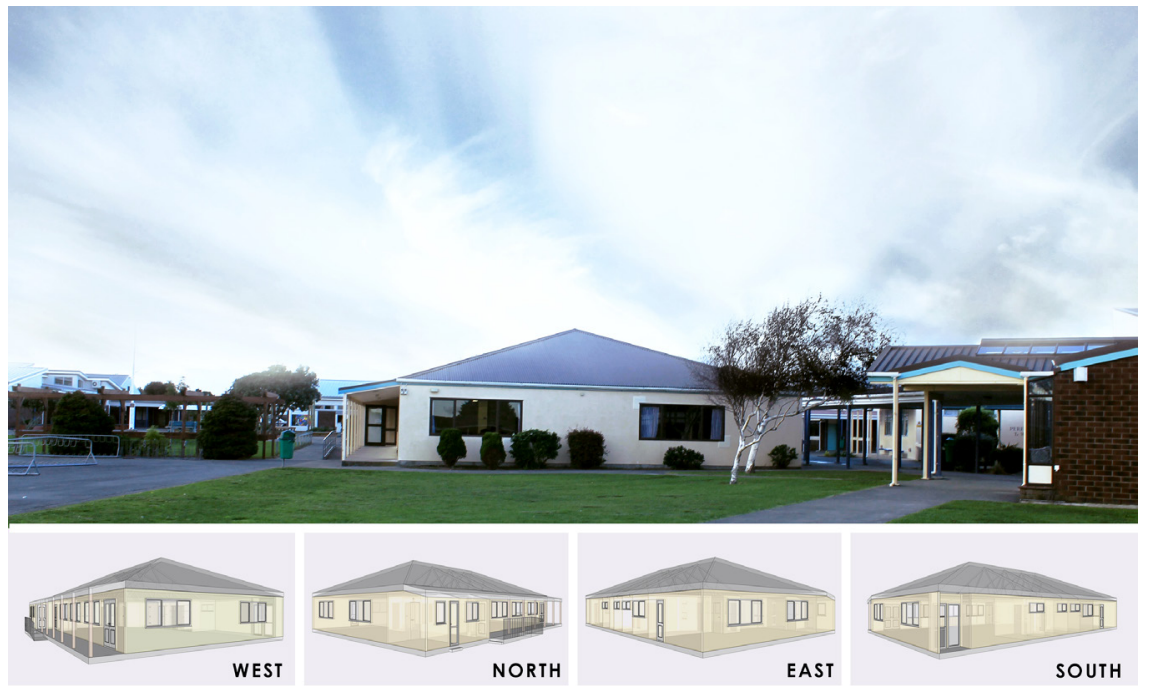

Figure 6: Existing Building 
A single storey structure, the building currently acts as a common room for Paraparaumu College's year thirteen students. While its location offers an opportunity that is unparalleled in terms of reaching a large community and student audience, the building, in it's current day context, is both uninspiring and dull in its existing environment. The Harditex, fibre-cement clad building does little to differentiate the centre from the structures that surround it, while the building offers no identity with which it presents to the passing community.
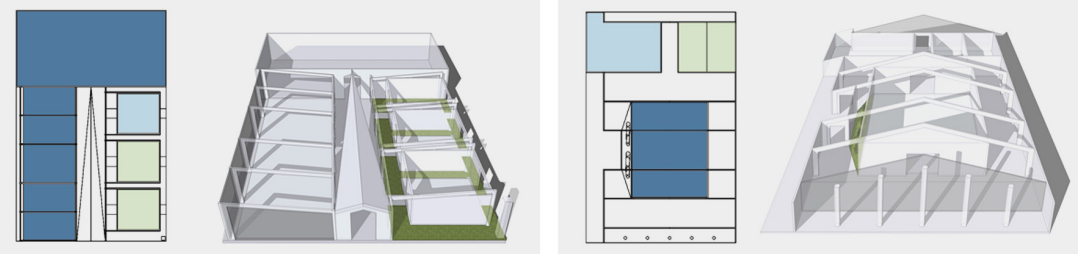

1.
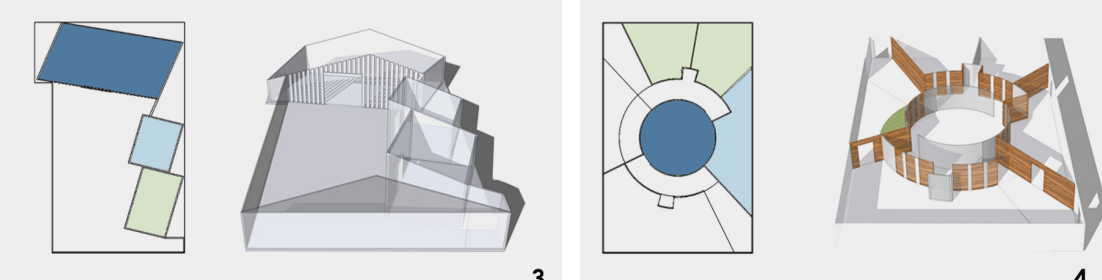

Figure 7: Preliminary Concepts 
The concepts shown left (fig. 7) reference certain characteristics of site as determined in the previous chapter. The first image takes its form from the kotuku, a rare bird of such significance in Paraparau$\mathrm{mu}$ that the college sought to name one of their school houses after it. The second image refers to a traditional marae layout and the segregation of certain areas as a means to preserve tapu. The third image is a response to the shifting grid the school sits upon as noted in the first chapter: Pre-Design Considerations. The last image takes the over arching theme of journey and manifests this concept into a compass, orientated in the corresponding direction.

While each of these concepts harness a tale significant to the area, improvements can be made to push the design further as a means to establish a stronger community connection. 
FULFIL THE BASICS 
It is instinctive to want to nurture our youth, to support them as they navigate the world in an attempt to gain independence. Yet that sense of support should be a common thread that follows our young into their educational environments. As interior architects it is our responsibility to provide a safe and happy space that supports their individual growth. Henry Sanoff remarks that,

The quality of student life and the quality of education is directly affected by the quality of the school environment. School environments might refer to physical provisions as well as the patterns of a school's operation. Students perception of their environment, whether supportive or hostile, interesting or boring, is also integral to an understanding of the school environment (Sanoff, 1993, p. 141)

This point will proceed to look into the pitfalls of modern educational architecture. When designing for the built world one is tasked with the experience of space and the control of human interaction.
As a result it is important that we, as interior architects, ensure the basic humanistic qualities are addressed through thought provoking and empathetic means. If we can achieve the basics of brief we provide ourselves with a foundation with which we can develop a stimulating educational and communal space 


\section{THEORETICAL ANALYSIS}

Henry Sanoff is arguably one of the most influential people in the discussion of educational architecture. Perhaps his most thoughtful comment was when he stated, "the amount of time young people spend in school is so significant that it is important to recognize that much of this time is devoted to living as well as learning." (Sanoff, 1993 , p. 141) What made this distinction so intriguing was the emphasis it placed on school being a place for living and learning. New Zealand distinguishes a period of thirteen years for formal education, from the start of primary school to secondary school graduation. Yet, in reality, the amount of time spent in educational institutes is much greater. Preschools, tertiary education and extra curricular activities are further factors that see our education space influencing students beyond the short time they spend in the classroom.

Certainly, it is not unusual for our focus to be on the act of learning when designing for educational institutes, yet, as designers, we must ensure the space we generate fosters the ability to encourage learning in addition to enabling it. "Children are ready to learn only when they're safe and secure, so it is vital to address those needs before considering any other aspect of a child's environment."(OWP/P Architects, VS Furniture, Bruce Mau Design, 2014) It is with this we acknowledge that schools are a staple of our community, an institution within which children are constantly passing through. As such, a school stands to be influenced by a child's home life, their personal affairs and a myriad of external influences that are outside the school environment. It is imperative that at the initial stage of design conception and discussion, that we acknowledge atmosphere as a fundamental design basic. "The requirement for physical and emotional safety is an essential characteristic for the success of any school. Learning cannot occur in an environment where people fear for their personal security." (Sanoff, 1993, p. 141)

If we are to look beyond the mere occurrences of the classroom we need to ensure that any moves we make are drivers to the end goal of a stimulating environment for our students. As Winston Elting claimed "a good building is well-planned to perform efficiently the 
peculiar use to which it is to be put. It is planned to take full advantage of its site, the function it fulfils on the campus"(Elting, 1951, p. 247). It is not unwise to suggest, as Elting alludes, that the first imperative of a successful intervention is fulfilling a set of basic needs. Basic needs referring to meeting the functional elements of a brief and providing the basic elements within which learning can occur. 


\section{DES I GN A N A L Y S I S}
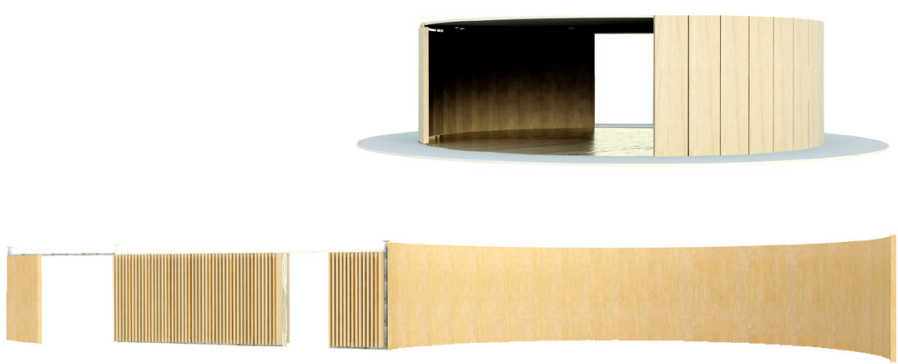

पIFIIII

\section{구밈}

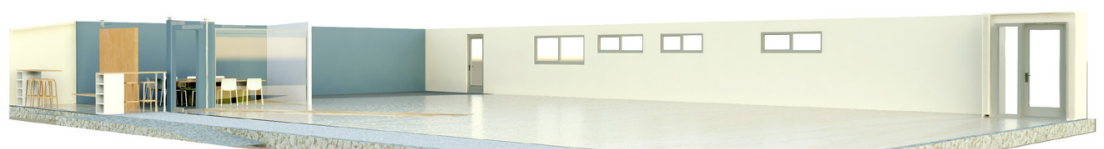

20

Figure 8: Component Diagram
Thus far, in relation to the cultural centre for Paraparaumu College, we can determine the fundamental basics will pertain to matters of functional space and atmosphere. With regards to atmosphere, this will reference an environment that is both nurturing and protective while the functional spaces will focus on meeting the school's dayto-day requirements. The image depicted left (fig. 8) shows the breakdown of spaces deemed vital as per discussions with the college staff, students, parents and iwi members. Furthermore, the point will proceed to explain the narratives behind each component as an instrument to implement a sense of atmosphere. 


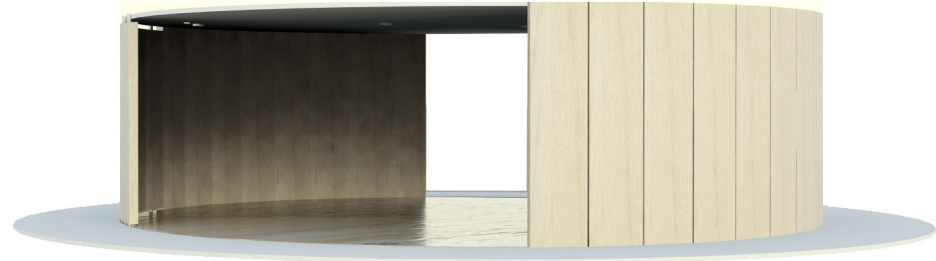

Figure 9: The Explorer

The overall scheme is centred on The Explorer. Named as such, The Explorer sits nestled in the heart of the intervention with the ability to open up and oversee life outside the cultural centre, or to withdraw even further into itself and become a more intimate setting. On a functional level, The Explorer will act as either a hireable community space or alternative classroom area.

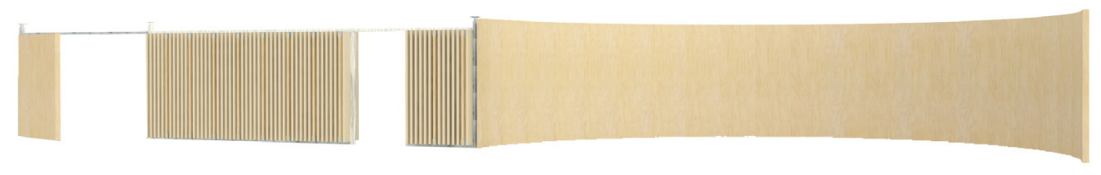

Figure 10: The Guide

Encircling The Explorer and stretching almost the length of the cultural centre, The Guide acts as a threshold between social and utility spaces. Its reference as The Guide is derived from the overall theme of journey and the component's orientation as a navigational point for north. While, from a practical standpoint, it acts as a physical distinction between changing environments it also serves as a display upon which the school's identity and history can be publicised to the student body and wider community. 


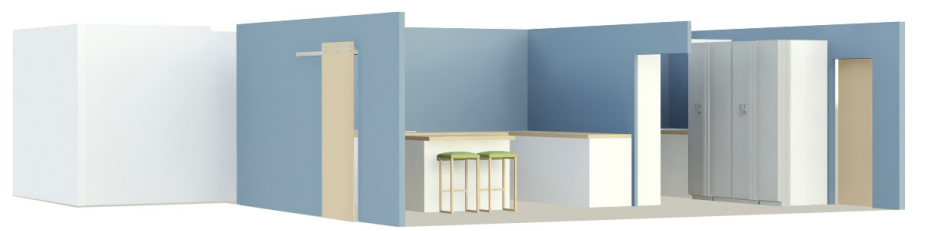

Figure 11: The Provider

The Provider houses the female and male toilets in addition to a kitchen and kitchen storage area. Its square form sits in stark contrast to the curved nature of The Explorer and reinforces the difference in environment between these components. Identified as being a utility area the linear nature of these spaces indicates a more controlled form of inhabitation in comparison to the informality of The Explorer.

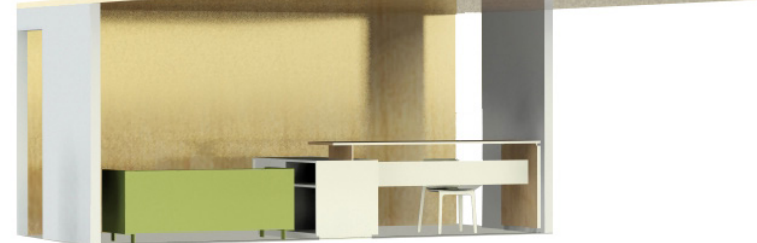

Figure 12: The Protector

The final space is The Protector, which is located directly behind The Provider. Small in form but following the squared nature of The Protector, The Provider houses a teacher's office that will also act as the guardian of this centre. Its form signifies its status as the protector as it attempts to shelter The Provider while reaching to grasp The Explorer. 


\section{CREATE A DESIGN ENVIRONMENT THAT'S FLEXIBLE}


This section will refer to the final point under the chapter: A Design Overview. The points so far have largely been concerned with the external influences of people, place and purpose. Certainly, as designers, we can draw inspiration from a multitude of situations, stories and methods, yet inevitably our focus will always returns to the smaller scale of the immediate internal environment.

This particular point will bring the focus back to the internal setting of Paraparaumu College's cultural centre by highlighting the importance of creating a design environment that is flexible. Flexibility gives rise to the opportunity to create a space that can be used in a multitude of ways. As the intention is for this centre to be used as both a classroom and a community space, it is pivotal that a sense of flexibility exists to allow this intervention to seamlessly cater to both groups of occupants.
However, the need for flexibility does not result from the purposes of community and classroom function alone. While these particular groups were distinguished in the initial point, Give the Design Purpose; we must remember that within these two groups exist a multitude of individuals with differing needs, expectations and a willingness to engage. If from the outset we recognise that this cultural centre will serve individuals rather than groups we can hope to generate a diverse space that will attempt to connect with individuals on a personal level. 


\section{THEORETICAL ANALYSIS}

Throughout this chapter the work of Henry Sanoff has served as a strong influence for the theoretical outlook expressed in this body of research. As an architect who dedicated much time and thought towards the rejuvenation of educational environments, his work has been paramount with regards to theoretical deliberations for this project. Arguably, one of his more poignant comments relates to the matter of catering to diversity within the classroom, stating that

"In a school that responds to its students' need for diversity, one would not find students all doing the same thing, at the same time, in similar rooms. One would not expect to see students sitting in neat rows of desks, all facing teachers who are lecturing or reading from textbooks. Indeed, in responsive schools, students and teachers would be engaged in different learning activities in and out of the classroom." (Sanoff, 1993, p. 140)
If, as Sanoff suggests, we begin to design with the mindset of individuals rather than target groups, the interior interventions we produce will be more dynamic and the schools we design for will be in possession of powerful educational tools. It is not beyond reason to propose a change in approach when discussing the interaction of students with space. Particularly "since young people vary in physical development, intellectual capability and interest, the need for diversity would be an important characteristic of a responsive school."

(Sanoff, 1993, p. 142)

From a learning standpoint "modern instruction requires varied and diversified forms of knowledge transmittal."(Walden, 2009, p. 106) If modern expectation is for the teacher to provide a varied system of learning then the environment within which this classroom is based should also harbour the ability to cater to this expectation. Elting further emphasises this point through recognising, like Walden, that "educational techniques change and a more organic architecture becomes apparent in all building categories. If we are alert to this 
trend, are aware of it, and understand it thoroughly we can do good things to our educational architecture. We can make of it what, at the very least, it should be, a contributing factor in creative expression." (Elting, 1951, p. 244) 


\section{S I TE A N A L Y S I S}

From an operational stance this cultural centre will predominantly function as a Māori Studies classroom. As a result, the discussion regarding flexibility has largely been from an educational perspective. However, with regards to the design considerations undertaken for this point, the design analysis has been separated into two further sections. One with respect to flexibility that will cater to a classroom environment, and a second breakdown that looks at considerations for community inhabitation. As depicted in the right image (fig. 13) also of particular interest is the relationship between the interior and exterior spaces.

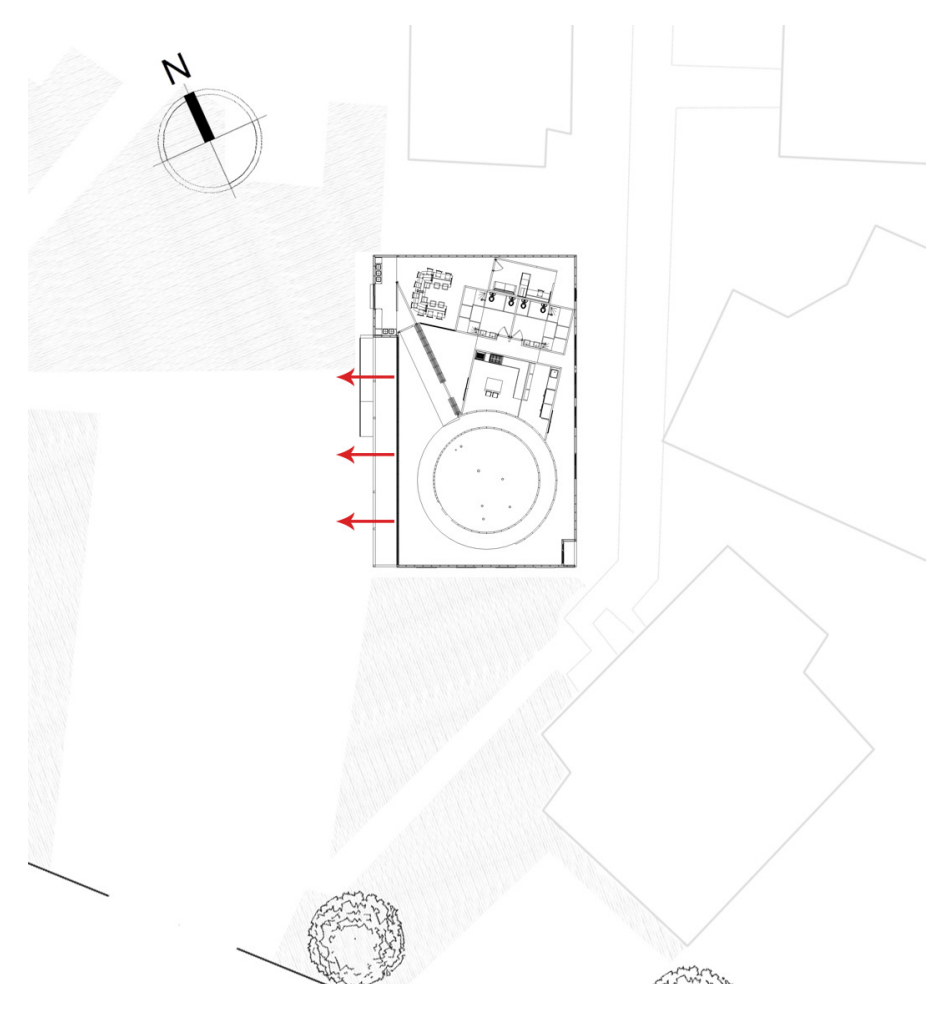

Figure 13: Diagrammatic plan of design 


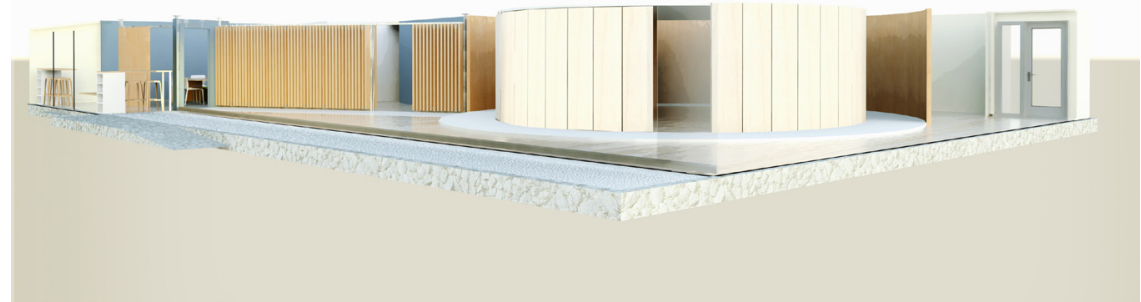

Figure 14: Intervention with Explorer closed

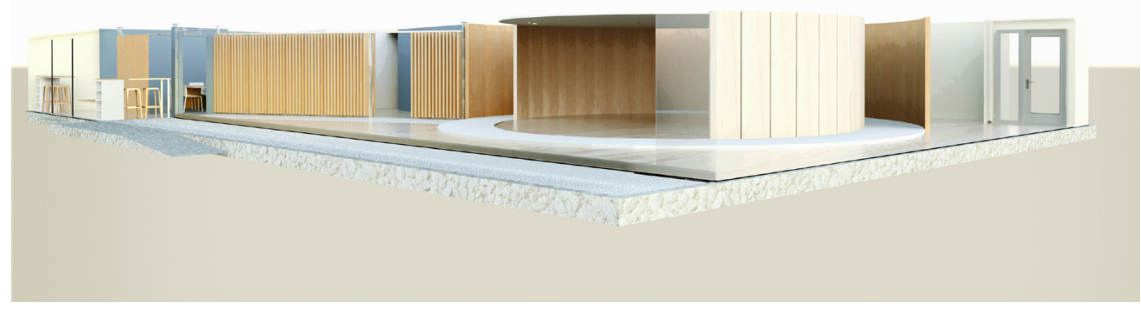

Figure 15: Intervention with Explorer open

\section{A Community Space}

At present the only community group that regularly hire what is Paraparaumu College's year thirteen common room is a church group, which occupies the space on a Sunday.(Fountain, pers. comm., 2014) As per discussions with both the school principal and College administration, it is hoped that the cultural centre will attract a wider community base as a centre for hire. As a means to appeal to a greater target audience, the centre needs to be able to accommodate a varying number of people in a multitude of ways.

As established in the earlier point: Embrace the Environment, the proposed site for this centre sits beside an open grassed area (fig. 13). The proposed scheme acknowledges this sense of openness within the interior intervention, culminating in a transformable space( fig. 14) that is able to open out (fig. 15) as a means to claim the outdoor area as potential community space for large functions. 


\section{DESIGN A N A L Y S I S}

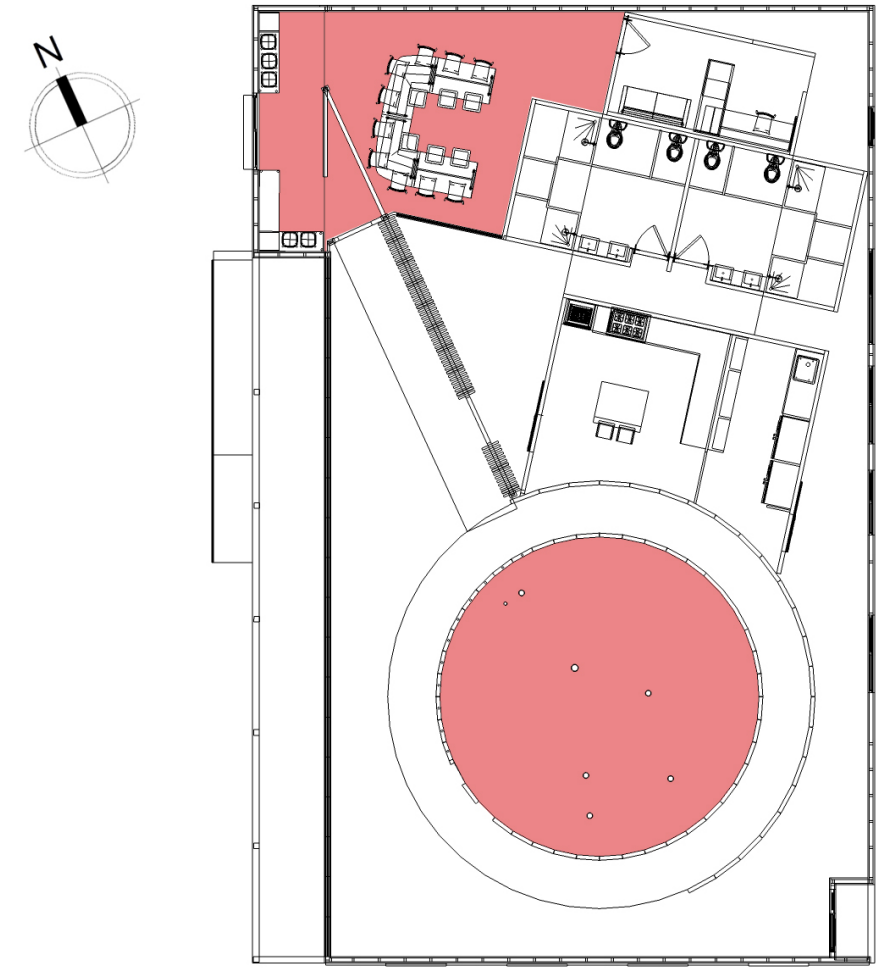

Figure 16: Diagrammatic plan showing multiple learning spaces

\section{A Learning Space}

The discussions between teachers and students differed greatly. The students expressed an ardent interest in informal learning environments where they were not subjected to traditional classroom furniture such as a desks and chairs.(Class, 2014). However, the staff expressed concerns over the effect such an environment would have on productivity levels and the student's ability to learn.(Class, 2014)

The following body of work is a result that attempts to navigate this debate while taking into account the theoretical work expressed earlier. As the centre is already divided into formal and informal spaces, the potential for a classroom exists in both areas (fig. 16). A formal learning environment that will operate in a standard table and chair environment will lie adjacent to The Protector. Within the informal space, The Explorer will serve as a space within which the student will have more control of their environment. 


\section{$C O N C L U S I O N$}

It is important to understand how a design functions as a whole and it is beneficial to grasp this understanding early in the design process. Under this chapter we have analysed the significance of embracing the environment, an inherent need to ensure the basics are fulfilled in the formation of a scheme, and the need for flexibility to be present in our designs.

Through the works of Sanoff and Walden we have learned the significance of designing responsive environments that seek to establish a sense of connection to their physical setting, in addition to testing the means by which this can take place through form. 


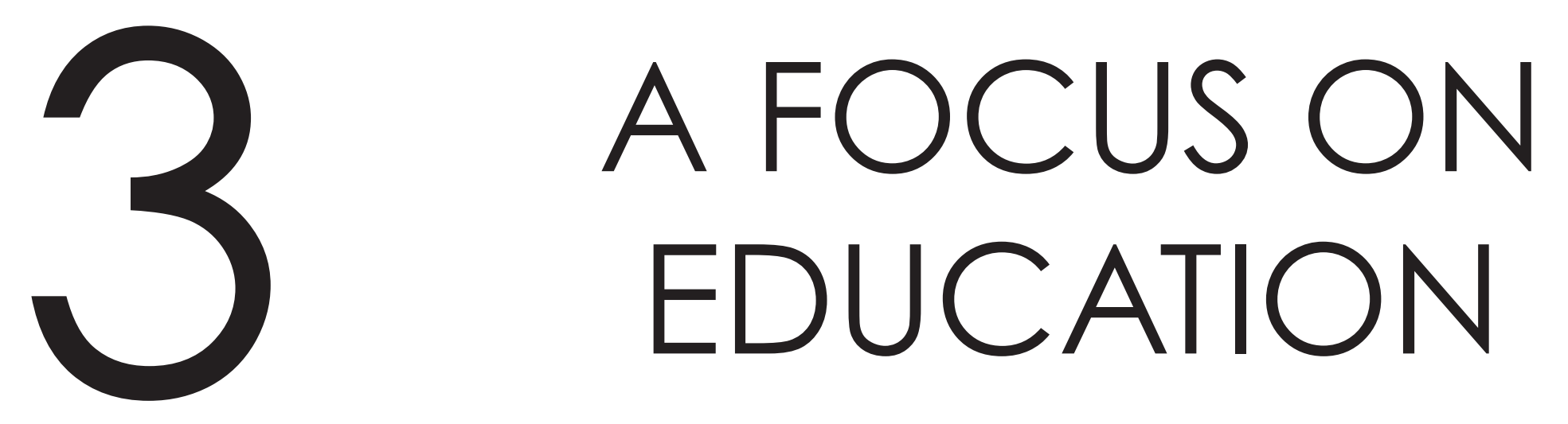


"Culture fills and largely determines the course of our lives"

(Herskovits, 1964, p.4)

This chapter harbours a specific focus on catering to a learning environment. As the intention of this centre is to house the Māori Studies class, it is paramount that education and a learning environment that facilitates a willingness to learn is handled with a great level of care.

To explore this notion of designing for the classroom, this chapter will delve into three distinct points. The first point will seek to make learning important in a traditional classroom environment. The second will encourage moments of learning outside the classroom, using the built form as a means by which knowledge can be gained. The final point under this chapter will delve into the importance of promoting success as a means to maintain the desire to learn.

While the research thus far has stated the importance of establishing a sense of connection to the built form, this chapter will focus specifically on harnessing the student's attention as a means to encourage them to achieve their academic potential. 
MAKE LEARNING IMPORTANT 
At the forefront of school planning is the efficiency of learning spaces. The means with which children learn has altered rapidly with both the changing social and technological landscapes, yet our built form has failed to mirror this transformation experienced in the modern world.

If we wish to support our students as they navigate these crucial schooling years then, as interior architects, we need to ensure that learning is put at the forefront of consideration. If we foster a willingness and interest in learning through the environments we produce we can inflame a sense of curiosity for the world that surrounds the student. If we can rouse awareness for their environment we can instil a sense of connection to their school and through this sense of connection we can harness an ambition to achieve and feel pride for the success they experience.
The world today is one full of options and choices, yet traditional school buildings see the same classroom format repeated in succession. There is little opportunity for customisation and even less scope for a variety of learning environments that have the ability to cater to an individual's preference.

The following point will look at the cultural centre in terms of a learning environment, focussing on its organisational structure as a means to cater to a diverse learning group. 


\section{THEORETICALANALYSIS}

Commonly, there are two variations of which traditional school design follows. The first is known as open schools, named as such due to their lack of walls and corridors. The second is often referred to as egg carton schools, which is characterised by enclosed classrooms positioned on either side of a corridor. (Sanoff) Today, both models can be evidenced in the layout of schools across New Zealand and each hold a certain benefit in the growth and development of children today.

"Open schools were envisioned as having distinct economic advantages since the space usually consumed by corridors becomes usable for learning. Additionally, this configuration also fosters a sense of unity, particularly with regards to team teaching, due to the lack of walls and defined spaces." (Sanoff, 1993, p. 141) Hertzberger also remarks "there is a greater sense of community and the galvanizing effect a view of each other and each other's work can have." (Hertzberger, 2008, p. 60) Certainly, there are distinct social benefits with an open layout in the cultivation of community spirit, yet it also gives rise to a clear absence of privacy and problems concerning noise and distraction. (Sanoff, 1993, p.141)

It is this absence of privacy that leads designers to look at enclosed environments as a foundation for school design today, as "privacy has been shown to contribute to a child's growth and development." (Sanoff) While, additionally "studies in the use of partitions to protect activity areas from community areas in secondary schools have shown that there were fewer interruptions where academic areas were distinct from non academic areas.” (Sanoff, 1993, p. 141)

It seems that in order to put learning at the forefront of our schemes our designs must harbour a degree of flexibility. Spaces need to be assigned in terms of use to ensure an environment is generated that enhances collaborative and individual endeavours. As Hertzberger expresses "we only make real progress when the work environment itself manages to bring about a good working atmosphere." (Hertz- 
berger, 2008, p. 60) A work environment that puts an unnecessary burden upon our teachers or distracts students from their tasks at hand is an environment that fails to meet the needs of its school. 


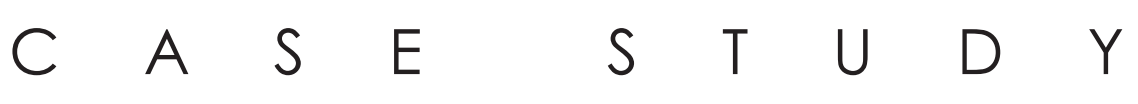

Rewi Thompson's Puukenga, located on Unitec's Mount Albert campus in Auckland will serve as the case study for an exploration into innovative spaces that focus on the importance of learning. The centre, in a similar fashion to what is proposed for Paraparaumu College, serves as the space for Unitec's Māori studies class.

The design seeks to combine modern day functionalism with traditional values as a means to bridge the gap between cultural learning and conventional teaching environments. The form itself "consists of a series of metal-clad teaching pods plugged into a large wooden whare-form that contains common space and administration facilities."(Barrie, 2014)

Thompson sought to distinguish the formal learning spaces from communal areas even further through his use of form and materiality. The public spaces are associated as being feminine, while the classrooms are defined as male forms. "These rooms are portrayed as the male influence in Puukenga to protect and compliment the female influence. For this reason, the classroom design expresses the male principles - rational and pragmatic. The external appearance reflects an ordered and formal format. The interiors are practical and focussed." (Thompson, 1995, p. 21) The robust and straight edged forms of the classrooms offer a strong visual contrast to the feminine curves of the communal spaces.

It is this clear distinction of space and use that presents itself as a fusion of the open school and egg carton layout discussed earlier. This blend of open and enclosed space gives rise to the opportunity of harnessing the benefits of both learning environments, ensuring the centre has a clear focus on the importance of learning. 


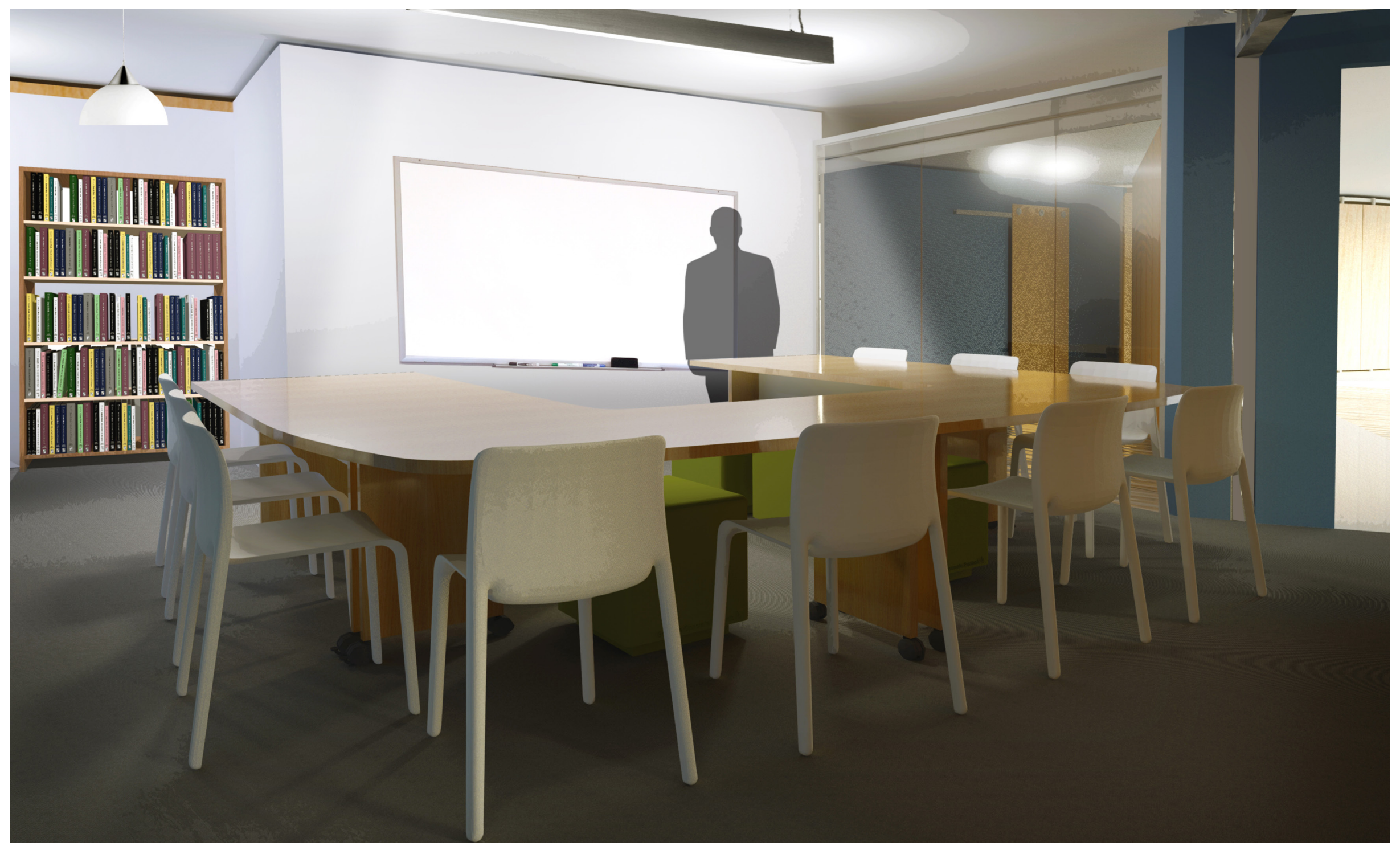

Figure 17: Formal Classroom

62 


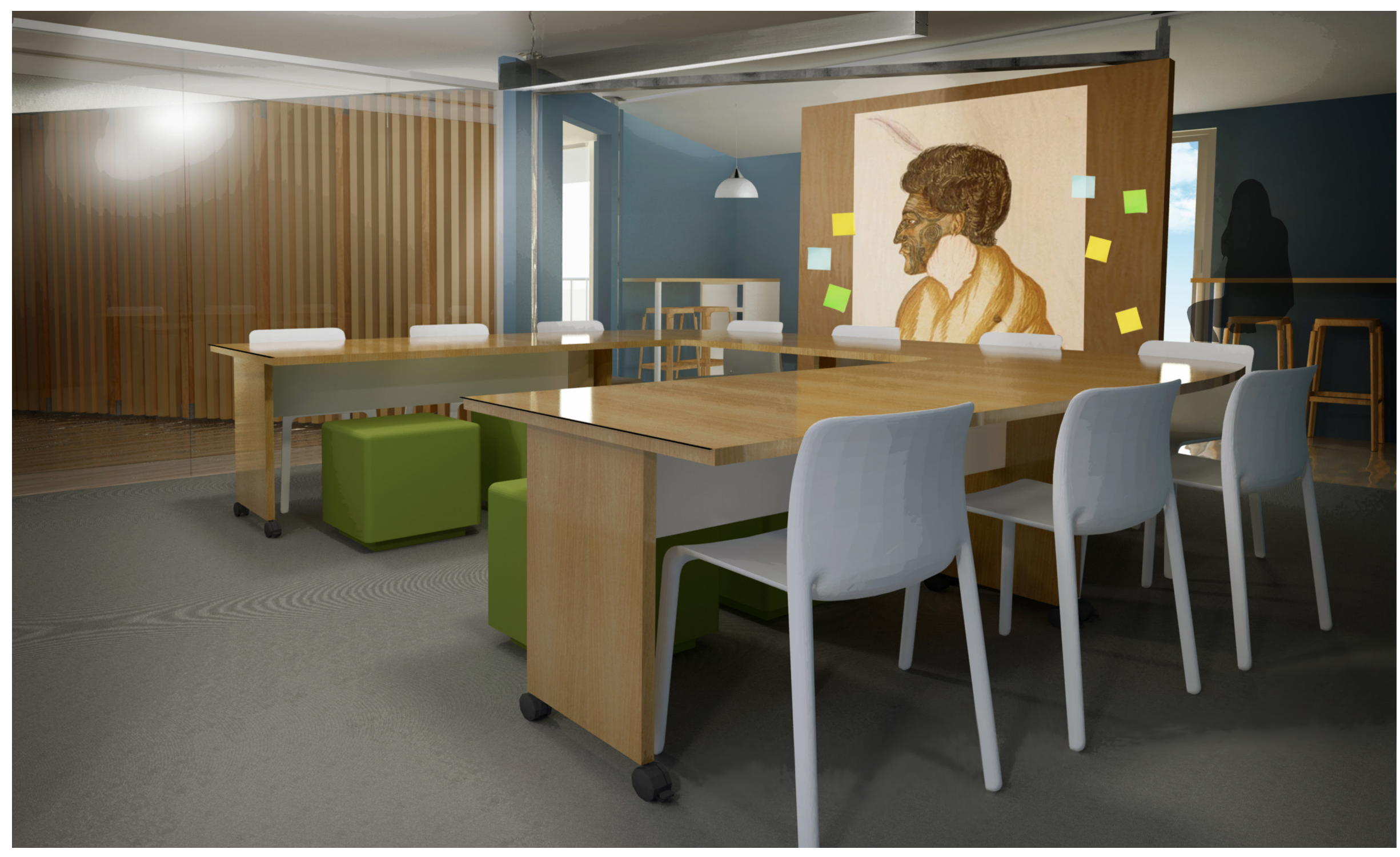

Figure 18: Formal Classroom 


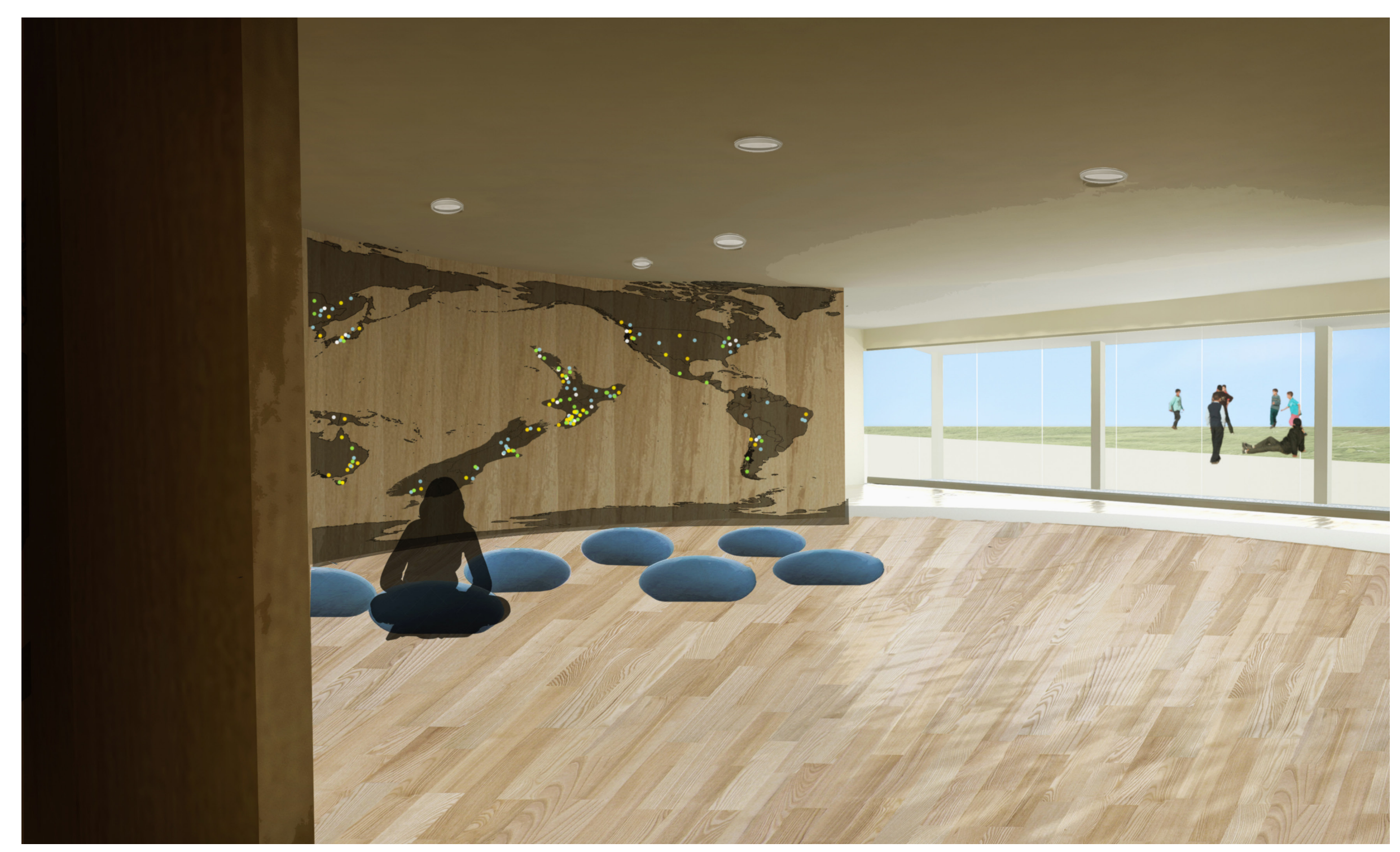

Figure 19: Informal Classroom 


\section{DESIGN A N A L Y S I S}

Thus far this point has explored two distinct learning environments prevalent in schools today. Each offers a form of student support that the other cannot provide, yet both have their drawbacks in being a holistic and functional space. Through the study of Rewi Thompson's Puukenga, this cultural centre will seek to provide the Māori Studies class of Paraparaumu College with a flexible space that has areas designated for both individual and group activities.

Both spaces have an element of openness to them, as a visual connection between students remains an important motivator in the success and completion of work. However, similar to Puukenga, both spaces are defined by their form as a means to differentiate the learning environment.

The above images (fig. 17 and 18) depict a traditional learning space. Located at the rear of the centre, the classroom's northern placement is to give it greater proximity to both the library, which sits to the rear of the centre, and the remaining school facilities. In terms of design the traditional classroom is comprised of strong lines that sit at odds with each other as an expression of the shifting grid upon which the entire school sits.

The second space sits within the heart of The Explorer (fig. 19) and will take on the role of an informal learning environment. Envisioned as a space that would cater for group discussions, The Explorer will lack conventional furniture in favour of instilling a more relaxed environment though the use of soft furnishings instead. Upon meeting with the student council and Māori studies class at Paraparaumu College, both groups stated that they desired a classroom where they felt at ease, calm and free from the binds of a traditional desk (Class, 2014) (Council 2014). The curved form of The Explorer will force the occupants to focus internally, minimising distractions from outside influences, while the simple seating of pillows and bean bags should encourage the relaxed environment that the students desired. 


\section{FIND MOMENTS OUTSIDE THE CLASSROOM TO ENCOURAGE LEARNING}


While ensuring the physical environment fosters a sense of learning is a fundamental basic in the design of a classroom, the intrinsic need to learn does not need to be satisfied purely by curriculum. To ensure a space that is fully engrained in the success of student's education, it is important that the centre offers moments of learning outside of the classroom.
This following point will discuss the notion of interior architecture as an educational tool. A means by which curiosity and moments of realisation can be experienced beyond the customary form of a preset programme of study. "Young adolescents require diversity, which entails different opportunities for learning and different relationships with a variety of people." (Sanoff, 1993, p. 140) While the configuration of learning spaces adheres to Sanoff's need to foster learning environments for different relationships, there is still a lack of true diversity in learning opportunities within this centre. 


\section{THEORETICAL ANALYSIS}

A familiar theme throughout this body of work has been the need to provide a diverse environment that can cater to a variety of social groups and situations. Therefore it is natural that this need for variety also extends to the learning opportunities that are available for students.

As Sanoff elaborates "young adolescents need opportunities for self-exploration as they integrate the change of adolescence into a new sense of self and as they begin to think about future vocations and avocations." (Sanoff, 1993, p. 140) It is this connection to self discovery and life beyond the construct of secondary school education that highlights the need to not only provide opportunities for learning but also to encourage the act of self discovery, to place them in better stead for their adult life.

Hertzberger further adds to the potential for self-educating spaces through his comparison of a school to a city, referring to this model as The Learning City. “The Learning City has to arouse one's curiosity and there must always be things left to be discovered" Further elaborating "This spatial condition is all about leaving space and making space for ambiguity, room to move and freedom of interpretation, allowing a more sophisticated, layered image of society to emerge." (Hertzberger, 2008, p. 252)

Both Sanoff's and Hertzberger's comments are important. Together they state the significance of ensuring the learning environment offers the opportunity of self-discovery as a means to both foster a student's sense of curiosity in their physical environment but also as a means to sharpen their sense of intuition. Hertzberger further elaborates on this notion though, by adding that these moments of discovery need to take place indefinitely, an evolutionary space. While Hertsberger makes this link it is Sanoff who presents the possibility for the manifestation of such a space, "(students) need opportunities for meaningful participation in school and community. Not only can schools provide the structure and means for young adolescents to 
have a real voice in the running of their schools, but they should also have the opportunity to identify and carry out projects that will improve the schools environments." (Sanoff, 1993, p. 140) 


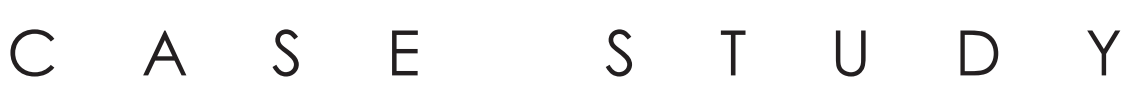

The juxtaposition of Puukenga's male and female forms gives rise to an intuitive mode of discovery regarding the union of space and the relationship between public and private domains. Giving the separate forms these distinct characteristics it aided Thompson in his quest to generate "an understanding of the importance of traditional protocol in the design of Māori buildings, in particular Tapu and Noa with the Marae context." (Thompson, 1995, p. 21) Indirectly it gives the occupant an insight into traditional Māori design and customs of which they control their depth of experience and learning.
However, the built form was not the only means by which Rewi Thompson endeavoured to take the occupant on a journey of self-discovery. The inclusion of "a watercourse that reinstates a fresh-water spring once used by local Māori” (Barrie, 2014) adds to Thompson's complex narrative while reinforcing Māoris connection to the land as part of Thompson's attempt to educate through form, of Māori values. 


$$
b
$$




\section{DES I GN ANALYSIS}

Following Hertzberger, Sanoff and Thompson's train of thought, the cultural centre will seek to educate outside of the traditional curriculum through two means. Firstly through direct design considerations that will be unchanging and intertwined with the narrative of journey that defines the cultural centre as a whole. Secondly, it will seek to educate through the direct contribution of inhabitant to form in order to create an organic and evolving interior space.

The first moment of discovery is exhibited as a compass and evidenced through the combined forms of The Guide and The Explorer (fig. 21). As The Guide runs along the navigational point of north it intertwines with The Explorer's form which sees its entry and exit points sitting on the east and west axis. This form of navigational narrative intertwines with the second discovery point, which sees the constellation of Matariki being depicted in the lighting configuration of The Explorer (fig. 20). As the stars were used as a navigational compass for Māori explorers, the representation of this constellation offers a connection to the overall narrative of the centre, while offering a visual reference of one of the most important star formations in Māori custom.

Thus far the focus has largely been on providing moments of direct learning through the built form. However all three architects have expressed the need for community contribution to the centre, both as means to foster a connection to the space but additionally to provide others with a new point of learning. As a method to facilitate this ideal the intervention has been designed with the intention of generating more surface area. It is anticipated that by having more workable planes upon which work can be displayed both from students and the wider community, as a society we can begin to learn more about one another while ensuring a sense of attachment to place. 
PROMOTE SUCCESS 
The final point under the chapter: A Focus on Education will reference the importance of promoting success within our schools. Until this point we have focussed on how the interior intervention contributes to the academic process of learning, this point will instead focus on the willingness to maintain a commitment to learn.
Schools today offer means by which they display the achievements of their students, however, this privilege is relegated to a very select few and in many cases is easily dismissed as an unattainable goal for most students. This dismissal ensures that schools lose a simple means by which they can engage and connect with their students. A physical showing of a student's achievement that is visible to their peers has the ability to spark both pride and self-belief in their academic pursuits that, if gone unrecognised, could leave a student feeling disengaged and insignificant in the machine that is the traditional education system.

The suggestion to promote student success through a visual display is primarily to encourage a tangible thread by which they can measure their achievements. Sanoff states that with regards to students, "they need to build confidence and a sense of worthiness, and opportunities to succeed. They also need the self satisfaction that comes from knowing that they have done something well, and it is recognised by others for its importance.” (Sanoff, 1993, p. 140) 


\section{THEORETICAL ANALYSIS}

While the ultimate goal of this centre is to establish a sense of connection for the student to the school, one must first try to determine why a number of students seek to leave school before gaining any formal qualifications. Raymond Padilla has delved into this topic through his text, Student Success Modelling: Elementary School to College. In this body of work he comments "student success involves more than preventing students from abandoning their studies. To promote student success one also must understand why many students, some of them under the most challenging circumstances, are able to complete all program requirements and actually graduate with a diploma or degree. If one can understand how it is that such students achieve their success, one can develop strategies and practices that will enable more students to perform as the successful ones do" (Padilla, 2009, p. 9)
Padilla proposes the use of monitoring success as a means to identify key factors that work in favour of the academic achievements of some students and applying these to students whom the traditional education system is failing. In contrast Sanoff speaks of the importance of success purely as a self-motivating form of encouragement for the student to persevere with their individual academic pursuits. While both maintain that there is an importance in promoting student achievement, it is Ero Saarinen in Robert Hershberger's text that relates this ideal back to an architectural language. If, as mentioned previously, we view the promotion of student success as a tool by which this cultural centre can look to achieve its goal of student retention, Saarinen's comment holds more weight.

"The late Ero Saarinen, for example, was the most emphatic about the communication function of architecture: "I have come to the conviction that once one embarks on a concept for a building, this concept has the be exaggerated and overstated and repeated in every part of its interior, so that whenever you are inside or outside, the building sings with the same message" (Hershberger, 1970, p. 36) 


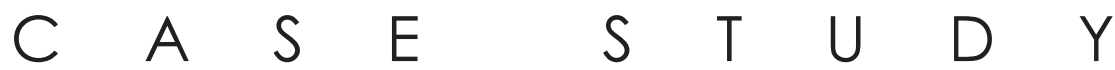

Having been built by Unitec apprentices, (Barrie) Puukenga is the embodiment of promoting student achievement. It's formation and construction at the hands of students ensures, in much the same way that Sanoff suggests, a sense of pride in their success is instilled upon viewing the structure. By giving the students the opportunity to contribute directly to the centre, Thompson ensured the students would become the guardians of the spaces and instil within each student a deeply rooted connection to the building that visitors to Puukenga would be unable to relate to. It fosters a unique bond for student to place that this centre will strive to emulate. 


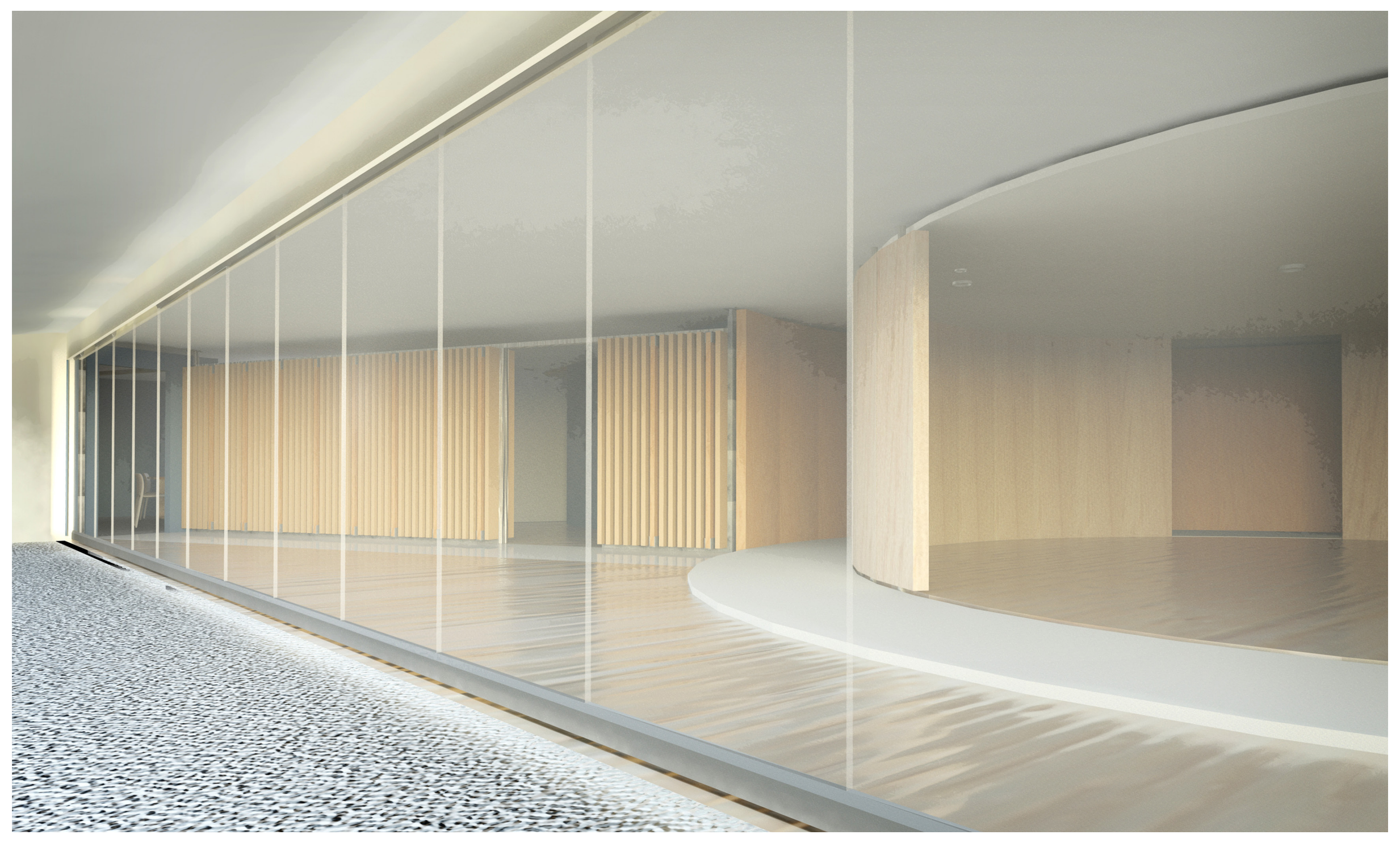

Figure 22: Guide with panels closed 


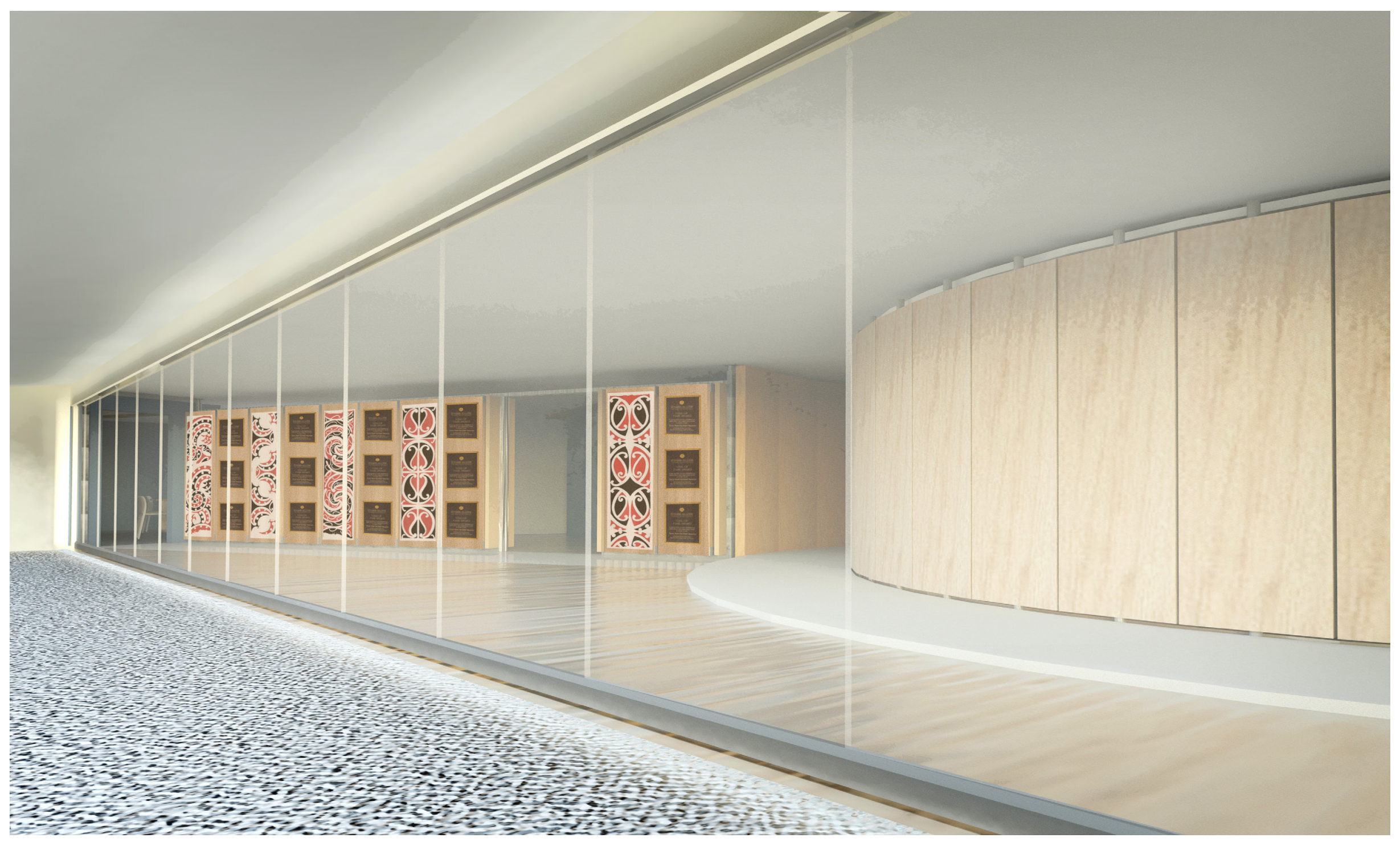

Figure 23: Guide with panels open 
As stated under the point: Find Moments Outside the Classroom to Encourage Learning, this cultural centre was designed with the intention of creating a greater surface area upon which carvings, imagery, or student work can be displayed. While this centre may not be able to replicate Thompson's act of having Puukenga built by the students, it does not mean that the students of Paraparaumu College will be unable to physically contribute to the formation of the centre in some way.

Certainly, while the option for direct contribution is both possible and encouraged, it is The Guide that acts as the main point of interest in ensuring student achievement is promoted within this space. As the intervention sits along the main traffic paths of the student body and within the sight lines of passing motorists, The Guide, running a significant length of the centre, is positioned to take advantage of this stream of people. 


\section{DES I GN ANALYSIS}

What is proposed is a transformable wall, comprised of a series of slatted panels $450 \mathrm{~mm}$ by $2150 \mathrm{~mm}$ in height, and lined the length of The Guide's northern orientation. Comprising of sixty-three panels in total, the sixth panel in sequence is able to slide out and flip to sit flush against the other panels of The Guide.

This wall is significant to the design for a number of reasons as, when it is closed (fig. 22) and each panel is situated in its original position, the design is perforated allowing an observer outside the centre a clear view to see the workings within. However this visual connection is disrupted once the wall is opened and the display panels unfasten. This then gives the occupants the power to control what is seen within and returns a sense of privacy to the realm of The Provider.
It is envisioned that this display, due to its location as the first point of visual contact, would make an ideal surface upon which student work can be displayed to the public outside (fig. 23). The panels themselves can fit three A2 sized printouts in portrait each and with 10 display panels it provides a large surface area to service the achievements of students who undertake Māori Studied as a class. 


\section{$C O N \quad C \quad L \quad U \quad S \quad I \quad O \quad N$}

Rewi Thompson's Puukenga is significant in showcasing the potential for learning outside the confines of a traditional classroom. Through his precedent, Paraparaumu College's cultural centre now harbours the ability to connect with its students on a multitude of levels while still maintaining the overall narrative of journey that lays the foundation for the centre's sense of purpose.

Ultimately, what seemed to weigh heavily in this particular chapter though was the conflict of public and private space. While openness was deemed necessary as a means to promote student success to those outside the centre, the actual endeavour of learning and educating required more a more personal and controlled atmosphere. What resulted was a conscious need for flexibility as a means to make maximum use of the designated space. 


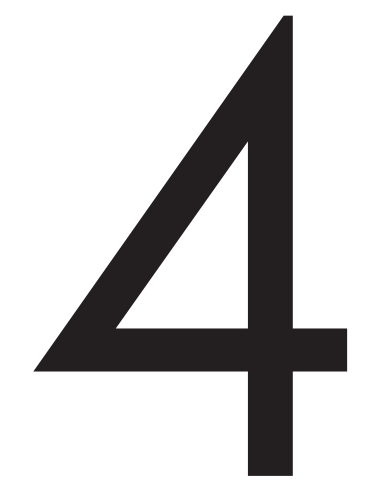

PEOPLE ARE

IMPORTANT 
“...Yet rarely intrudes into conscious thought."

(Herskovits, 1964, p.4)

The final points in this body of work will be covered by the chapter: People Are Important. Where the previous chapter was dedicated to looking at the centre from an educational standpoint, this chapter, and its subsequent two points, will endeavour to analyse the scheme from its secondary function as a community space.

With the intention of this centre being a hireable space for community groups, it is important that the intervention will be able to meet the needs of these groups.

The remaining two points will articulate the need to highlight the cultural differences of people both as a showcase of diversity and as a means to education people on the structure of their community. The second, and final, point will remark on the importance of designing for the present. Additionally, the work of Lyonel Grant will serve as the case study for this chapter, analysing the formation of his wharenui, To Noho Kotahitanga. 
HIGHLIGHT THE CULTURAL DIFFERENCES 
The first point under the chapter: People are Important, conveys the significance of highlighting the cultural differences. Schemes purporting a cultural agenda lend themselves to matters of cultural awareness. Yet, when we aim to address a community defined by location we cannot ignore the fact that this geographic locality is an amalgamation of cultures and lifestyles. Therefore it is important that we recognise this diversity and cater our designs to be inclusive of the differences that define us.
The following point will analyse the design intervention as used by members of the public. It will not reference matters of educational consideration, but rather how the space will operate as a multipurpose environment to meet the changing needs of various community groups and opportunities for cultural expression. 


\section{THEORETICALANALYSIS}

Thus far there has been a significant emphasis placed on the meaning of the intervention and its ability to be viewed by an observer. Michael Hays acknowledges this relationship by suggesting if "culture is the cause and content of built form; the task of the interpreter then becomes the study of objects and environments as signs, symptoms and instruments of cultural value." (Hays, 1984, p. 16)

If we begin to view the students as observers and the intervention as the manifestation of culture, following Hay's theory the centre is reduced to a study tool for public inspection. Tariq Modood remarked "there is an ethnic assertiveness, arising out of the feelings of not being respected or of lacking access to public space consisting of counter-posting 'positive' images against traditional or dominant stereotypes.” (Modood, 1997, p. 292). This centre seeks to fill this void of positive cultural promotion in an effort to instil a sense of pride and respect for the differences that help to define us as people. Madood further states "it is the politics of projecting identities in order to challenge existing power relations; of seeking not just toleration for ethnic difference but also public acknowledgement, resources and representation." (Modood, 1997, p. 292). If we can move the field of cultural discussion to an open, public forum we can aim to progress towards a community that is increasingly accepting, aware, and excited by the multitude of cultures that exist within our communities.

Following this call for cultural representation and openness, Baydar, when expressing his views on Homi Bhabha's work involving thirdspace comments "Bhabha calls for the recognition of cultural difference based on the negation of the notion of culture as a stable system of reference. He insists that all cultural systems are constructed in an ambivalent space of enunciation and a discontinuous time of translation and negotiation" (Baydar, 2004, p. 20) If culture does in fact exist in a space of such ambiguity as Bhabha purports then a social anchor, such as this cultural centre, would serve to stabilise and present these cultures visually through a means that can be grasped by the students and teachers in this modern age. 


\section{$\begin{array}{llllllllllll}C & A & S & E & S & T & U & D & Y\end{array}$}

Te Noho Kotahitanga Marae, which is located on Unitec's Mount Albert campus will serve as the case study for cultural portrayal in an educational environment. Designed by Lyonel Grant the centre is a marvel of bicultural architecture due to Grant's ability to combine traditional techniques with modern media. (Unitec Institute of Technology, 2010) The result is an interior that resonates with the wistfulness of Māori form combined with elements inspired by the modern world. "The carvings may be traditional in format, but each element has been remodelled to fit modern society and to reflect its influences," (Unitec Institute of Technology, 2010) a move that highlights the cultural differences between traditional Māori architecture and the society with which we are trying to connect to today.
Perhaps Grant's most significant move is his design of one of the later poupous, which serves as "the physical manifestation of Unitec's Te Noho Kotahitanga document - featuring jigsaw pieces that represent the many different people that make up society and the community associated with this marae. Visible across the jigsaw is a tekoteko figure that echoes the figure atop the wharenui - 'He Mihi' literally personifies the moment of encounter between those who meet. As a result of some of these encounters it could be said that the mana of this marae belongs to all different cultures." (Unitec Institute of Technology, 2010) Through the implementation of a unifying concept, Lyonel Grant is able to offer a thread by which people of any culture can feel at one with the space. With regards to Te Noho Kotahitanga, that reference is the representation of Unitec though the built form, which cloaks the Marae in an aspect of familiarity that any Unitec student can identify with. 


\section{DES I GN ANALYSIS}

When taking into account the work of Lyonel Grant, it became evident that to instil a sense of cultural connection to the space there needed to be an element that resonated with people of any background, culture, age or profession. The concept for such a moment was formulated at a discussion with a group of parents and teachers at Paraparaumu College. What was proposed was a large-scale world map where visitors to the school, as part of a powhiri, could place a mark on the location that they identify as being home (fig. 24).

This map would seek to ignite a sense of curiosity for the students of the college regarding the world, and tie back with the centre's overall theme of journey. By having visitors place a mark on the spot that they identify as home it also serves as a visual depiction of the diversity present at Paraparaumu College.

Furthermore, a sense of excitement was also generated after talks with iwi members regarding the formation of this cultural centre and the contributions Whakarongotai could make to the scheme as a whole. From this discussion, what became apparent was the need to generate a canvas upon which Whakarongotai, the community, and the school could begin to display their works. Therefore, as mentioned previously, the intervention needed to offer a means by which visual connection was paramount. In addition to reaching an audience, the design also needed to provide a greater workable surface area for traditional and contemporary work to be displayed. A curved layout created by a number of flat, faceted panels succeeds in offering a greater surface area for exhibition, while the circular nature allows an observer to view a greater number of works from a fixed point (fig. 25).

The aim is to ensure that people of any culture feel a sense of connection to the centre. To foster a renewed interest in the culture and histories that helped to shape us as people, and to ensure that students leave Paraparaumu College with a sensitivity and respect for the qualities that differentiate us as people in the world today. 


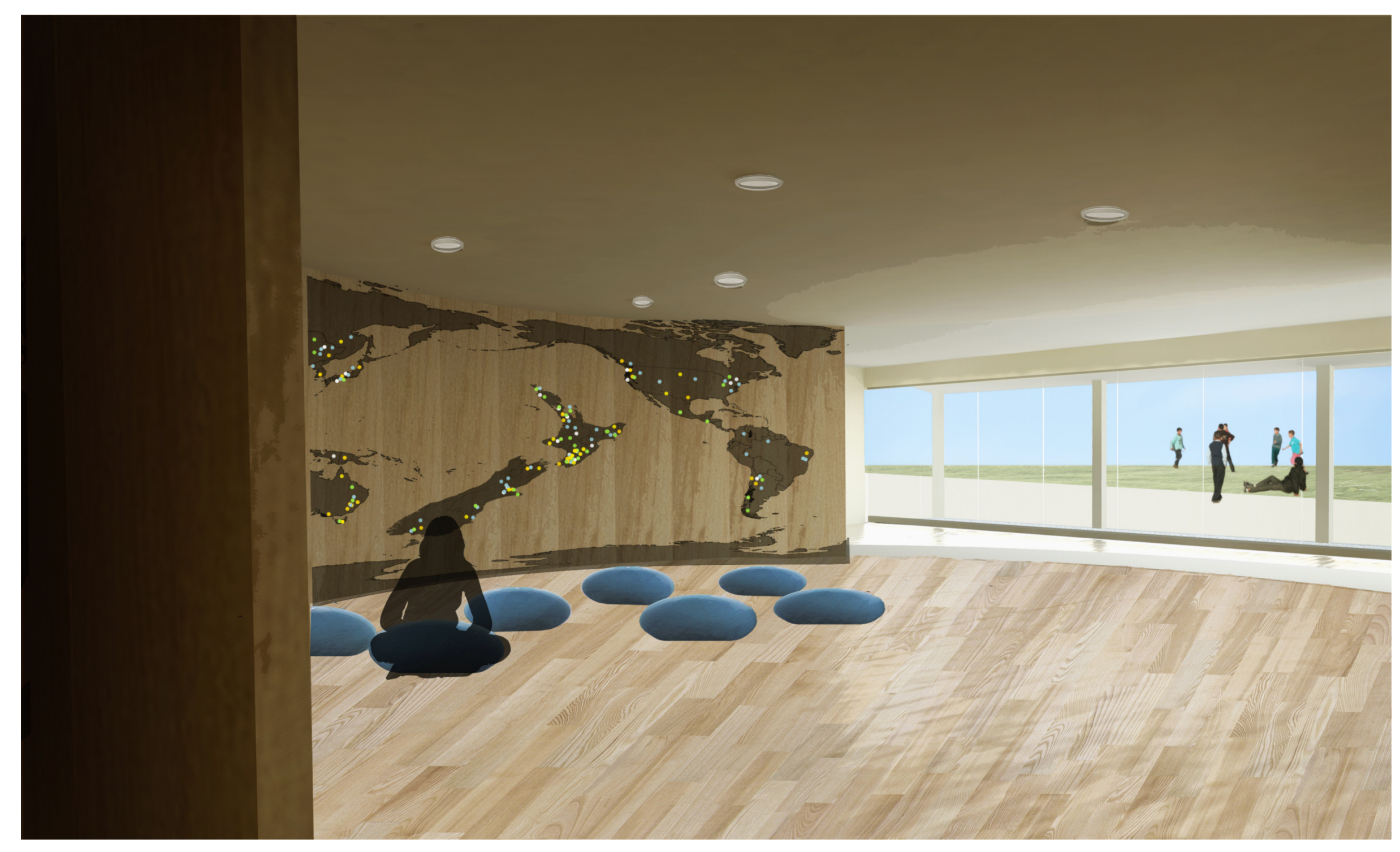

Figure 24: Global map within explorer 


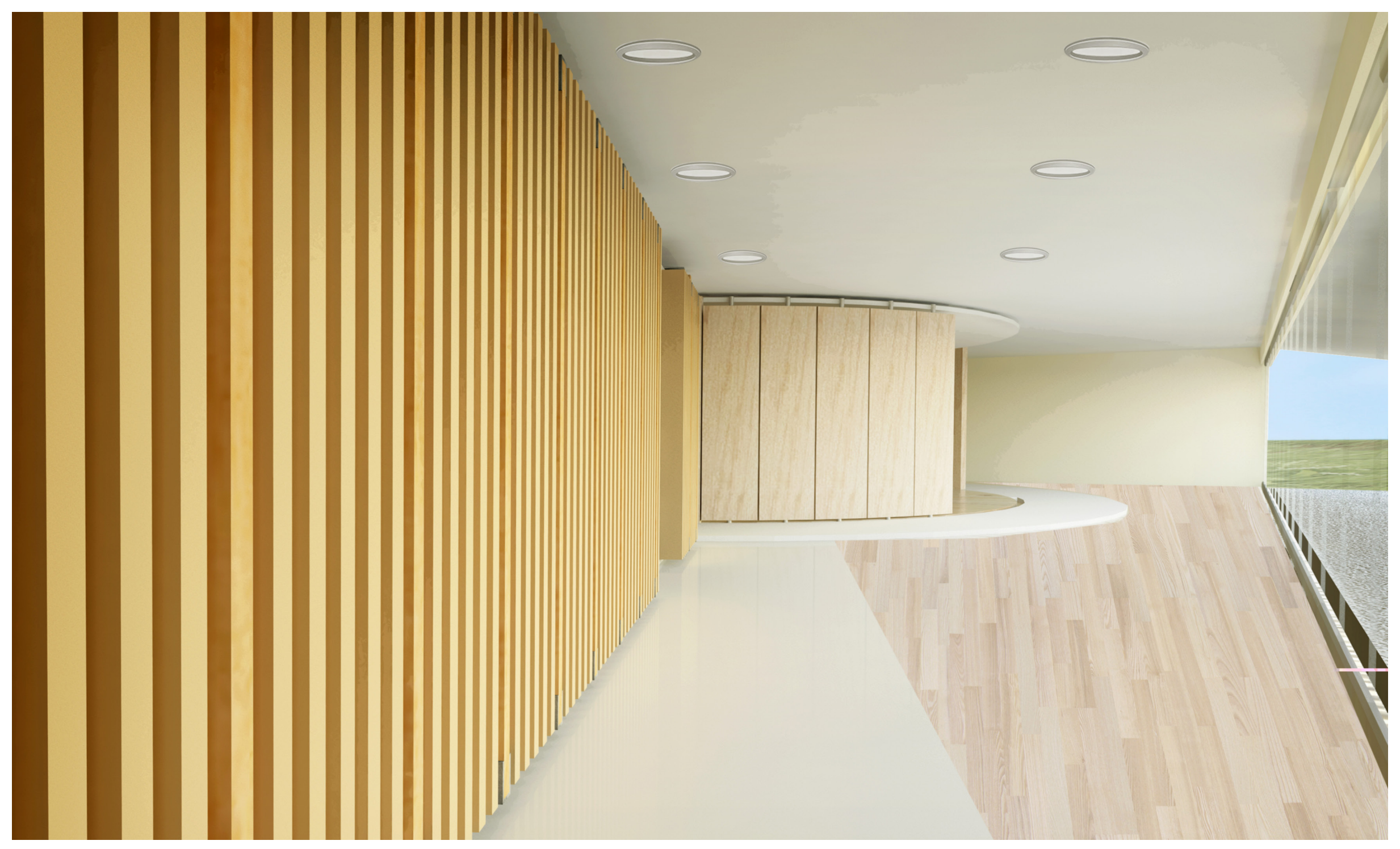

Figure 25: Guide and The Explorer 


\section{DESIGN FOR THE TIME}


Designing for the time can be interpreted in two ways. On face vaue it references what is current, the moment in time within which we stand. However the present changes with each occupier. If we take into account the changing nature of what is current as we move through time it also references an element of future planning. Granted the majority of our educational environments are a stagnant design that has been reproduced for decades. The appeal of this centre is the wish for an intervention that shatters this idea of normal in the hope of creating something unique, current and identifiable.
The following chapter takes note of the importance of designing for the time. That time being now and the time for those who will experience this space in the future as the world and school continue to develop. It is important that if our purpose is defined as fostering a sense of school identity, that this identity is not bound to present day factors and constraints. Once we acknowledge the changing landscape upon which our schools are built we can begin to cater our design to overcome this challenge.

Rotraut Walden observed "investments in children are investments in the future of a country." (Walden, 2009, p. 18). If we choose to invest our time and resources in cultivating a supportive and modern learning environment for our students, our communities will reap the rewards in the future. 


\section{THEORETICAL ANALYSIS}

Architectural theorists have discussed the advantages of designing for the modern world in numerous publications. The Bruntdland Commission labelled the process of meeting current needs as sustainable development, defining it as "development that meets the needs of the present without compromising the ability of future generations to meet their own needs." (Leupen, Heijne and van Zwol, 2005 , p. 43) As a cultural centre that looks to embed itself in the community, it is the forethought of future planning that will contribute to the success of this venture. "The ability of a building to cope with changing uses is becoming increasingly important" (Leupen, Heijne and van Zwol, 2005, p. 98) and is an issue that interior architecture can combat through the repurposing of existing spaces. By designing for the current, as mentioned by Walden previously, we are investing in our future. If we seek to generate an intervention that can adapt to future generations, we continue a cycle that invests in the success of our youth.
There is an inherent need to move away from what has been done as a means to embrace what is to come. Hertzberger identifies this problem and states that in order to achieve this

"The designer of schools must inevitably engage with the dialectics of modern education. We are still building schools for education where pupils are taught what society expects of them and what they have to know and be able to do to stand firm and develop in the society with which they are rooted. It is also about granting space for learning in a broader sense: it's not just a question of satisfying and thus adapting to the requirements made of you but of passing comment, not just accepting but thinking for yourself. Not just adapting to the world, then, but getting the world to adapt to you, to become suited to you." (Hertzberger, 2008, p. 68) 
Winston Elting adds to this notion stating, "by guaranteeing uniformity it insures mediocrity. By endorsing tradition it condemns progress." (Elting, 1951, p. 244) As designers we must be forward thinking. Certainly, we can aim to meet current and future demands through design, yet this should not restrict our ability to take cues from what has been before us. 


\section{CASE STUDY}

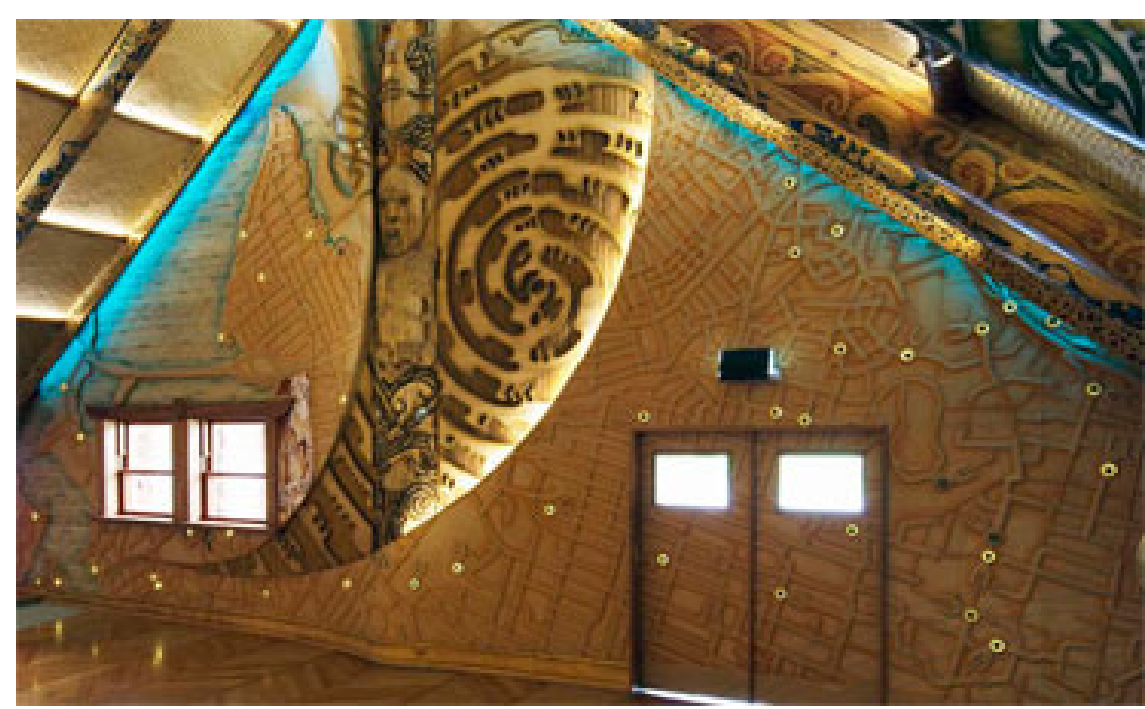

Figure 25: Te Noho Kotahitanga Front Wall
As we look at the importance of designing for people and the integration of a built form that is relevant in an ever-changing world, Te Noho Kotahitanga Marae, will once again serve as the case study for this exploration. With regards to designing for the time, this marae is a marvel of narrative creativity. It pays homage to where we have been, where we are, and where we hope to go; yet uses carved surfaces as a means to uniform the concept.

While the marae itself is a poignant example of cultural design embracing a modern audience, the most significant design move Grant has made with respect to this progression through time, is arguably his design of the front wall (fig. 25). "The internal front wall speaks of today via an expanded roadmap that occupies the entire wall. It can be observed that the modern suburban façade is being stripped back to reveal the old landscape still present beneath modern-day Auckland." (Unitec Institute of Technology, 2010) Grant's contemporary subject matter of an urban street grid speaks of the now, yet the depiction of the old landscape beneath the map ties us to our past. 
$N$

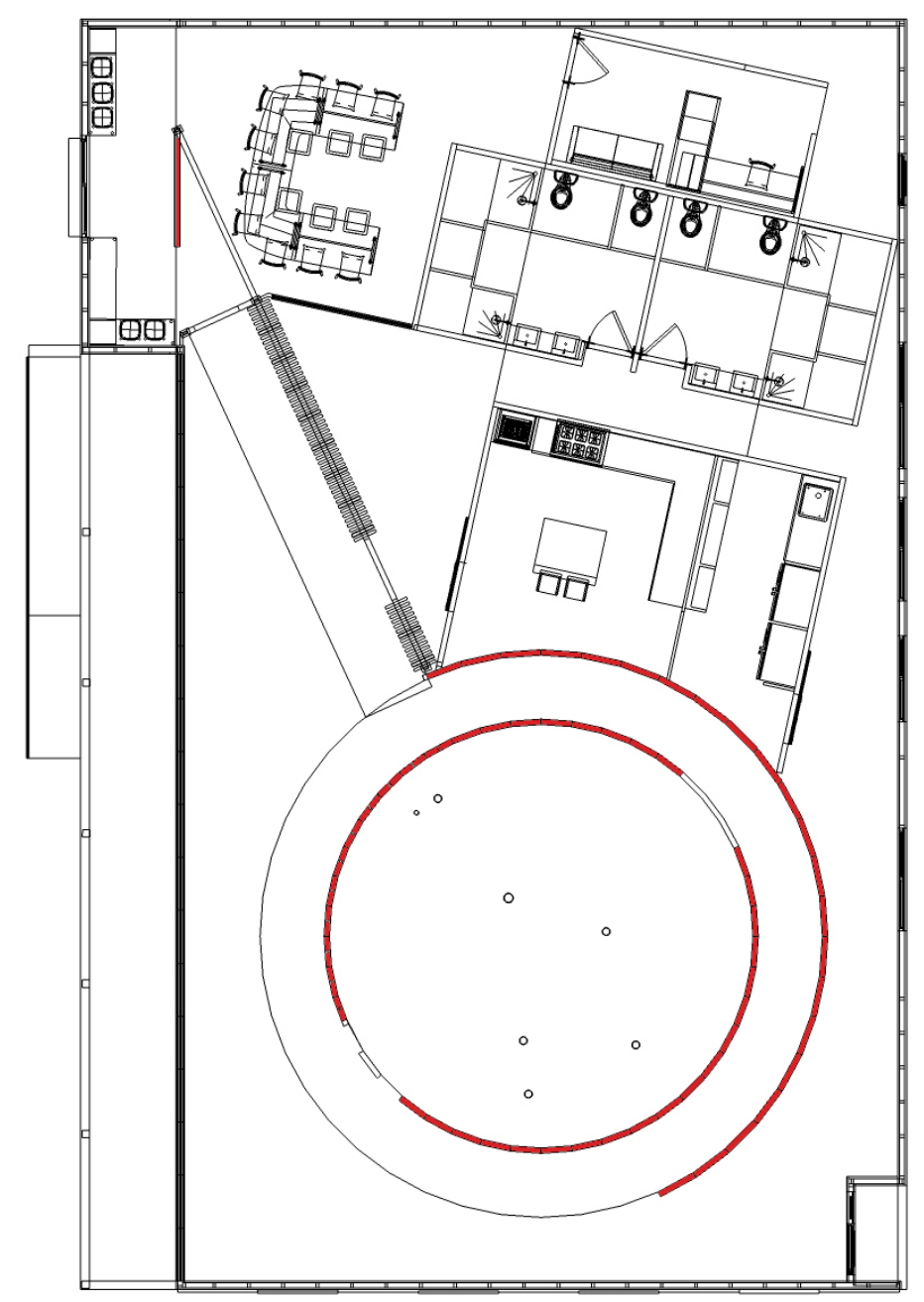

Figure 26: Diagrammatic plan showing walls designated for display 


\section{DESIGN ANALYS I S}

As Lyonel Grant demonstrated, designing for the now can mean more than a simple nod towards the inclusion of technology. Through his carvings, a traditional art form, Grant managed to instil the essence of the present in Te Noho Kotahitanga. Perhaps it is the reworking of such a tradition form to be moulded into a contemporary piece that ensures his space echoes with the presence of a relevant and modern environment.

The inclusion of traditional Māori art forms is anticipated for this cultural centre since talks began with kaumatua of whakarongotai marae (Kaumatua, 2014). At this meeting they expressed an interest in providing carvings to be displayed in the centre as a show of their connection and strengthened relationship with Paraparaumu College.
With the intention of the cultural centre to house these artefacts, special attention was made to ensure adequate wall space was available to display these pieces. As shown left, in red (fig. 26), The Explorer's faceted surface will serve as the canvas upon which the present relationship between iwi and school will be showcased 


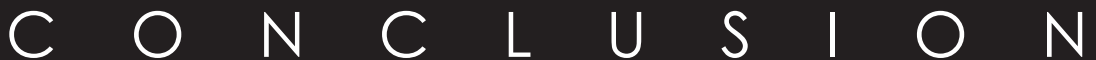

In order to design for the present, this intervention called for more than simply responding with technological integration. As a centre the aims to anchor itself in the community landscape, the opportunity to connect with the present needed to reflect these same social considerations. As a result, the fostered relationship between Whakarongotai and Paraparaumu College became the vessel by which the concept of designing for the present was explored. Designing for a present relationship as a means to cultivate a stronger bond both groups going forward.

While this chapter sought to discuss the inhabitation of people with space, what really became apparent was the opportunity for social progression that this centre provides. As an icon for community advancement it is important that this centre, like Lyonel Grant's Te Noho Kotahitanga marae, maintains a relevance that keeps it connected to the people of Paraparaumu and anchored within the landscape. 


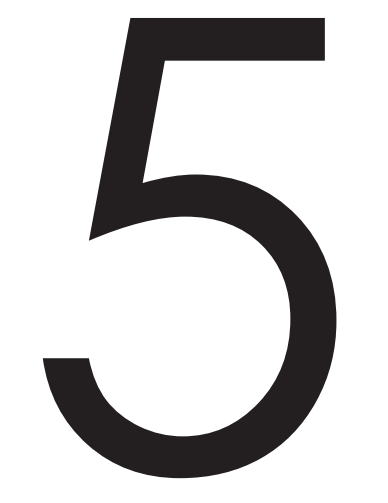

\author{
FINAL \\ CONCLUSION
}


This body of research has analysed the cultural centre proposed for Paraparaumu College through three different means, firstly as a tool for social change, then as an educational environment that will support a Māori studies class, and lastly as a community space that seeks to engage with the public. With the centre's sense of purpose tied to the concept of journey, this overall theme acts as the conceptual fastening for a space that is rich in narrative meaning.

As a whole, this scheme is a strong depiction of socially conceptual design reworked to cater to a modern day audience. This form of biculturalism offers an environment that is unique and individualistic to the people of Paraparaumu, while seeking to embrace people of varying cultures and backgrounds.

The intent of this project is to ignite a sense of enthusiasm within the student with regards to their education. It is anticipated that through fostering this sense of interest the school will retain a greater number of pupils and see an increase in students achieving their academic potential.

While the proposed scheme offers a venture that deviates from the traditional educational environment, opportunities for personalisation, flexibility, and functionality are still present. As a body of work interested primarily in the operation of the interior environment, there is a missed opportunity to inhabit the surrounding space outside the exterior shell.

If this project were to be pushed further, moves could be made to occupy beyond the existing shell of the building. Furthermore the educational environment could be challenged to encourage different methods of learning, engaging other senses and really pushing the envelope for an involved learning experience

Certainly, as designers, we can seek to contest the notion of normal through complex interventions. Yet, no matter the intricacy of a project its success is still determined by people. If people fail to resonate with the message the centre portrays then the space has failed to serve its purpose. Thus far the proposal of this centre has garnered a positive reaction from all parties involved, a strong sense of support for the goals it seeks to acheive.

Therefore it is of great importance that we continually seek to push our educational environment and arm our youth with the right tools and mindsets to see them flourish in their adult life. This centre, and the work explored in this thesis,makes some positive moves in this direction. 
BIBLIOGRAPHY 


\section{Book:}

Herskovits, Melville Jean. Cultural Dynamics. New York: Knopf, 1964.

Hertzberger, Herman. Space and Learning: Lessons in Architecture 3. Rotterdam: 010 Publishers, 2008.

Lackney, Jeffery A. "A Design Language for Schools and Learning Communities." Schools for the Future: Design Proposals from Architectural Psychology. Ed. Rotraut Walden. Cambridge: Hogrefe \& Huber Publishers, 2009. 155-168.

Lasdun, Denys. "Architecture in an Age of Scepticism: A Practitioner's Anthology." Lasdun, Denys. The Architecture of Urban Landscape. London: Heinemann, 1984. 137-139.

Leupen, Bernard, René Heijne and Jasper van Zwol. Time-based Architecture. 010 Publishers, 2005.

Modood, Tariq. "Culture and Identity." Modood, Tariq, et al. Ethnic minorities in Britain: diversity and disadvantage. Policy Studies Institute, 1997. 290-338.

OWP/P Architects, VS Furniture, Bruce Mau Design. The Third Teacher: 79 Ways You Can Use Design to Transform Teaching \& Learning. New York: ABRAMS, 2014.

Padilla, Raymond V. Student Success Modeling: Elementary School to College. Sterling: Stylus Publishing, 2009.

Walden, Rotraut. "Conclusion: What Makes a School a School of the Future." Schools for the Future Design Proposals from Architectural Psychology. Ed. Rotraut Walden. Cambridge: Hogrefe \& Huber Publishers, 200

\section{Article in Journal:}

Baydar, Gülsüm. “The Cultural Burden of Architecture.” Journal of Architectural Education (2004): 19-27.

Brown, Deidre. "The Architecture of the School of Māori Arts and Crafts." The Journal of the Polynesian Society 108.3 (1999): 241-276.

Elting, Winston. "Educational Architecture." College Art Journal 10.3 (1951): 244-247.

Hays, Michael K. "Architecture: Between Culture and Form.” Perspecta 21 (1984): 14-29.

Hershberger, Robert G. “Architecture and Meaning.” Journal of Aesthetic Education 4.4 (1970): 37-55.

Leach, Neil. "Belonging: Towards a Theory of Identification with Place." Perspecta 33 (2002): 126-133.

Sanoff, Henry. “Designing a Responsive School Environment." Children's Environments 10.2 (1993): 140-153.

Thompson, Rewi. "Puukenga Māori Education Centre at Carrington Polytechnic." Transition 12 October 1995: 20-23. 


\section{Web Material:}

Barrie, Andrew. "Itinerary n.20." Architecture Archive. 15 June 2014 $<$ http://www.architecture-archive.auckland.ac.nz/docs/block-digital/2009-02-Digital-Rewi-Thompson-Guide.pdf $>$.

Paraparaumu College. Houses. 01 January 2014. 01 April $2014<\mathrm{http}: / /$ www.paraparaumucollege.school.nz/students/student-information-booklet/our-values-Māori-and-engilsh/tertiary-information-for-year-13-1>.

Unitec Institute of Technology. Blend of classic and contemporary design. 2010. 30 January $2015<$ http://www.unitec.ac.nz/marae/Blend\%20of\%20 classic\%20and\%20 contemporary\%20design.php>.

Winter, Gareth. "Place names cast light on legend's rich tapestry." 2 August 2010. Wairarapa Times-Age. 12 June $2014<$ http://www.nzherald.co.nz/wairarapa-times-age/news/article.cfm?c_id $=1503414 \&$ objectid $=10999607>$.

\section{Interview:}

Class, Māori Studies. Student Interview Jazmyn Edwards. Paraparaumu, 20 August 2014.

Council, Student. Student Council Interview Jazmyn Edwards. Paraparaumu, 20 August 2014.

Fountain, Gregor. Preliminary Meeting Jazmyn Edwards. Paraparaumu, 28 February 2014.

Kaumatua, Whakarongotai. Te Ati Awa Interview Jazmyn Edwards. Waikanae, 27 August 2014.

\section{Images:}

Figure 1

Sourced from North Island 1:1 Million Crown Copyright Reserved

Zealand, Land Information New. "New Zealand small scale topographic maps." Land Information New Zealand. 1 May $2014<$ http://www.linz. govt.nz/land/maps/linz-topographic-maps/new-zealand-small-scale-topographic-maps>

Figure 2

Gilfillan, John Alexander. "Wai-Kanae Pa and Kapiti. [Before 1847]." Downes, Thomas William :Old Whanganui. Hawera, W. A. Parkinson. Wellington: Alexander Turnbull Library, 1845.

Figure 3

Sourced from Topo50 map BP32 - Paraparaumu Crown Copyright Reserved

Zealand, Land Information New. "Map Chooser - BP32." Land Information New Zealand. 1 May 2014 <http://www.linz.govt.nz/land/maps/ linz-topographic-maps/map-chooser/map-chooser---bp32>

Figure 25

Sourced from Unitec Gallery Marae Copyright Reserved

Technology, Unitec Institute of. "Gallery.” 2010. Marae Te Noho Kotahitanga. 13 April $2014<$ http://www.unitec.ac.nz/marae/Gallery.php>. 
APPENDIX 


\section{NTRODUCT ION}

As a project undertaken in partnership with another party, the following appendix will include the material formulated for the meetings that took place with Paraparaumu College throughout the course of this project.

As Paraparaumu College was the main party with whom feedback and discussion was garnered it was an important part of this research that participants be sourced from a varying group to establish a holistic opinion. As a result, staff, students, parents, community members and local iwi were invited to take part in a discussion group.

Upon the completion of these discussion groups a design was formulated and then presented to the group at large during a Board of Trustees meeting that took place at Whakarongotai Marae in October 2014. From this meeting the final design, which is portrayed in this thesis, was formulated.
The final meeting was with Paraparaumu College's Board of Trustees and took place in April 2015 as a final presentation of this body of work.

The reaction to this project was overwhelmingly positive from all parties involved, with the final design being described as inclusive and an exciting interpretation of the brief provided by the school.

What will follow in this appendix is the material presented at these meetings, including the participant information sheet and questionnaire from the initial discussion groups that took place in the early part of 2014.

Following this is the booklet that was handed to those that attended the first design presentation in October, and lastly the booklet as was seen by members of the Board of Trustees in April. 


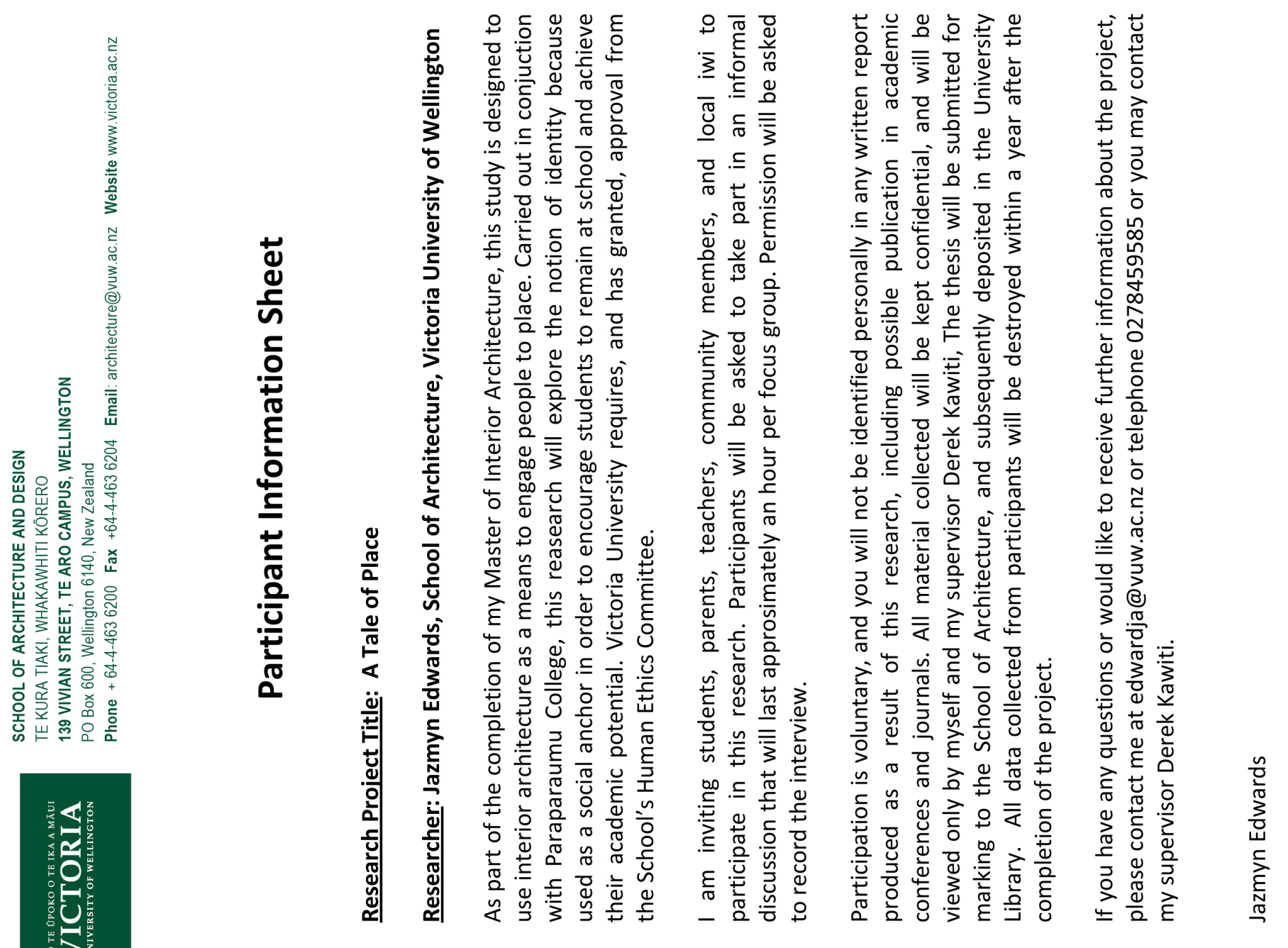




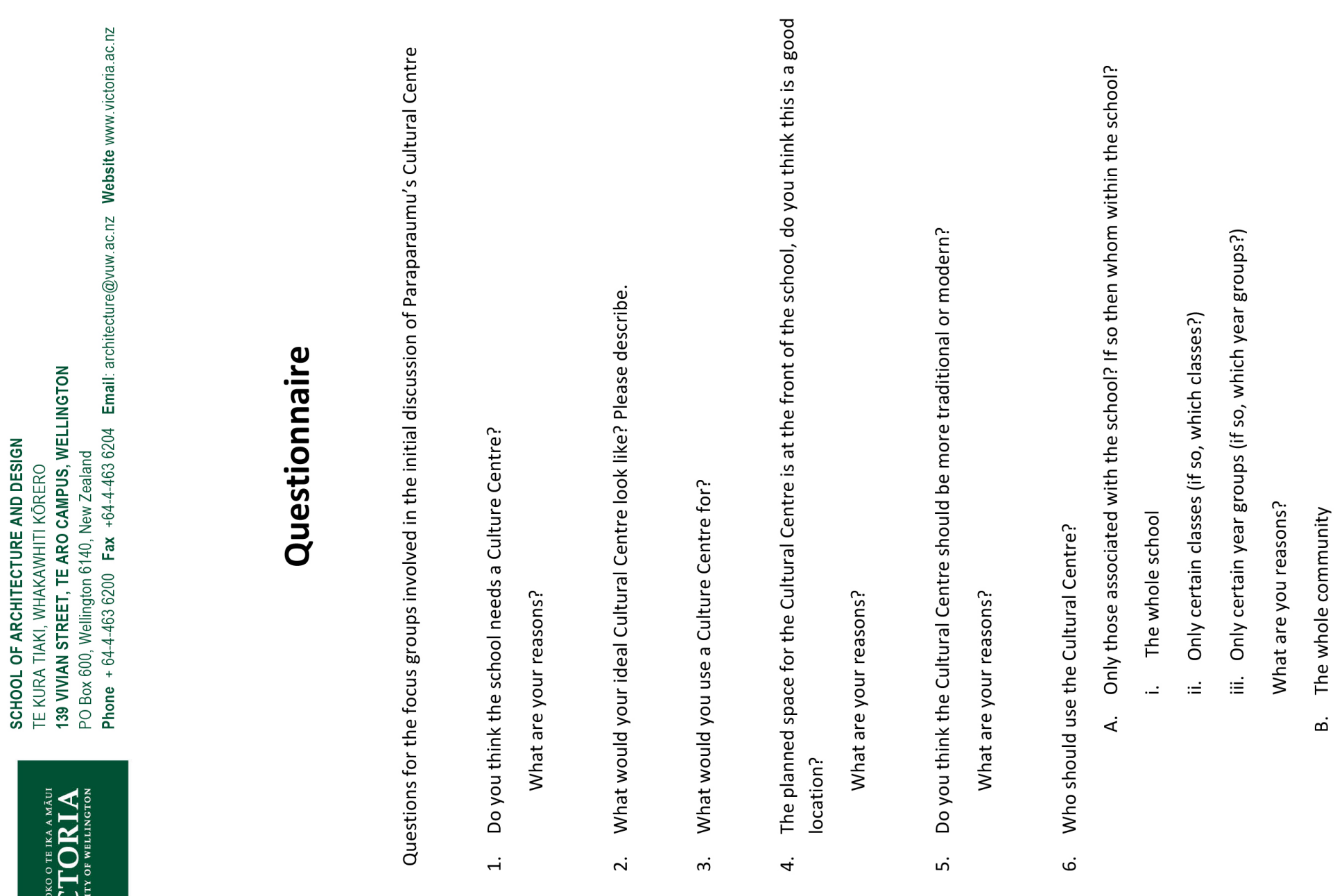


OCTOBER 2014 BOOKLET 


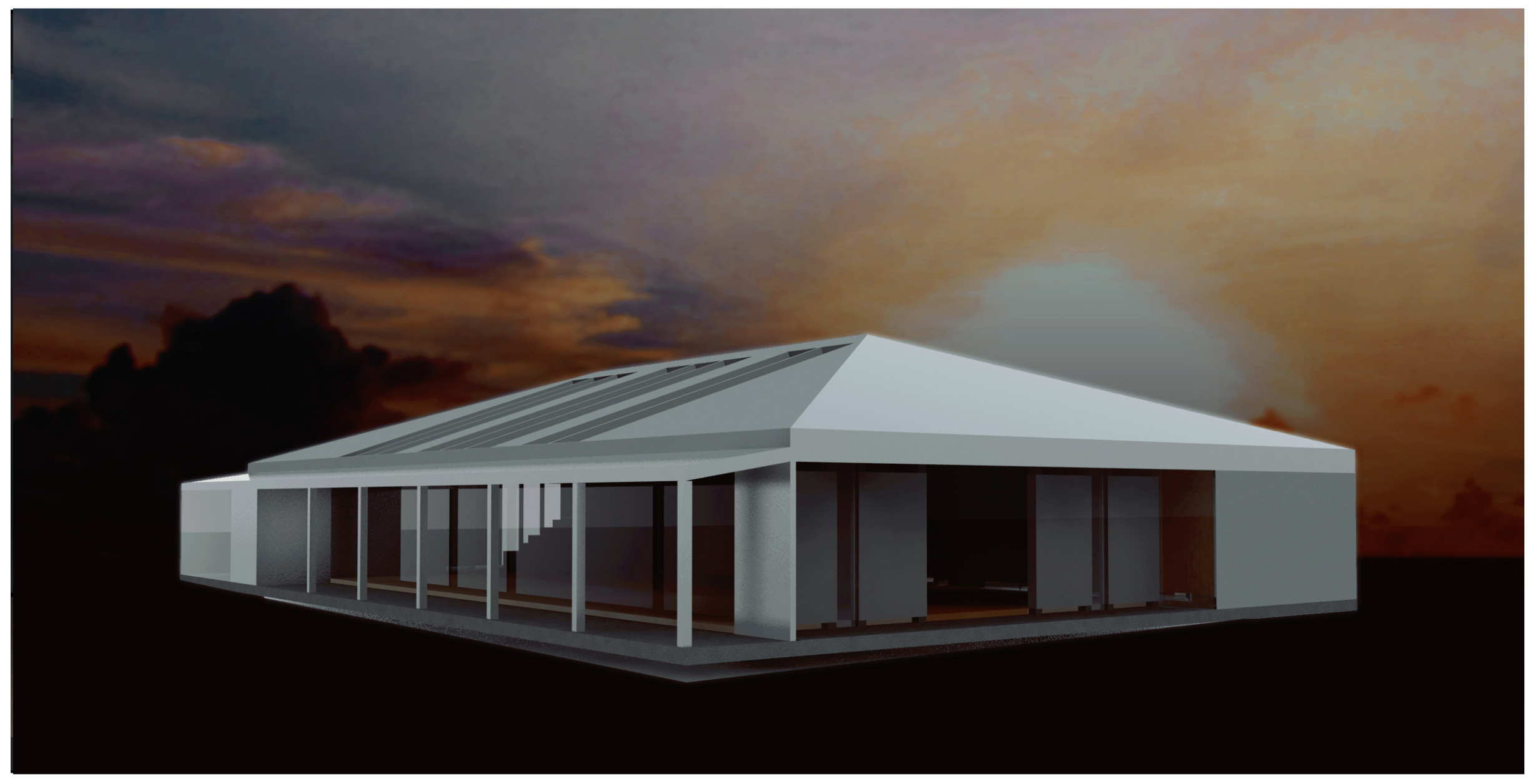




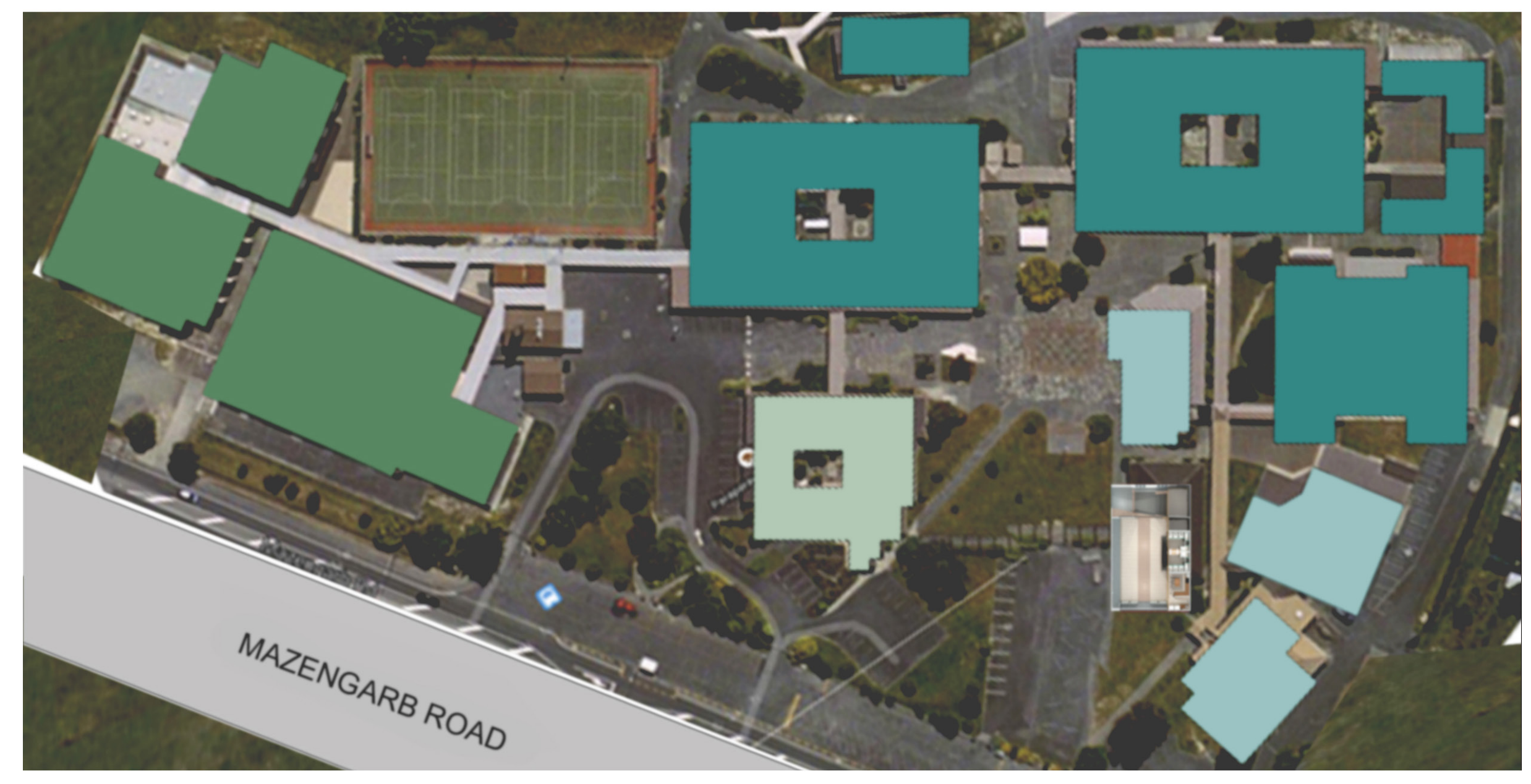




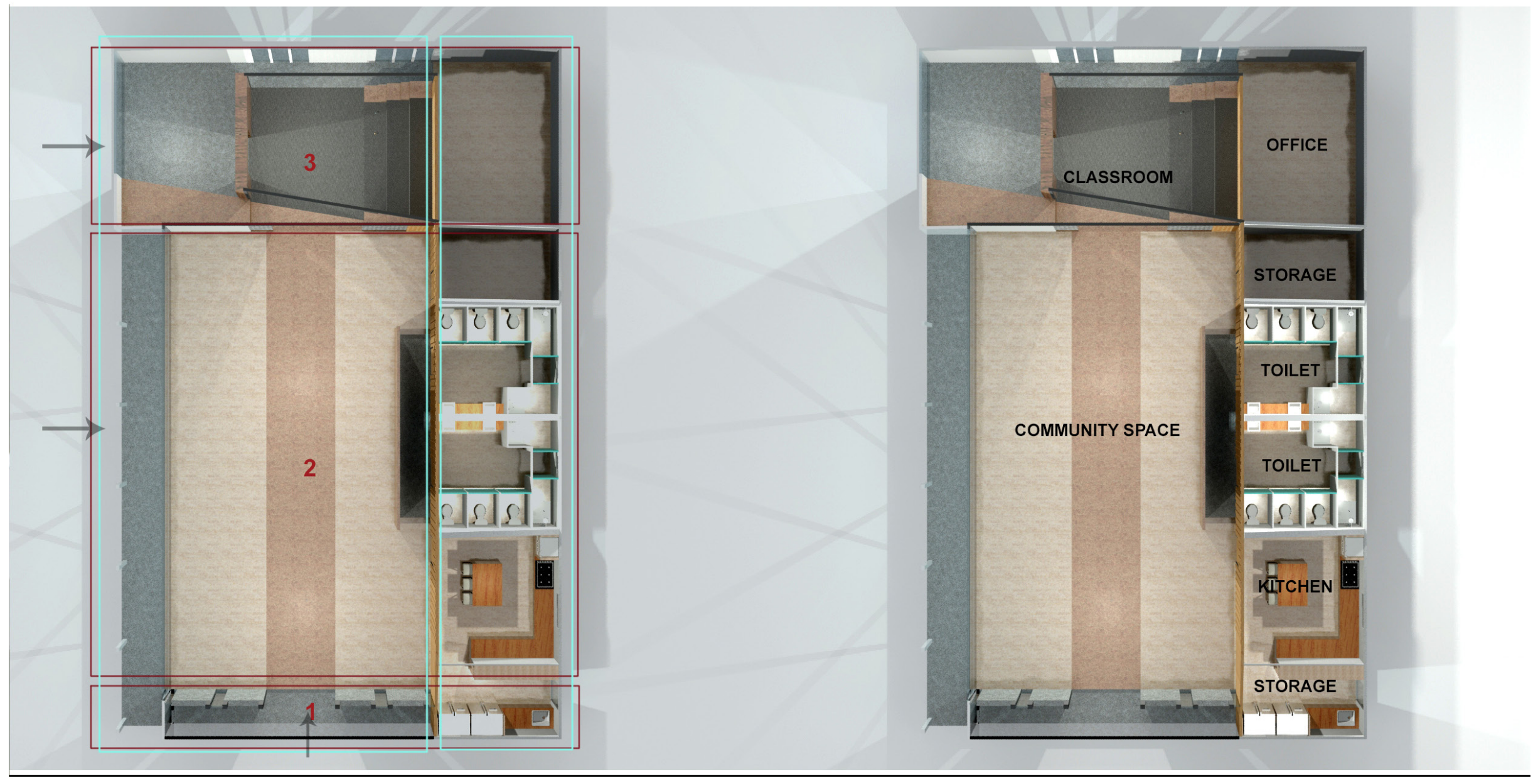




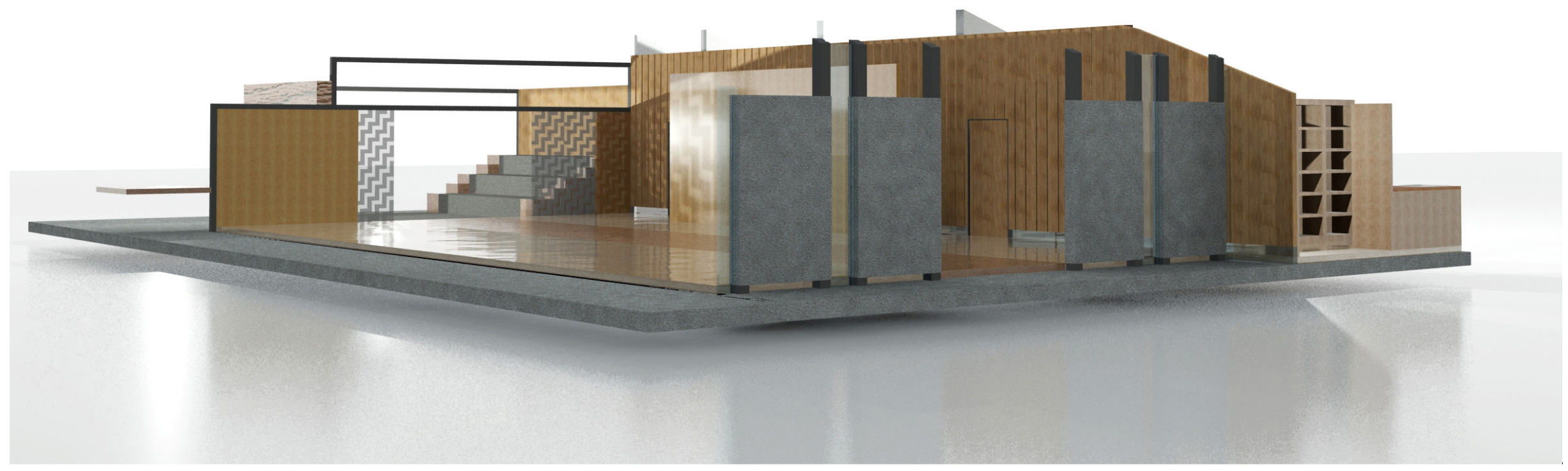




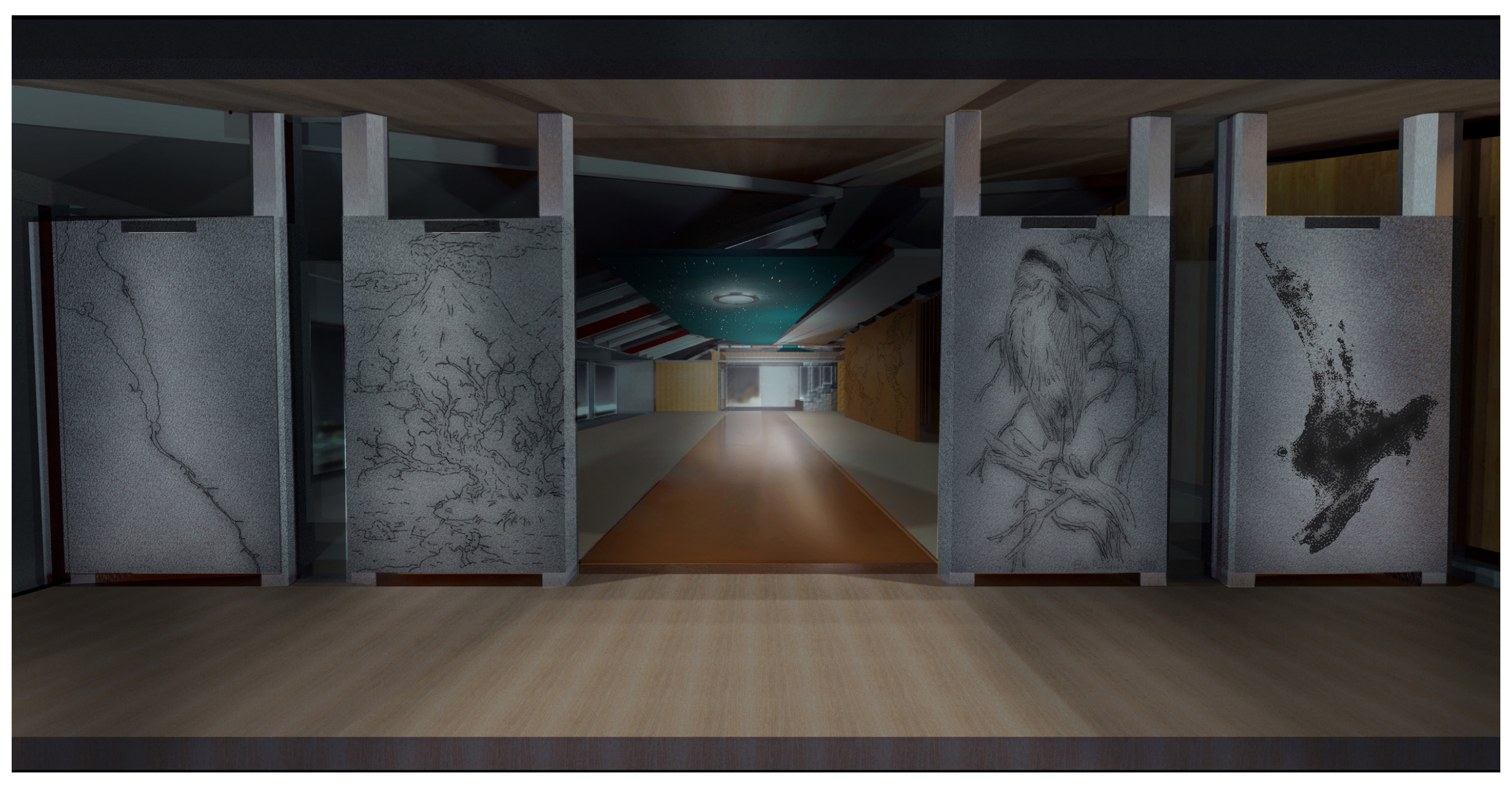




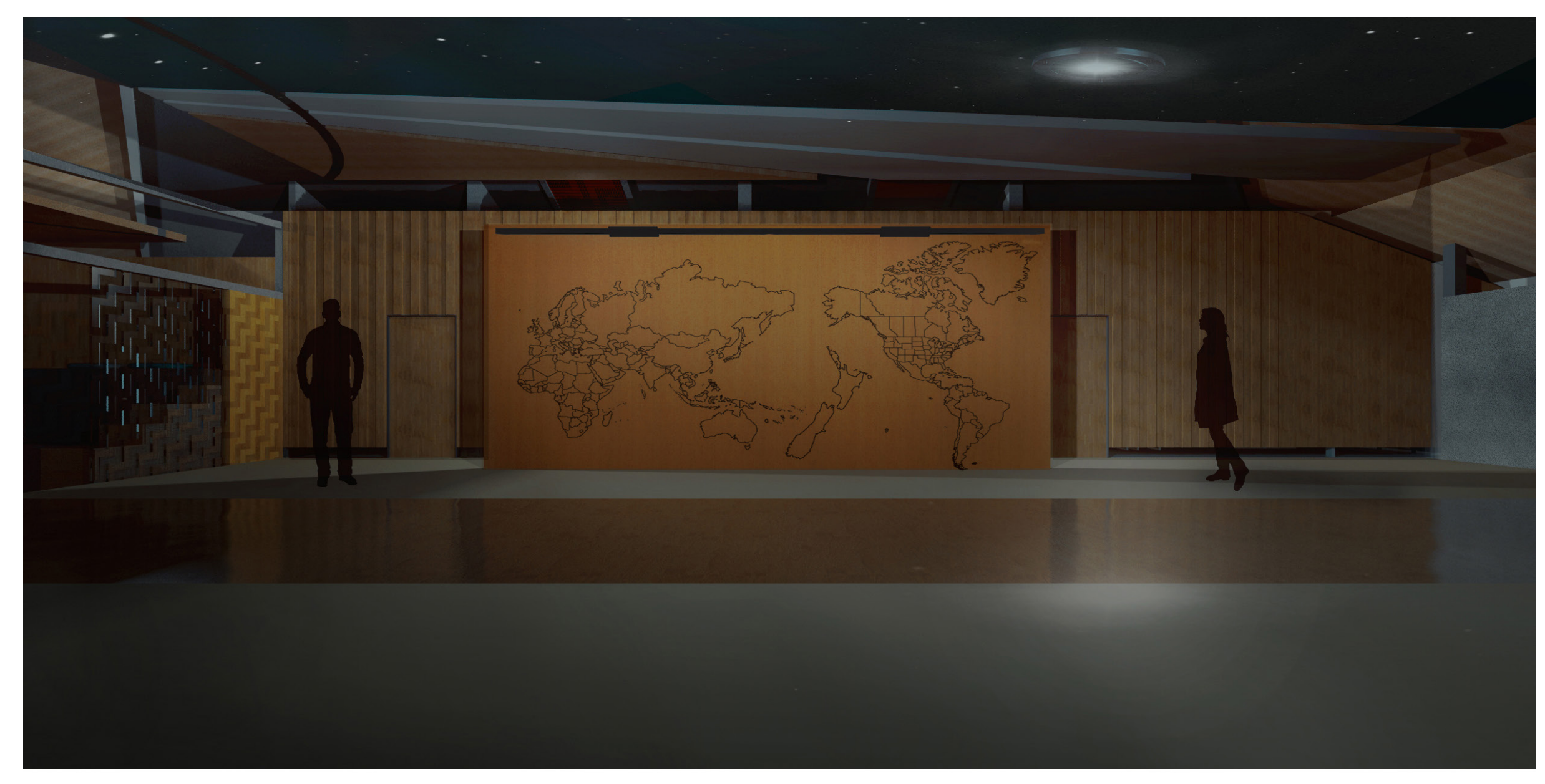




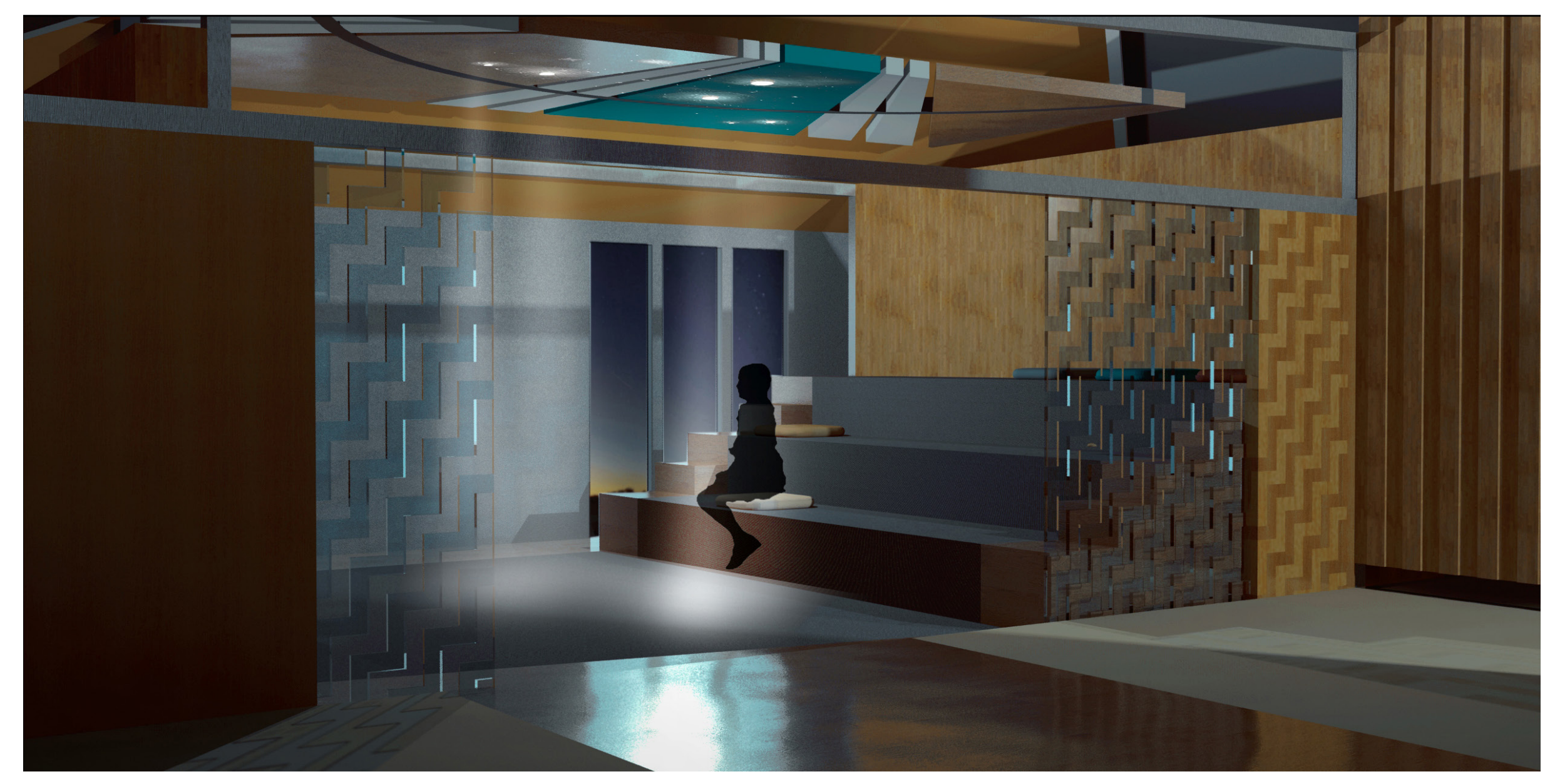




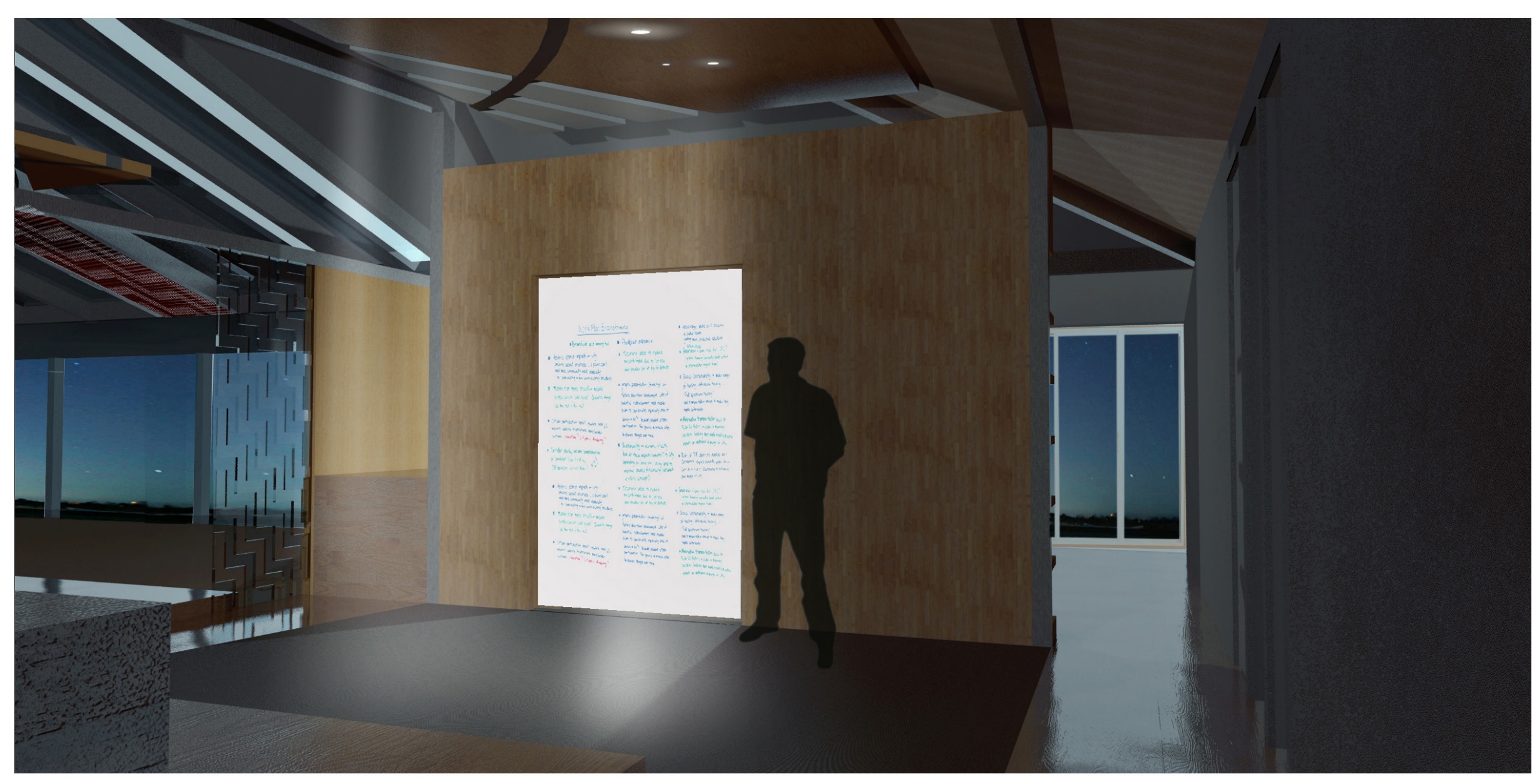




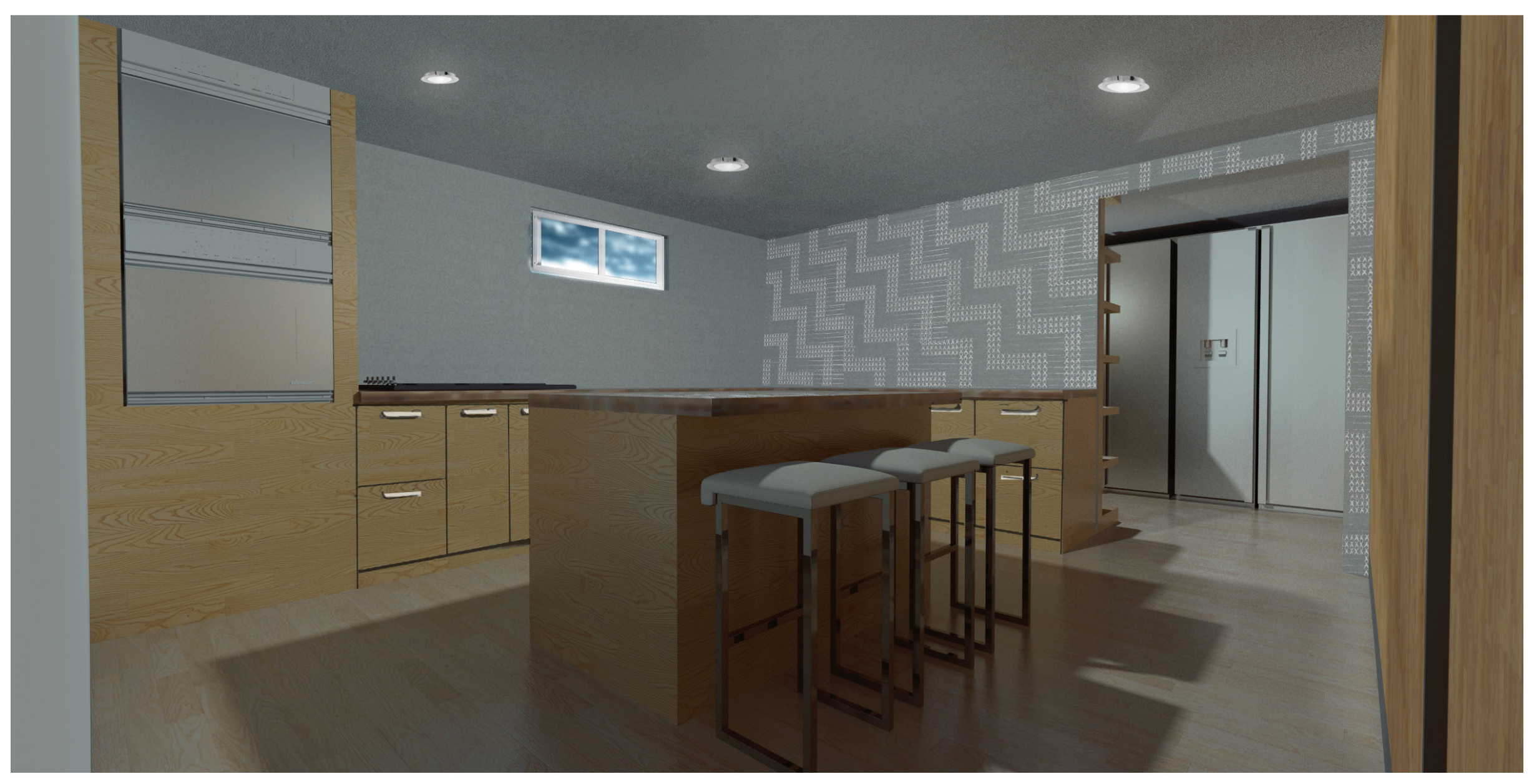




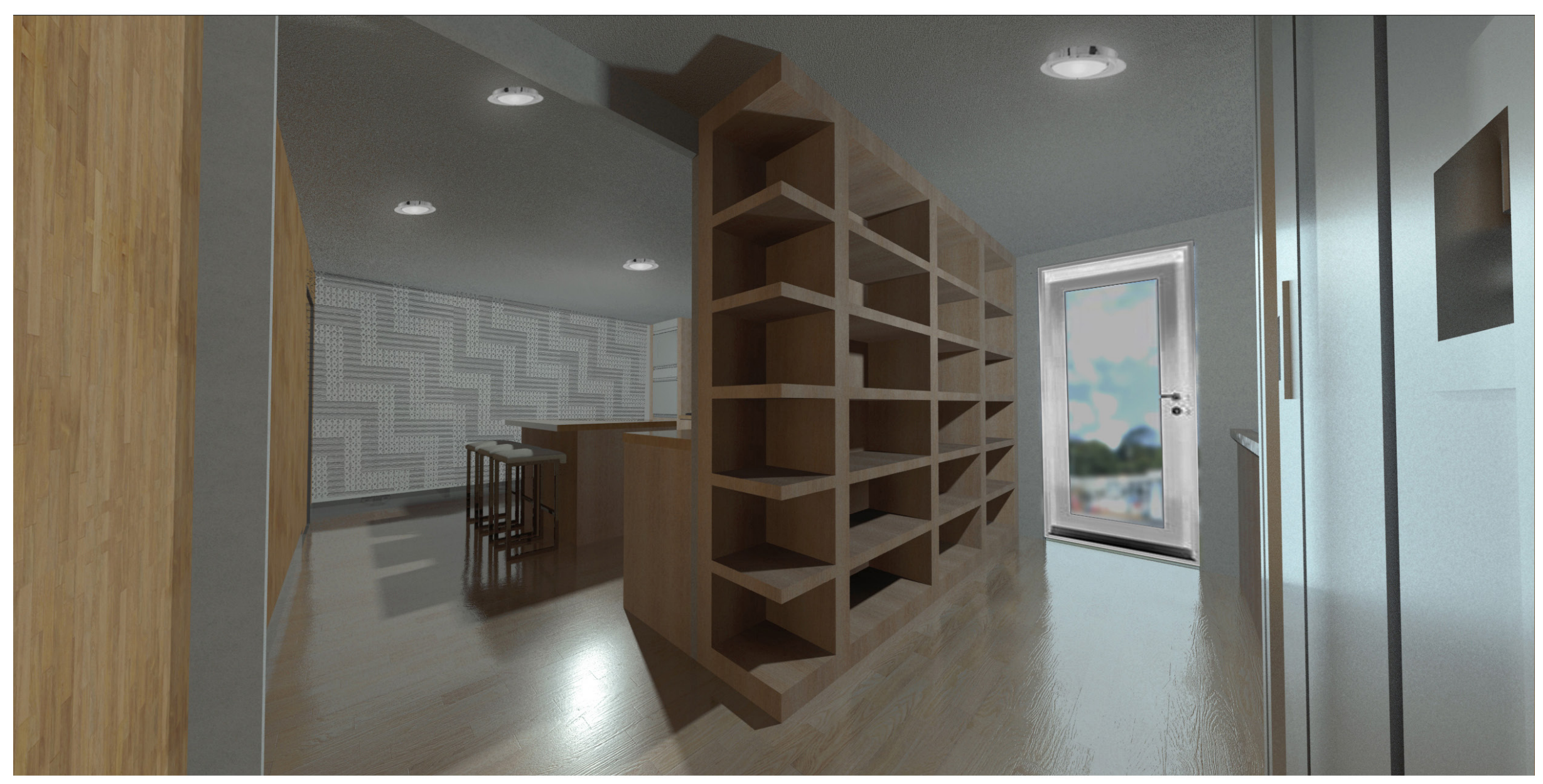




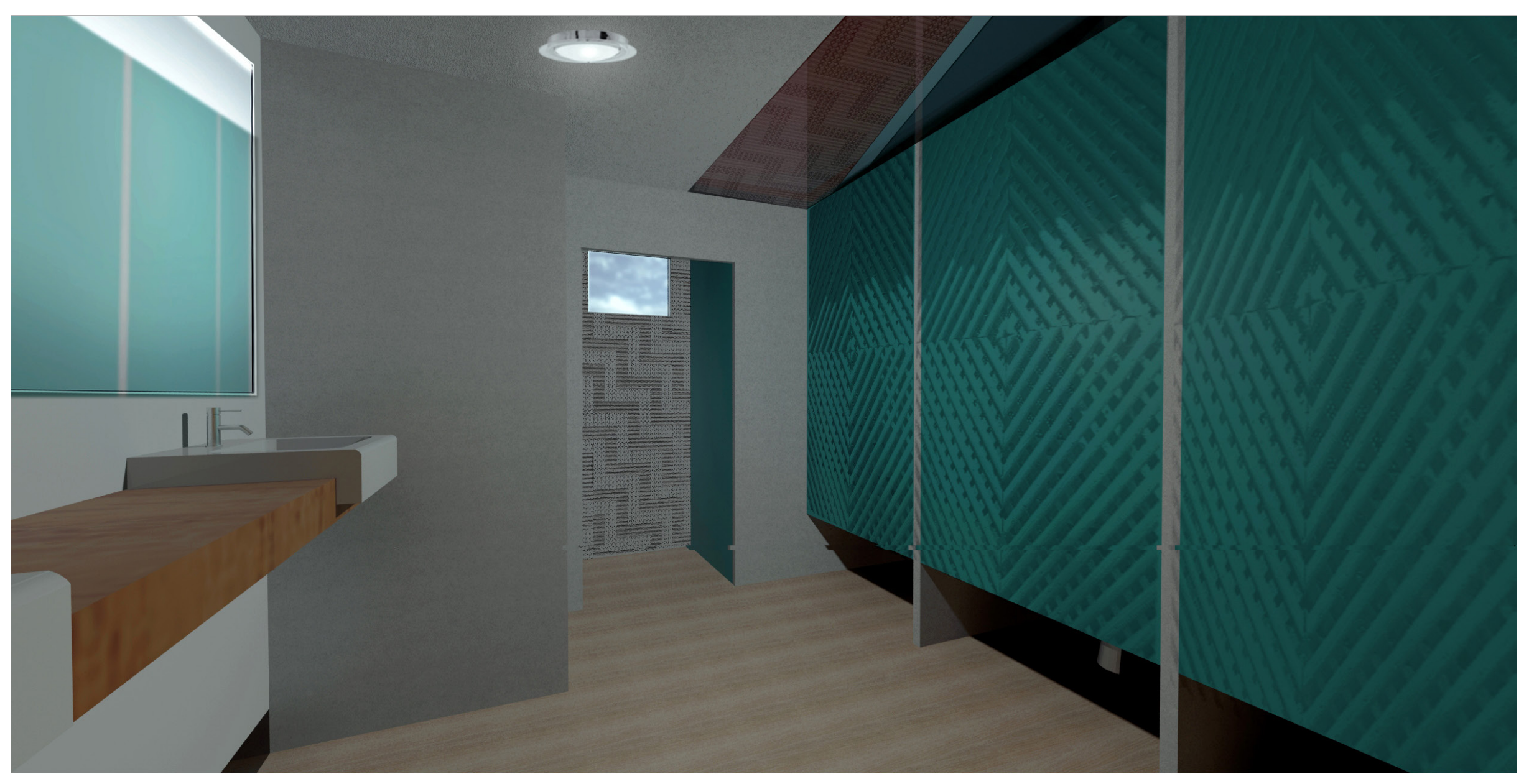


APRIL 2015 BOOKLET - FINAL DESIGN 


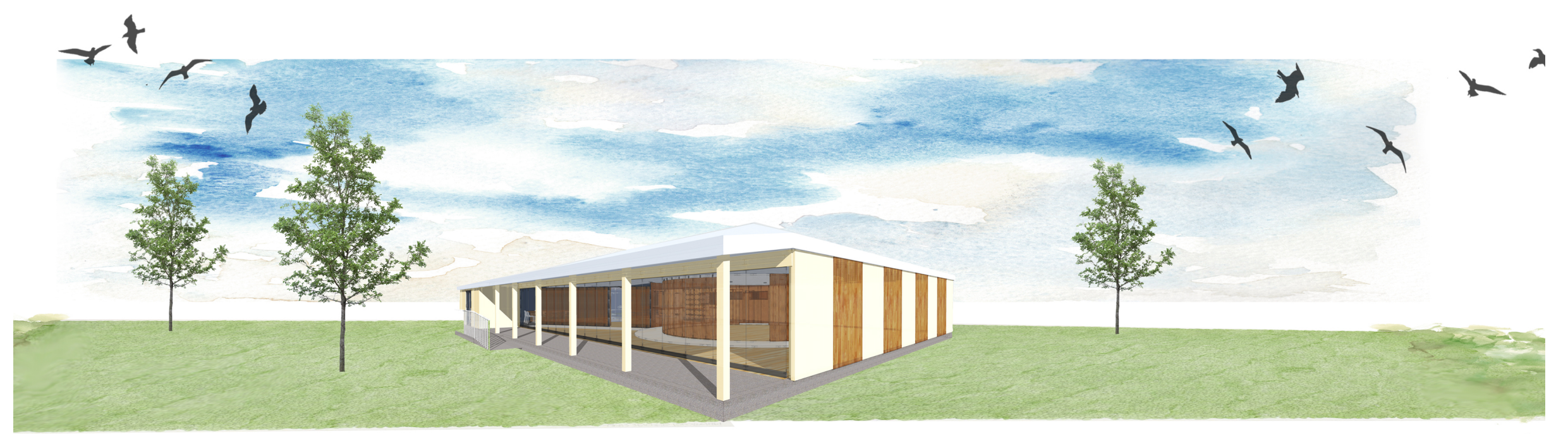

A TALE OF PLACE

A Cultural Centre for Paraparaumu College 
A sliding door will replace the existing office door on the west facade. Through this sliding door you will access the classroom

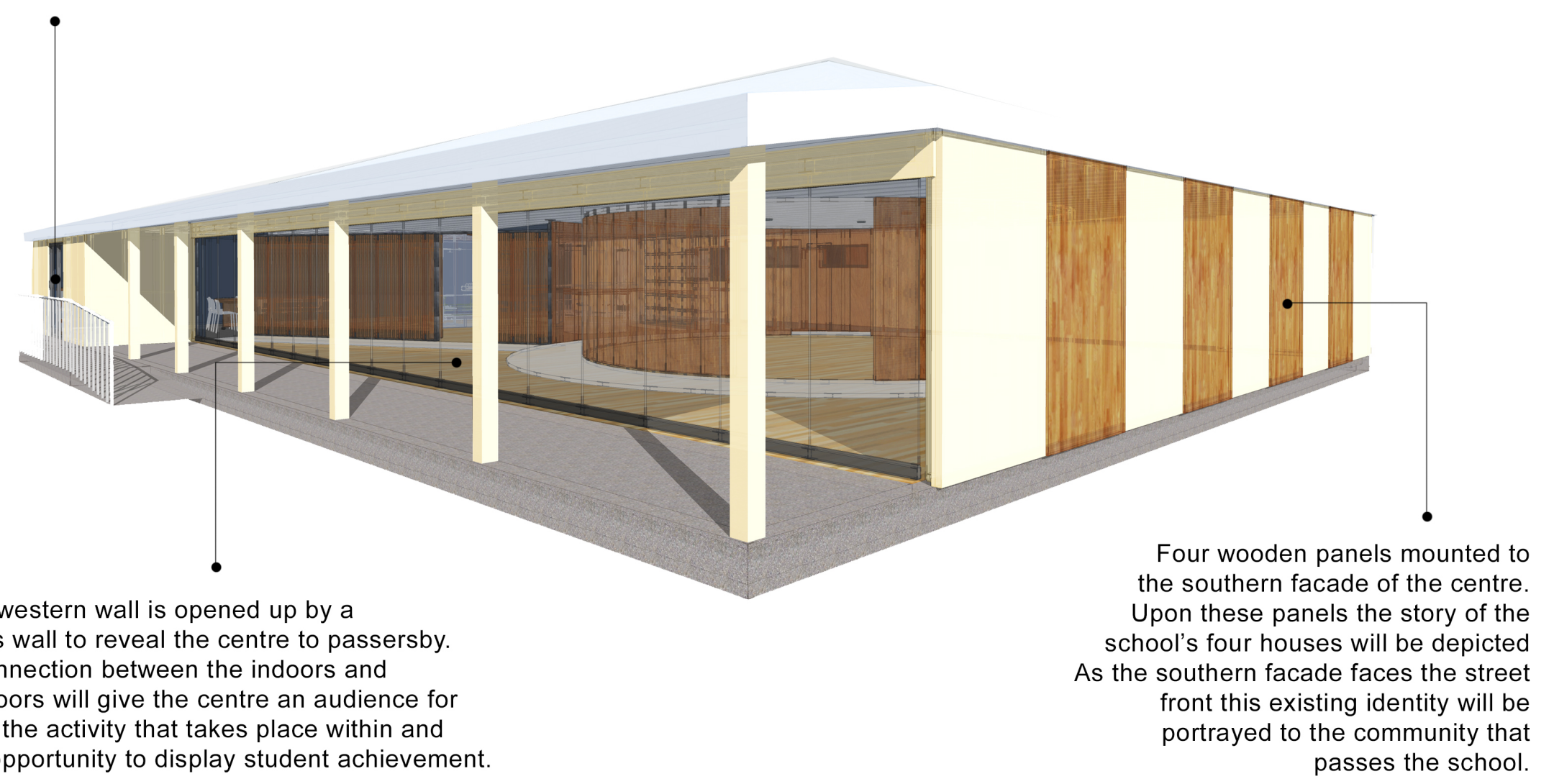

CHANGES TO EXISTING BUILDING 


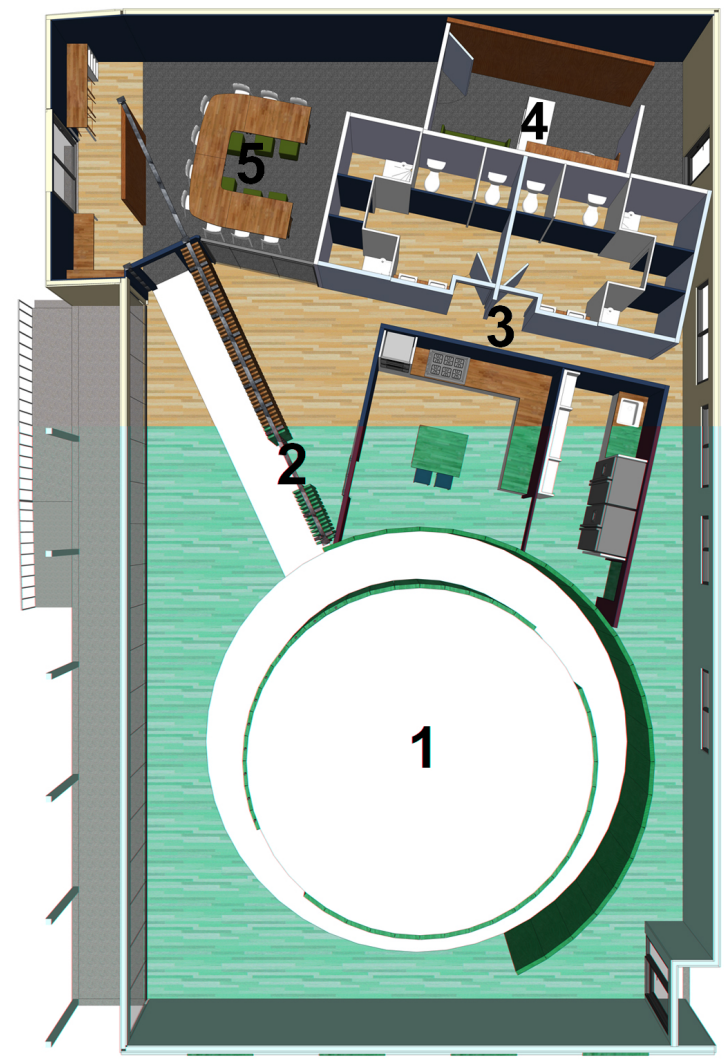

The overall design is made up of five components:

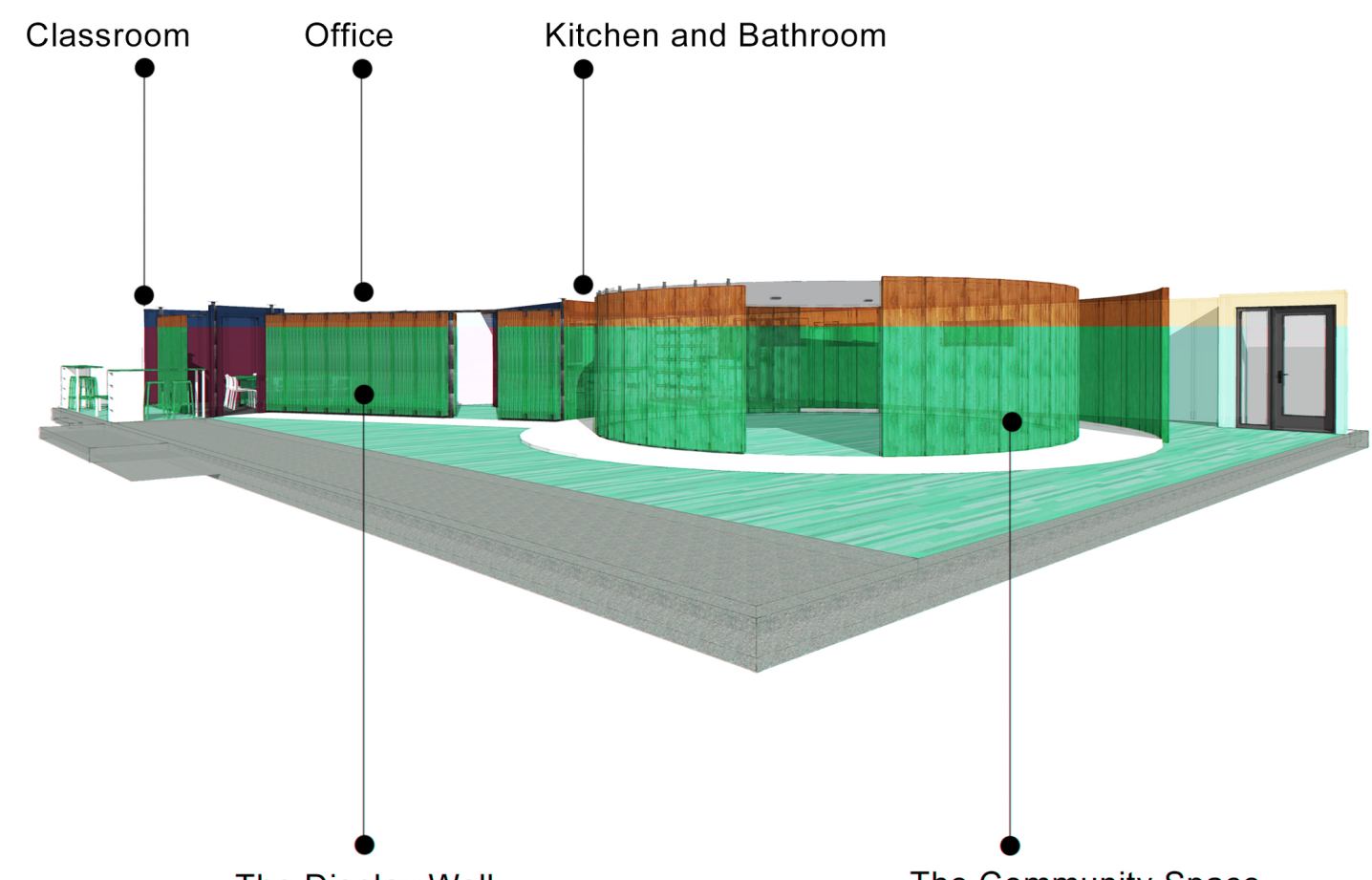

The Display Wall

The Community Space

To minimise the impact on the existing building, the propsed design does not touch the shell of the building. Instead it nestles into it's existing environment. Also to showcase the difference in use the community space is curve while the school facilities are linear and square. It highlights the change in environment and use

\section{OVERALL DESIGN}


The walls of the community space can slide open, revealing the global map and making use of the visual access the open glass facade offerrs.

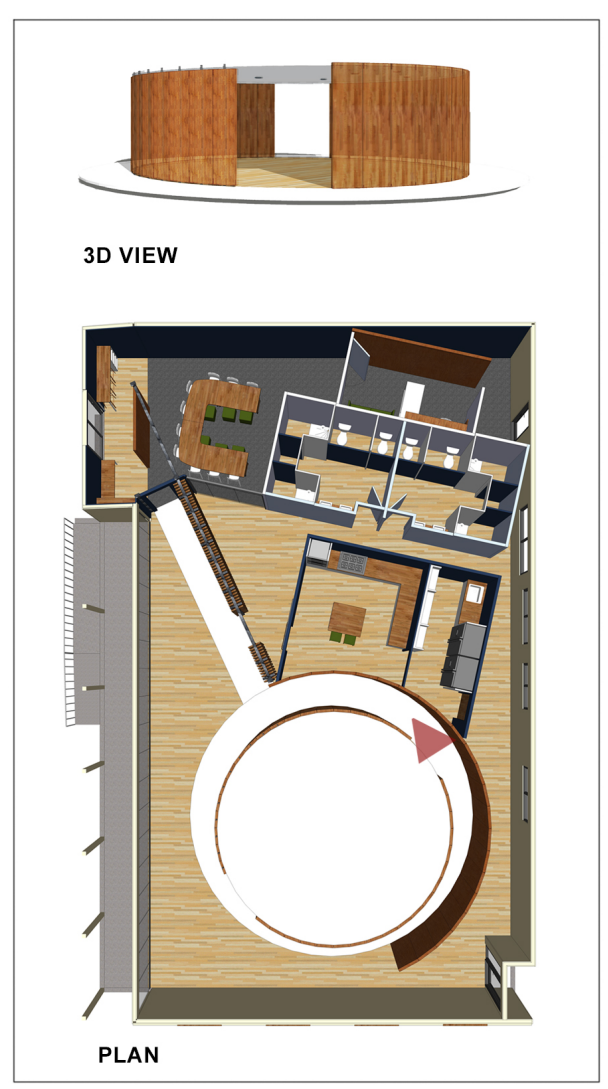

PLAN

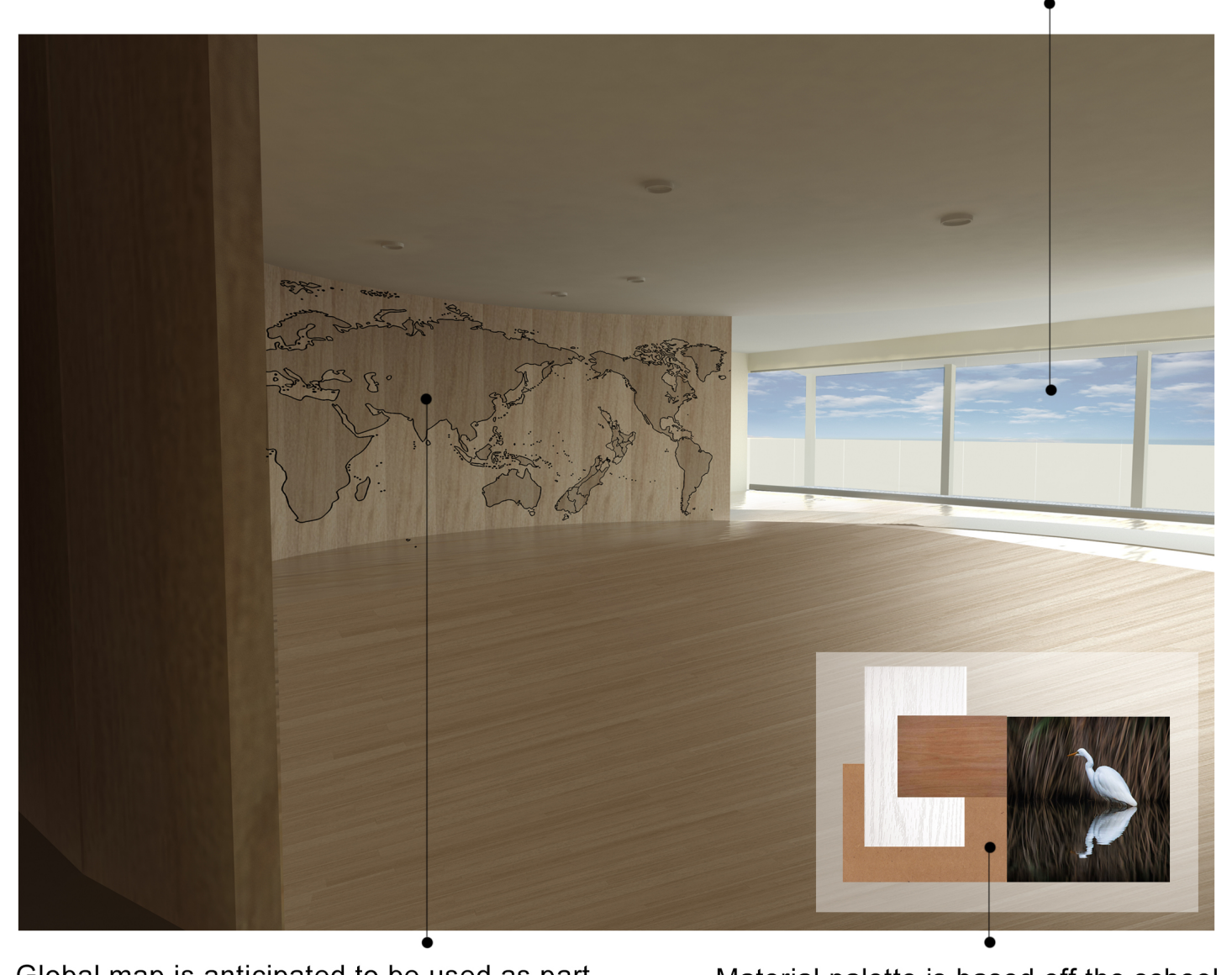

Global map is anticipated to be used as part of a powhiri. Students and visitors to the school will make the place they call hom to show the diversity of people. house Maungakotukutuku.

COMMUNITY SPACE 
The display wall is the link between the classroom and community space while being a barrier between the public and private areas of the cultural centre

4

3D VIEW

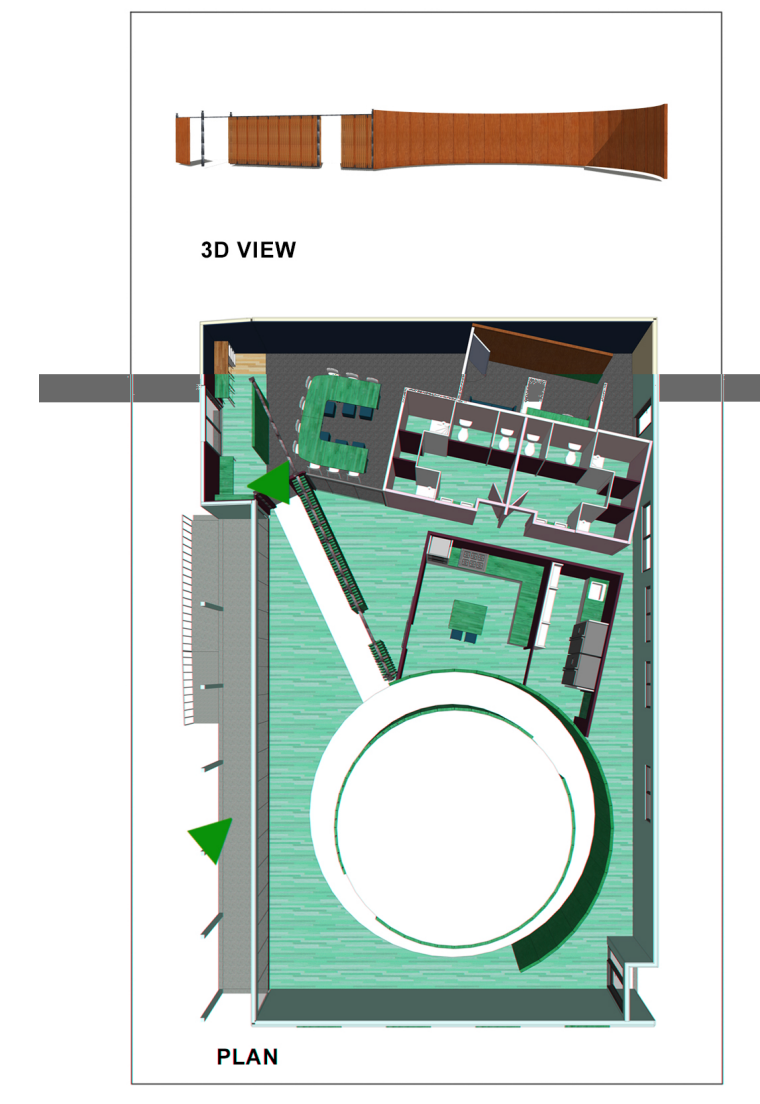

PLAN
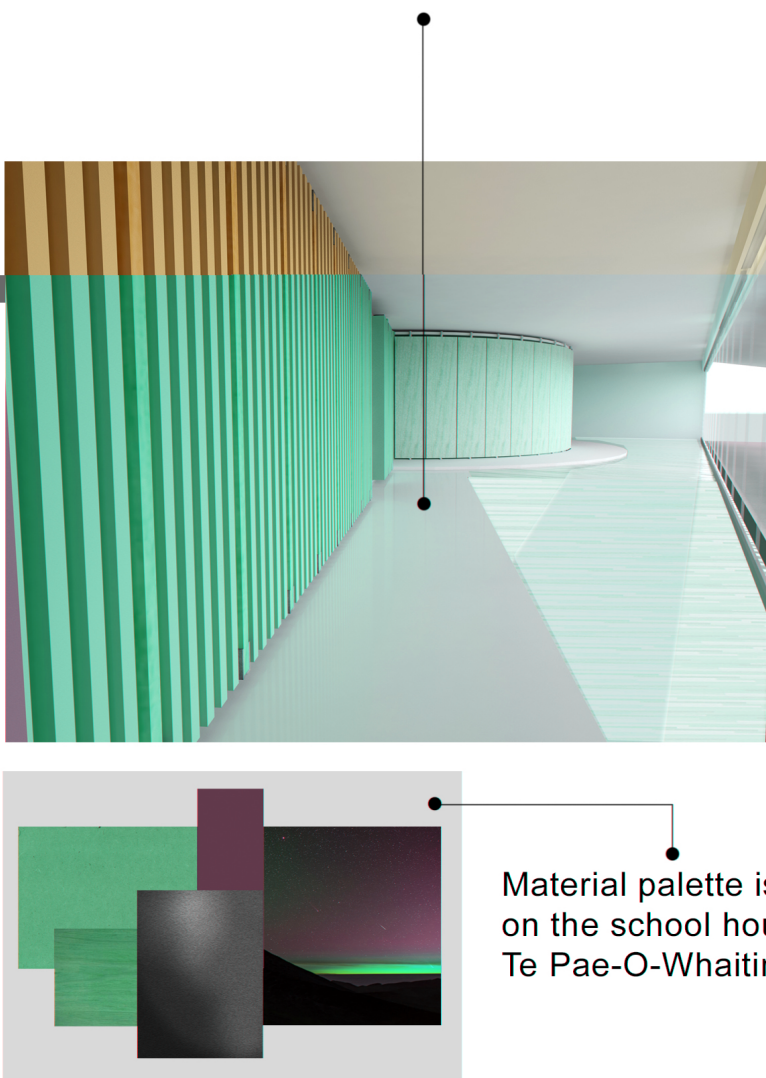

The orientation of the display wall is designed to take advantage of the glass facade connecting passersby with the centre's interior.
Material palette is based on the school house

Te Pae-O-Whaitiri
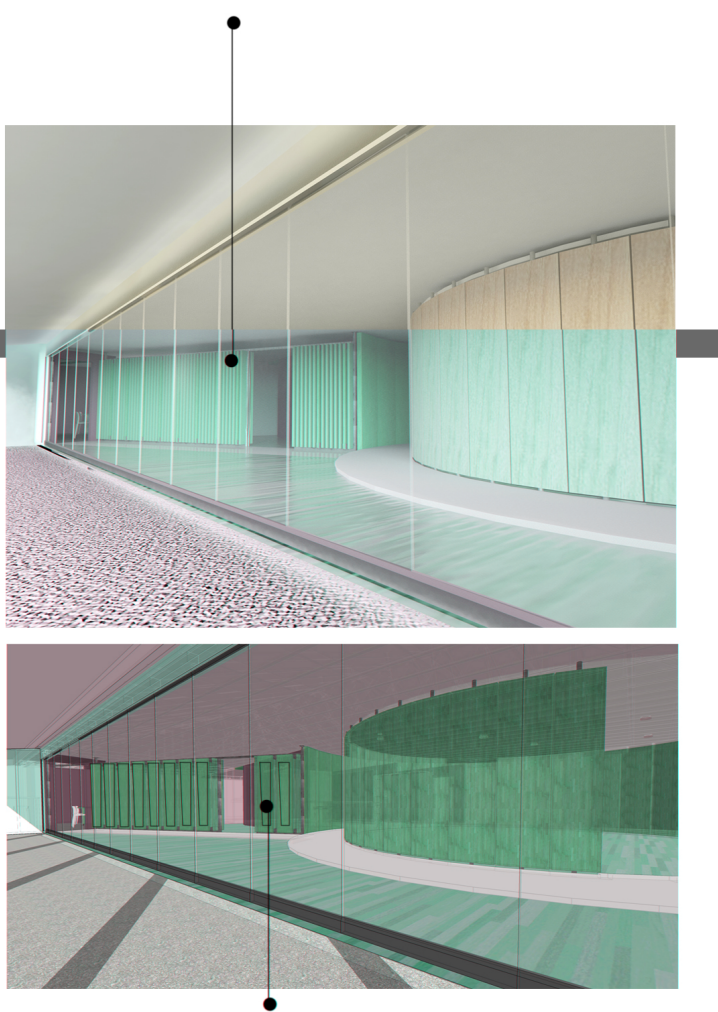

The main function of the display wall is to publicly showacase student achievement. To achieve this the wall is transformable, every 6th

panel sliding out and lying flat against the remaining slats.

DISPLAY WALL 


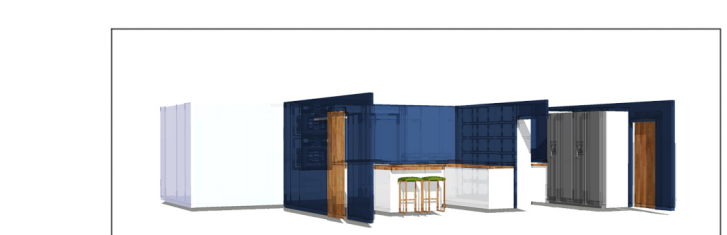

3D VIEW

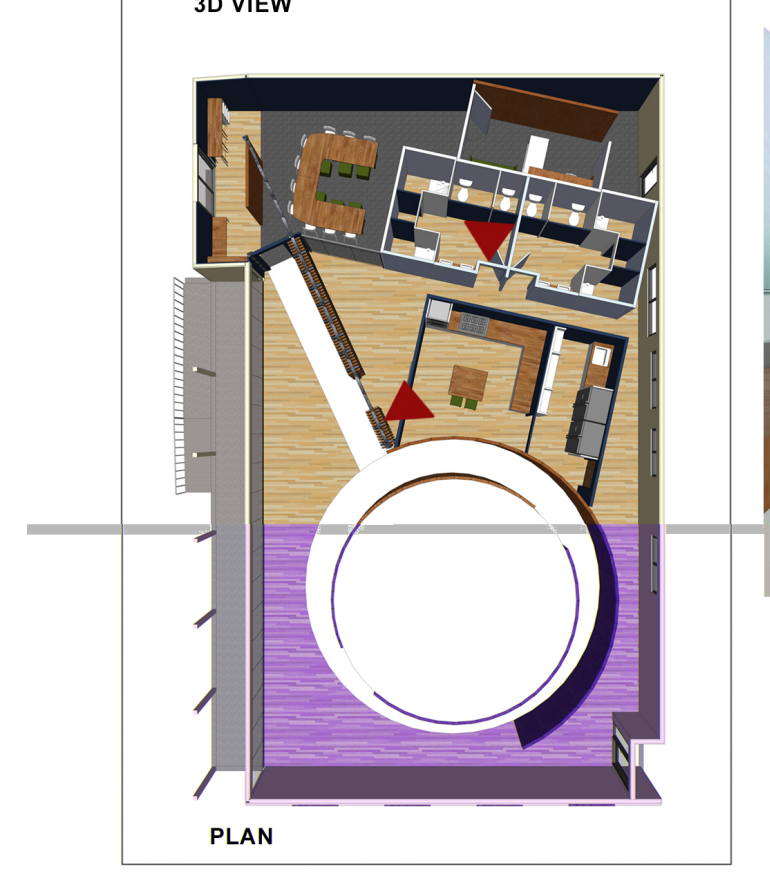

To provide the opportunity of Noho Marae, the bathrooms have increased in size comapred to the existing. Each bathroom has $3 x$ toilets. $2 x$ showers and $2 \times$ handbasins

$\bullet$
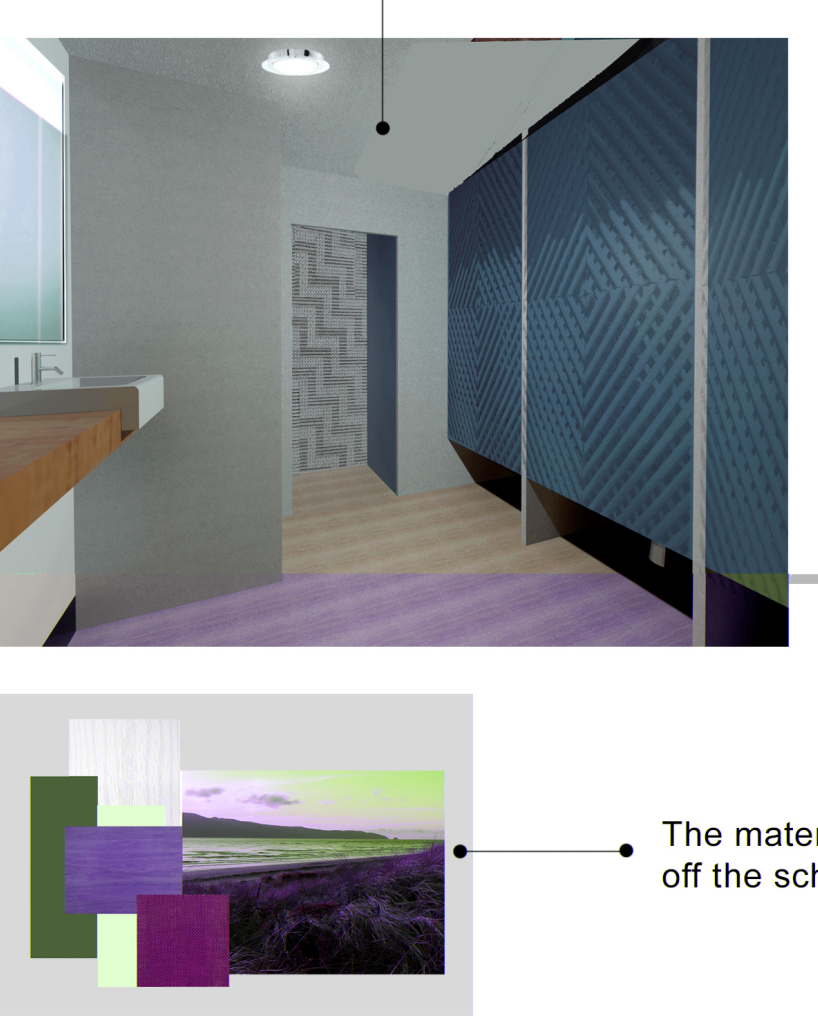

The kitchen has also increased in size, now encompassing a kitchen and food storage area. The dimensions of the extended kitchen is $5 \mathrm{~m} \times 7 \mathrm{~m}$.

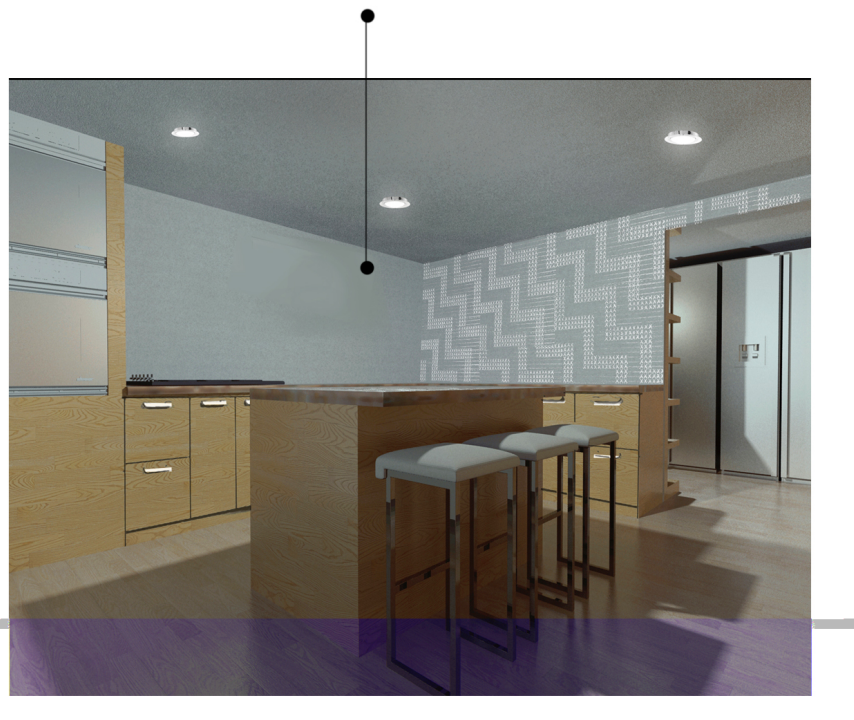

The material palette for the service areas is based off the school house Te Wai-O-Rongomai

KITCHEN AND BATHROOMS 
The office sits at the very rear of the design. Located beside the classroom, it can be closed off to ensure privacy or open. It also has it's own entry and storage space along the eastern wall. In the office there is space for a large desk and couch/seating area $-4.9 \times 2.8 \mathrm{~m}$

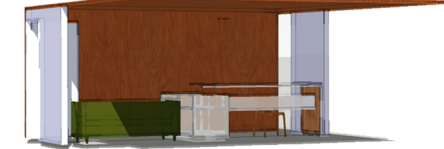

3D VIEW

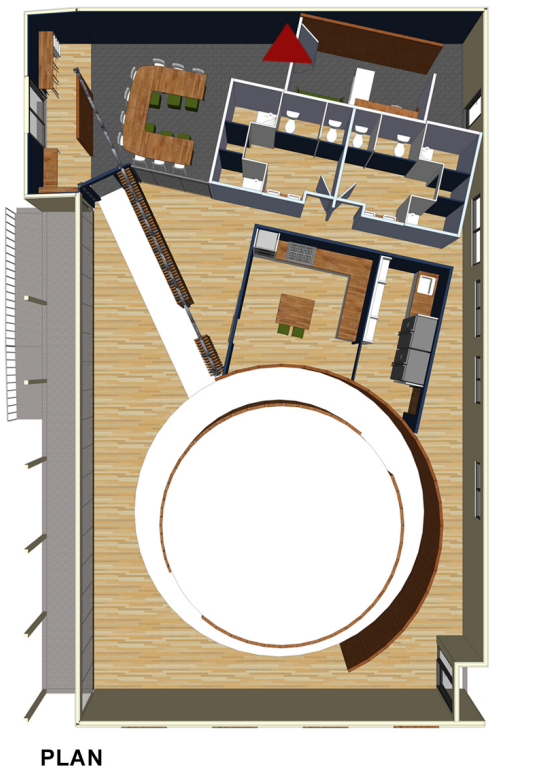

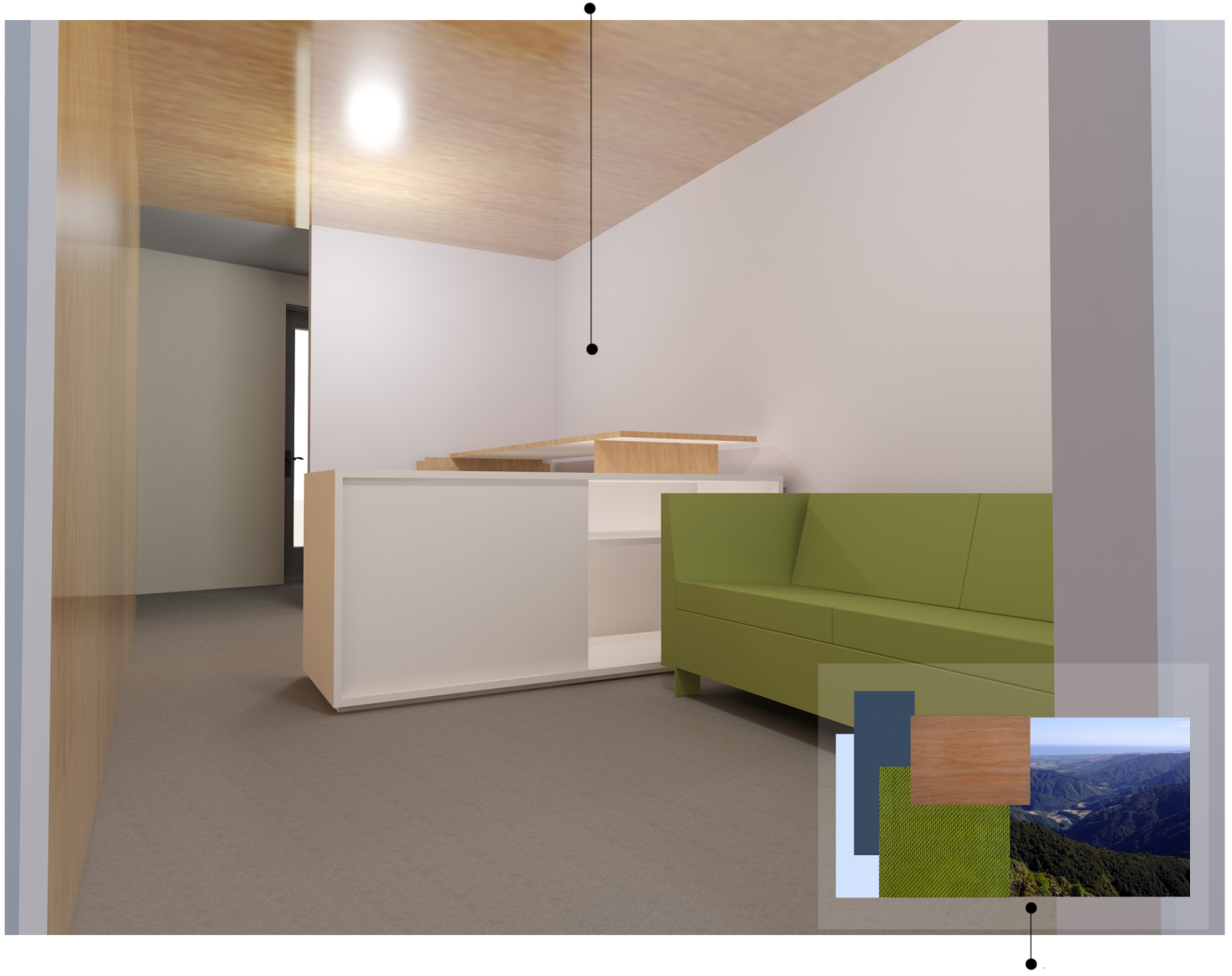

Material palette is inspired by the school house Te Ake Tarewa

OFFICE 
The display wall ends with a final panel that can only be viewed from the classroom. This wall also serves to provide privacy from the

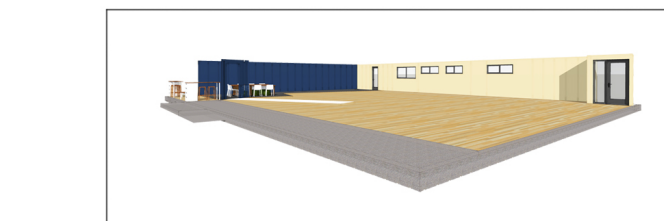

3D VIEW

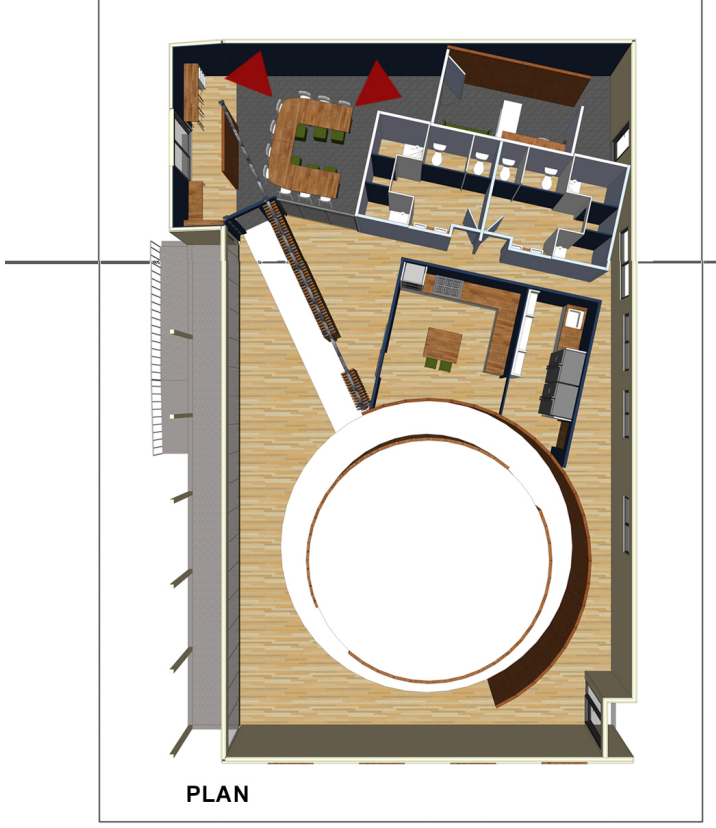

Informal bench seating is also

provided at the rear of the classroom

to provide an additional work space
The classroom furniture is a large conference style table to encourage group discussions, with two different types of seating. Standard chairs at the back and informal ottomans at the front

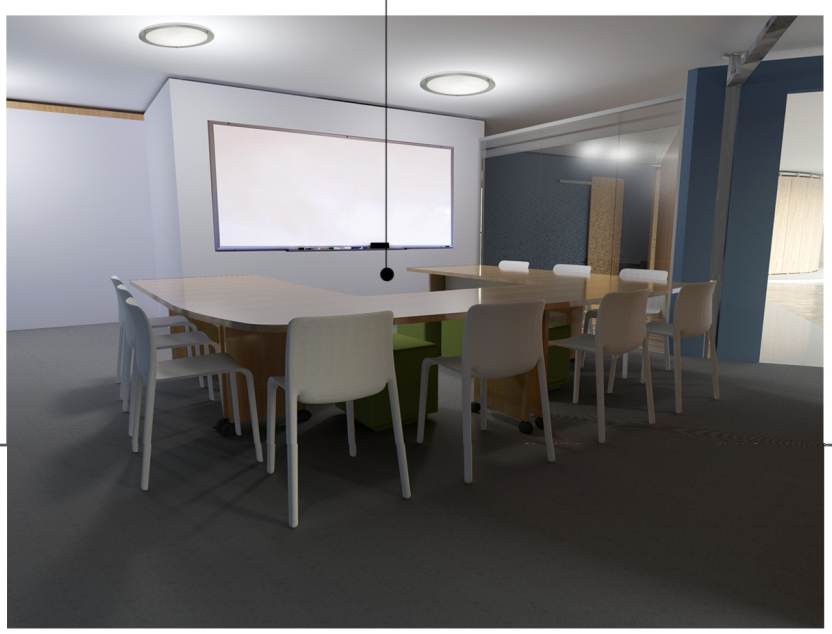

Like the office the material palette for the classroom is based off the school house Te Ake Tarewa.

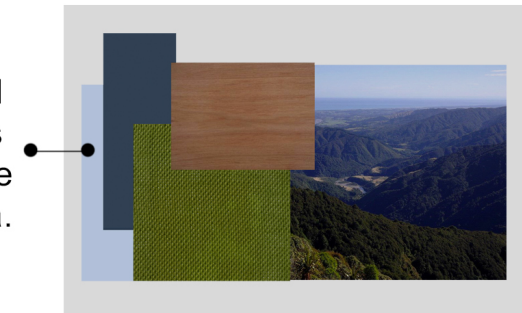

CLASSROOM 
